\title{
Diffusion in Pyroxene, Mica and Amphibole
}

\author{
D.J. Cherniak \\ Department of Earth \& Environmental Sciences \\ Rensselaer Polytechnic Institute \\ Troy, New York 12180, U.S.A. \\ chernd@rpi.edu
}

A. Dimanov

Laboratoire de Mécanique des Solides, UMR C 7649

Ecole Polytechnique

Route de Saclay, 91128 Palaiseau, France

dimanov@lms.polytechnique.fr

\section{INTRODUCTION}

This chapter presents an overview of diffusion data for pyroxenes, amphiboles and micas. These minerals are grouped together since amphiboles and micas are closely related in structure to pyroxenes, with amphiboles essentially constructed of alternating layers with structures of mica and pyroxene. We begin with discussion of diffusion in pyroxenes, for which an extensive literature exists, with diffusion studies of major, minor and trace elements. We consider diffusion mechanisms in light of present understanding of defect chemistry, and discuss various crystal-chemical factors that may affect cation diffusion. The last section of the chapter presents a review of diffusion data for amphiboles and micas. Selected Arrhenius relations for these all these mineral phases are summarized in the Appendix Tables A1, A2, A3 and A4. This chapter focuses primarily on cation diffusion, since oxygen, hydrogen and noble gas diffusion are discussed in other chapters; readers interested in more detailed discussion of diffusion of these species in pyroxene, amphibole and mica are directed to Chapters 10 (Farver 2010, this volume) and 11 (Baxter 2010, this volume).

\section{CATION DIFFUSION IN PYROXENES}

Since the early 1970s, solid state diffusion of cations in pyroxenes has been recognized to play a fundamental role in numerous geodynamical, petrological and geochemical processes involving mass transport. Knowledge of diffusion coefficients allows constraints to be placed upon time scales and thermodynamic conditions in many natural contexts where mass transport is dominated by solid state diffusive processes. Pyroxenes are major mineral phases at depth (in the lower crust and upper mantle) in both the earth and extraterrestrial bodies. Pyroxene composition evolves with temperature and pressure due to diffusive exchanges of major cations (i.e., $\mathrm{Ca}, \mathrm{Mg}$, $\mathrm{Fe}, \mathrm{Mn}, \mathrm{Al}$ ) with surrounding mineral phases. The crystalline structure of pyroxenes is also influenced by diffusionally-induced compositional changes, including order-disorder, spinodal decomposition, exsolution and coarsening of lamellae. Equilibrium compositions of pyroxenes and their state of order can provide geothermobarometric constraints. One example is the exchange of $\mathrm{Al}$ between pyroxenes and the aluminous phases garnet, spinel, and plagioclase (Gasparik and Lindsey 1980; Gasparik 1984). Chemical zoning within individual crystals is frequently observed (Fraser and Lawless 1978; Sautter and Harte 1988, 1990), because slow intracrystalline 
diffusion kinetics may contribute to the formation of zoning (e.g., Watson and Liang 1995) and its preservation (e.g., Cherniak and Liang 2007). Compositional zoning and isotopic disequilibria may in some cases be interpreted in terms of cooling rates, as in applications to geospeedometry (Dodson 1973, 1986; Lasaga et al. 1977; Hofmann and Hart 1978; Lasaga 1983; Ganguly and Tazzoli 1994; Jaoul and Sautter 1999; Ganguly et al. 2000; Coogan et al. 2005). Cation diffusion in pyroxenes also controls the kinetics of solid state reactions and corona growth (Brady 1983; Joesten 1991; Yund and Tullis 1991); the length scales of such growth allow for estimations of residence times, providing constraints for geothermochronology (Freer 1979). Diffusion-related mechanisms are also controlling processes in microstructural evolution, including grain coarsening, and ductile deformation mechanisms such as dislocation climb (Raterron and Jaoul 1991; Jaoul and Raterron 1994) and grain sliding (Dimanov et al. 2003; Dimanov and Dresen 2005; Dimanov et al. 2007). Therefore, the knowledge of diffusion kinetics is clearly of fundamental importance in enhancing our understanding of geological and planetary processes.

Over roughly the past three decades, numerous studies have been undertaken to estimate and directly measure diffusion in pyroxene and apply these data. In this chapter we review the extant diffusion data for major cations, trace and minor elements in pyroxenes, obtained either by direct experimental measurements or indirect estimates from natural and experimental observations. Direct measurements are based on analysis of chemical or isotopic profiles as a function of depth, or with step scans across an interface by means of electron microprobe, electron microscopy (coupled to Energy Dispersive X-ray (EDX)), accelerator-based ion beam techniques (RBS, NRA), or ion probe (SIMS) analysis. The utility of these various techniques for analysis will depend on the experimental configuration and magnitude of diffusion coefficients. Depth profiling techniques (RBS, NRA, SIMS) are characterized by the highest spatial resolution, and permit analysis of the chemical or isotopic composition beneath the sample surface parallel to the diffusion direction. Hence, they are well adapted to slow diffusing species, but the experimental design must allow the retrieval of an intact sample surface (or interface) perpendicular to the diffusion direction. The usual geometries for diffusion experiments involve diffusive exchanges between a substrate and a surface thin film, or a surrounding medium (powders, gaseous environments). Conversely, electron microprobe, SEM and TEM-EDX and transverse mode SIMS are used for experimental geometries where step by step scans are made on a cross-section perpendicular to the diffusion interface. With the exception of TEM-EDX, these are best suited for fast diffusing species, due to limitations of spatial resolution related to the scan step size and spot size of the analyzing beam.

Indirect estimates are based on experimentally derived kinetics of homogenization of exsolution lamellae, order-disorder on crystal sites, and solid state reactions with moving interfaces, such as exsolution coarsening, intergrowths, grain growth and spinodal decomposition. While these can be evaluated through controlled laboratory studies, similar estimates may also be inferred from interpretation of chemical and structural inhomogeneities preserved in natural assemblages, but with larger uncertainties given the limitations in precisely knowing time-temperature conditions, pressure, and other critical parameters. Most of the indirect estimates are also subject to the assumption that the observed changes are solely a result of diffusion-controlled kinetics. However, for solid state reactions which involve moving interfaces the kinetics of the process may also be influenced by interface related phenomena (e.g., solute drag mismatch strain). Also, there may be several species which could control the kinetics of solid state reactions for complex silicates. Estimates of diffusion from natural zoning are further dependent on estimates of thermal histories. Hence, indirect estimates should be evaluated with caution, and under most circumstances will provide constraints on the order of magnitude of the diffusion process rather than yielding precise diffusion coefficients. In addition to experimental and empirical determinations of diffusion, we also consider the results of numerical modeling, which has recently been applied to better understand the mechanisms of cation diffusion in pyroxene. 
The diffusion data for major elements will be presented chronologically, and by mineral group, in order to follow the technological evolution and improvement of the spatial resolutions of analytical techniques, which have permitted more and more precise data to be collected and an extension of measurement capabilities to lower diffusion coefficients. The details of reliable diffusion data (parameters of diffusion coefficients, diffusion type and mechanisms, measurement techniques, experimental conditions) are presented in Table A1. This will be followed by sections on pyroxene defect chemistry, and the phenomenon of early partial melting (EPM) and its potential effects on diffusion. Diffusion of trace and minor elements will be grouped by elemental species, and by pyroxene composition for diffusion of a particular element. These data are presented in Table A2. We also consider relative diffusivities of cations in diopside and enstatite, and various parameters that might affect diffusion.

\section{Pioneering approaches}

In slowly cooled basic igneous rocks, augite and subcalcic clinopyroxene solid solutions commonly experience spinodal decomposition and exsolution of orthopyroxene or pigeonite lamellae (parallel to (001) planes); growth kinetics of these features are controlled by Ca(Fe, Mg) interdiffusion (Huebner et al. 1975; McCallister and Nord 1981; Jantzen 1984; Miyamoto and Takeda 1977, 1994; Weinbruch and Müller 1995; McCallum and O'Brien 1996; Weinbruch et al. 2001, 2003). The lamellar thickness and compositional zoning of adjacent lamellae that result from lamellar coarsening kinetics may be modeled to retrieve cooling rates (e.g., Schwartz and McCallum 2005), provided the interdiffusion coefficients are known.

The earliest attempts to estimate interdiffusion rates of major divalent octahedral cations $(\mathrm{Fe}, \mathrm{Mg}, \mathrm{Ca}$ ) in pyroxenes were motivated by the interest in constraining cooling rates and annealing durations of extraterrestrial assemblages. Huebner (1976) and Stanford and Huebner (1979) applied comparative analysis of compositionally zoned olivine and pyroxene xenocrysts from lunar basalts (Huebner et al. 1975; Huebner 1976; Stanford and Huebner 1979; Huebner and Nord 1981), on the basis of the known Fe-Mg interdiffusion coefficients for olivine (Buening and Buseck 1973). Assuming as a first approximation isothermal annealing and growth of pigeonite rims by $\mathrm{Ca}-(\mathrm{Fe}, \mathrm{Mg})$ exchange between augite cores and the surrounding matrix, they estimated $D_{\mathrm{Ca}-\mathrm{FeMg}} \sim 4 \times 10^{-15} \mathrm{~m}^{2} / \mathrm{s}$ at $1050{ }^{\circ} \mathrm{C}$. Huebner et al. (1975) also first attempted to directly measure $\mathrm{Ca}-\mathrm{Mg}$ interdiffusion rates through cation exchange between orthopyroxene powder and augite single crystals, but electron microprobe analysis failed to detect any chemical profiles even after 628 hours at $1266{ }^{\circ} \mathrm{C}$. Considering the microprobe spatial resolution $(\sim 3 \mu \mathrm{m})$, the authors estimated a maximum value for $D_{\mathrm{Ca}-\mathrm{Mg}} \sim 4 \times 10^{-20}$ $\mathrm{m}^{2} / \mathrm{s}$, which they assumed to be unrealistically low. Later Huebner and Nord (1981) attributed this failure to the experimental difficulty in producing adequate diffusion couples and argued in favor of experimental studies of lamellar growth (McCallister 1978) coupled with electron microprobe and analytical TEM to determine diffusion coefficients.

McCallister et al. (1979) attempted direct measurements of diffusion of radioactive ${ }^{45} \mathrm{Ca}$ and ${ }^{57} \mathrm{Fe}$ tracers. Isotopically-enriched thin films were deposited onto (001) polished diopside faces by evaporation of chloride solutions. The diffusion couples were annealed for up to 6 months, then sectioned perpendicular to (001) in order to obtain radiotracer concentration profiles by exposing samples to $\beta$-particle sensitive emulsions. Self-diffusion rates were obtained, but Brady and McCallister (1983) later recognized that the results were not fully consistent with diffusion-controlled processes. Freer et al. (1982) made efforts to measure diffusion of major element cations in diopside single crystals with electron and ion microprobe analyses by attempting to induce $\mathrm{Al}$ and $\mathrm{Fe}$ interdiffusion between $\mathrm{Al}$ - and Fe-rich sintered powders and diopside, and tracer diffusion of ${ }^{26} \mathrm{Mg}$ and ${ }^{43} \mathrm{Ca}$ between isotopically enriched synthetic glass and diopside. Transverse mode analysis of samples failed to show any measurable diffusion profiles, but permitted the setting of new upper limits on diffusivities of $\sim 4 \times 10^{-19} \mathrm{~m}^{2} / \mathrm{s}$ at 1200 ${ }^{\circ} \mathrm{C}$ for $\mathrm{Al}$ and $\mathrm{Fe}$, and less than $\sim 7 \times 10^{-19} \mathrm{~m}^{2} / \mathrm{s}$ at $1250{ }^{\circ} \mathrm{C}$ for $\mathrm{Ca}$ and $\mathrm{Mg}$. These upper limits 
for diffusion rates were significantly lower than all previously published tracer-diffusion data for pyroxenes (McCallister et al. 1979; Sneeringer and Hart 1978; Seitz 1973; Lindner 1955). By evaluating marginal and discontinuous zoning in Ca-poor and $\mathrm{Ca}$-rich clinopyroxenes from natural assemblages, Rietmeijer (1983) estimated that $\mathrm{Ca}-(\mathrm{Fe}, \mathrm{Mg})$ interdiffusion rates along the $c$-axis in iron-rich clinopyroxenes may be as low as $\sim 6 \times 10^{-24}$ to $\sim 2 \times 10^{-21} \mathrm{~m}^{2} / \mathrm{s}$ at $900{ }^{\circ} \mathrm{C}$.

In the early eighties, the most reliable cation interdiffusion data were reported by Brady and McCallister (1983). The authors performed lamellar homogenization experiments at 2500 $\mathrm{MPa}$ (in piston cylinder apparatus), between $1100-1250^{\circ} \mathrm{C}$. The homogenization kinetics were analyzed in terms of $\mathrm{Ca}-(\mathrm{Mg}, \mathrm{Fe})$ interdiffusion normal to (001) between pigeonite lamellae and a sub-calcic diopside host. The average pseudo-binary interdiffusion coefficient obtained by Brady and McCallister (1983) at $1150-1250{ }^{\circ} \mathrm{C}$ confirmed the observations of Freer et al. (1982) of the sluggishness of divalent cation diffusion in clinopyroxenes. However, the interdiffusion rates reported by Brady and McCallister (1983) possessed quite large uncertainties (e.g., an activation energy $E_{\mathrm{a}}=361 \pm 190 \mathrm{~kJ} / \mathrm{mol}$ ). The limited data did not permit any interpretation in terms of diffusion mechanisms and point defect chemistry, or any quantification of dependence of diffusion rates on pyroxene composition. Moreover, the very few extant diffusion coefficients in clinopyroxenes were all obtained under very different experimental conditions. Most experiments were performed at ambient pressure, in air (e.g., McCallister et al. 1979; Freer et al. 1982), i.e., at extremely oxidizing conditions $\left(\mathrm{pO}_{2}=0.021 \mathrm{MPa}\right)$, while the data of Brady and McCallister (1983) were obtained for experiments under high confining pressure, very low oxygen fugacity (graphite-oxygen buffer), and probably the presence of traces of water. At the time theoretically and experimentally derived frameworks of point defect chemistry of enstatite (Stocker 1978) and olivine (Nakamura and Schmalzried 1983) were available, and indicated that point defect concentrations (and hence, diffusion rates) would depend on $p \mathrm{O}_{2}$ for both of these iron-bearing silicates. The lack of rigorously controlled thermodynamic conditions in terms of component activities and volatile fugacities added to the difficulty in comparing the few extant diffusion data.

\section{More recent investigations of major element diffusion}

From the middle 1980s to date, experimental investigations of diffusion have progressively increased in numerous minerals, including pyroxenes. Among the primary areas of concentration for experimental diffusion studies of clinopyroxenes have been self-diffusion or interdiffusion, and data have been obtained by the depth profiling techniques SIMS, RBS and NRA, all with sufficient spatial resolution $(\sim 15-30 \mathrm{~nm})$ to resolve short diffusion profiles and access small diffusivities. Some of these studies also considered the effects of sample composition, confining pressure, diffusional anisotropy, and control of point defect chemistry. Considerable effort has also been directed toward the refinement of reliable techniques for diffusion couple preparation. For instance, while self-diffusion in pyroxenes is sometimes evaluated by direct isotopic exchange between simple oxide sources and samples (Schwandt et al. 1998; Ganguly et al. 2007; Zhang et al. 2010), some studies have been designed so that there is isotopic exchange between source materials and samples with the same bulk chemical composition, which may avoid interfacial chemical reactions and changes in chemical composition during diffusion experiments, ensuring that self-diffusion processes can be exclusively quantified (Dimanov and Ingrin 1995; Béjina and Jaoul 1996; Pacaud 1999).

In the following section we chronologically present the published diffusion data for major alkaline earth $(\mathrm{Ca}, \mathrm{Mg})$, transition metal ( $\mathrm{Fe}, \mathrm{Mn}, \mathrm{Cr}$ ) and metalloid ( $\mathrm{Al}, \mathrm{Si}$ ) cations in pyroxenes obtained by the state of the art techniques. When they have been determined, we will report the dependences on temperature, oxygen fugacity, crystallographic direction, and composition in terms of Fe content. In these cases, the diffusion coefficients will be presented in the form:

$$
D=D_{0}\left(p \mathrm{O}_{2}\right)^{m} \exp \left(n \cdot X_{\mathrm{Fe}}\right) \exp \left(-E_{\mathrm{a}} / R T\right)
$$


where, $D_{0}$ is the pre-exponential constant, $m$ is the oxygen fugacity exponent, $n$ is the coefficient of dependence on the iron content $X_{\mathrm{Fe}}$ of the pyroxene, $E_{\mathrm{a}}$ is the activation energy, $R$ is the universal gas constant, and $T$ the absolute temperature.

\section{Diffusion of major element cations in clinopyroxenes}

Aluminium. Sneeringer et al. (1984) and Sautter et al. (1989) were the first to apply accelerator-based ion beam analysis techniques to study cation diffusion in diopside, with Sneeringer et al. (1984) using Rutherford Backscattering Spectrometry (RBS) and Sautter et al. (1989) using Nuclear Reaction Analysis (NRA). Sautter et al. (1989) measured Al diffusion in diopside in order to constrain conditions for use of geothermobarometers based on aluminum exchange. Thin film ( $35 \mathrm{~nm}$ ) diffusion couples were prepared by radio-frequency (RF) sputtering of $\mathrm{Ca}-\mathrm{Tschermak}\left(\mathrm{CaAl}_{2} \mathrm{SiO}_{6}\right)$ onto oriented, polished and chemically cleaned (by $\mathrm{HF}$ etching) natural diopside substrates with $X_{\mathrm{Fe}}=[\mathrm{Fe}] /([\mathrm{Fe}]+[\mathrm{Mg}]+[\mathrm{Ca}]) \sim 0.025$. Al diffusion profiles were measured along the $c$-axis by NRA (using the nuclear reaction ${ }^{27} \mathrm{Al}(\mathrm{p}, \gamma){ }^{28} \mathrm{Si}$ ). Two experiments were performed at $0.1 \mathrm{MPa}, 1180{ }^{\circ} \mathrm{C}$ and $p \mathrm{O}_{2}=10^{-14} \mathrm{MPa}$ (controlled by a flowing $\mathrm{Ar}-\mathrm{H}_{2}-\mathrm{H}_{2} \mathrm{O}$ gas mixture), for 3.8 and 16.8 days, respectively. The two penetration profiles yielded the same concentration-independent Al diffusion coefficient $\left(\sim 3.7 \times 10^{-21} \mathrm{~m}^{2} / \mathrm{s}\right.$ and $\sim 2.7 \times 10^{-21} \mathrm{~m}^{2} / \mathrm{s}$ ). Jaoul et al. (1991) reported additional Al diffusion data obtained at $1000{ }^{\circ} \mathrm{C}$ and $1100{ }^{\circ} \mathrm{C}$, constraining the activation energy to $E_{\mathrm{a}}=273 \mathrm{~kJ} / \mathrm{mol}$. However, due to the use of an $\mathrm{Ar}-\mathrm{H}_{2}-\mathrm{H}_{2} \mathrm{O}$ mixture of constant composition, the dataset was obtained at oxygen fugacity that varied with temperature, equivalent to about an order of magnitude lower than that of the quartz-fayalite-iron (QFI) buffer. This pioneering work confirmed the extremely low diffusivities in clinopyroxenes, but did not clarify whether $\mathrm{Al}$ exchanged with $\mathrm{Mg}, \mathrm{Si}$ or both, nor the atomistic nature of the diffusion process.

Silicon self-diffusion. RBS and NRA (using the ${ }^{30} \mathrm{Si}(\mathrm{p}, \gamma){ }^{31} \mathrm{P}$ reaction) techniques were applied to investigate Si self-diffusion in diopside (Béjina and Jaoul 1996). The experimental approach was similar to that for Al. Thin films of synthetic diopside enriched in ${ }^{30} \mathrm{Si}$ were deposited by RF-sputtering onto oriented, polished and chemically cleaned natural diopside single crystals with $X_{\mathrm{Fe}} \sim 0.018$. Experiments were performed at $T=1040{ }^{\circ} \mathrm{C}, 1200{ }^{\circ} \mathrm{C}$ and $1250^{\circ} \mathrm{C}$, and at $p \mathrm{O}_{2}=4 \times 10^{-14}, 1.3 \times 10^{-14}$ and $8 \times 10^{-17} \mathrm{MPa}$, respectively. Oxygen fugacity changed with temperature due to the use of a single-composition $\mathrm{Ar}-\mathrm{H}_{2}-\mathrm{H}_{2} \mathrm{O}$ gas mixture, with oxygen fugacities about two orders of magnitude lower that of the QFI buffer. Si self-diffusion along the $c$-axis proved to be about an order of magnitude slower than Al. Due to the extremely slow diffusivities, only limited data were obtained and the activation energy was constrained with a large uncertainty: $E_{\mathrm{a}}=211 \pm 110 \mathrm{~kJ} / \mathrm{mol}$. The authors argued that this value may only be an apparent activation energy because it was not obtained at a fixed $\mathrm{OO}_{2}$ value. They speculated that if Si self-diffusion in diopside operates by an interstitial mechanism, as it does in olivine (Houlier et al. 1990), the diffusion coefficient might have been enhanced at lower oxygen fugacity, which would result in a lower apparent activation energy. In order to hypothetically illustrate this effect, the authors corrected their data using the theoretically derived dependence on oxygen fugacity for the concentration of Si interstitials, which is defined by the power law exponent $m=-3 / 16$ (e.g., Jaoul and Raterron 1994). Correspondingly, they calculated a possible activation energy of $280 \mathrm{~kJ} / \mathrm{mol}$ (see Fig. 1), which coincides with the previously reported value for Si self-diffusion in iron-bearing olivine (Houlier et al. 1990).

Calcium self-diffusion. Ca self-diffusion in diopside was first investigated by Dimanov and Ingrin (1995), Dimanov et al. (1996), Dimanov and Jaoul (1998), and recently by Zhang et al. (2010). All studies measured ${ }^{44} \mathrm{Ca}$ tracer diffusion at $0.1 \mathrm{MPa}$ total pressure. The first of these studies (Dimanov and Ingrin 1995; Dimanov et al. 1996; Dimanov and Jaoul 1998) considered Ca self-diffusion in various synthetic and natural iron-bearing diopside single crystals as a function of temperature, $p \mathrm{O}_{2}$, iron content and crystallographic orientation. Thin-film diffusion couples were prepared by RF sputtering of isotopically enriched synthetic diopside onto 
chemically etched diopside substrates; profiles were measured with RBS. These studies covered temperature ranges from $1000{ }^{\circ} \mathrm{C}$ up to near the melting point of diopside. Oxygen fugacity was controlled from ambient down to $10^{-18} \mathrm{MPa}$ by flowing gas mixtures of $\mathrm{Ar}-\mathrm{H}_{2} / \mathrm{Ar}-\mathrm{H}_{2} \mathrm{O}$. Depending on the experimental conditions, depth penetration profiles ranged between several tens to hundreds of $\mathrm{nm}$. Diffusion rates were found to depend on iron content, but exhibited little if any anisotropy along the $c$ - and $b$-axes over the investigated temperature range. The authors observed several diffusion regimes, depending on temperature and $p \mathrm{O}_{2}$ (Fig. 1c, Fig. 2). The most recent study (Zhang et al. 2010) was performed using tracer enriched thin films of $\mathrm{CaO}$, which were thermally evaporated onto natural, iron-bearing diopside single crystals. Experiments were performed at $950-1150{ }^{\circ} \mathrm{C}$, with oxygen fugacity controlled by $\mathrm{CO} / \mathrm{CO}_{2}$ gas mixtures to attain conditions equivalent to the iron-wüstite (IW) buffer. Diffusion profiles were analyzed by SIMS. Zhang et al. (2010) determined slight anisotropy in diffusion (Fig. 1c), with the lowest activation energy and the fastest diffusion rates along the $c$-axis, while diffusivities along the $b$ - and $a^{*}$-axes were found to be slower than along the $c$-axis (by about half an order of magnitude at $950{ }^{\circ} \mathrm{C}$ ) but nearly identical to each other.

For ${ }^{44} \mathrm{Ca}$ diffusion between $1000-1380{ }^{\circ} \mathrm{C}$, along the $b$-axis in synthetic iron-free diopside, Dimanov and Ingrin (1995) observed two regimes characterized by very different activation energies: $E_{\mathrm{a}}=280 \pm 26 \mathrm{~kJ} / \mathrm{mol}$ and $E_{\mathrm{a}}=951 \pm 87 \mathrm{~kJ} / \mathrm{mol}$ below and above $1242{ }^{\circ} \mathrm{C}$, respectively (Fig. 1c). In spite of the low impurity content of the synthetic diopside, it was suggested that the lower temperature regime was extrinsic. The higher temperature regime was considered intrinsic diffusion, with the process proceeding via $\mathrm{Ca}$ interstitials related to $\mathrm{Ca}$ Frenkel-type

Figure 1. (see next two pages) Arrhenius plot of diffusion coefficients for major cations in iron-bearing natural and synthetic pyroxenes (with low Fe). When possible (depending on the experimental results), the data are recalculated to $\mathrm{pO}_{2}=10^{-12} \mathrm{MPa}$ with the appropriate oxygen fugacity exponent $m$. When the dependence on oxygen fugacity was not investigated, the reported data correspond to the original buffering conditions (given in brackets).

a) Diffusion along the $c$-axis in clinopyroxene (diopside): $\mathrm{Ca}-(\mathrm{Mg}, \mathrm{Fe})-$ Brady and $\mathrm{McCallister}$ (1983); Al - Sautter et al. (1989); $\mathrm{Ca}^{1}$ - Dimanov et al. (1996); Si - Béjina and Jaoul (1996); Mg ${ }^{1}-$ Pacaud (1999); (Fe,Mn)-Mg ${ }^{1}$ - Dimanov and Sautter (2000); Fe - Azough and Freer (2000); (Fe,Mn)-Mg - Dimanov and Wiedenbeck (2006); $\mathrm{Mg}^{2}-$ Gasc et al. (2006); $\mathrm{Mg}^{3}-$ Zhang et al. (2010); $\mathrm{Ca}^{2}-\mathrm{Zhang}$ et al. (2010); Fe-Mg - Chakraborty et al. (2008). Although oxygen fugacity dependence was not explicitly investigated for Si (Béjina and Jaoul 1996), we have used their empirically suggested dependence $(m=$ $-3 / 16$ ), in order to show an example of how data obtained at varying oxygen fugacities (solid line, buffering conditions along QFI - 2 log units) may result in an apparent activation energy substantially different from the activation energy obtained at fixed $p \mathrm{O}_{2}$ (dotted line, data recalculated to $p \mathrm{O}_{2}=10^{-12} \mathrm{MPa}$ with $m=$ -3/16). The extrapolation of the data for $\mathrm{Mg}^{2}$ (Gasc et al. 2006) to lower temperatures is performed with the activation energy $E_{\mathrm{a}}=214 \mathrm{~kJ} / \mathrm{mol}$ proposed by Azough and Freer (2000).

b) Diffusion along the $c$-axis in orthopyroxene (enstatite): Fe-Mg ${ }^{1}-$ Ganguly and Tazzoli 1994; $\mathrm{Mg}-$ Schwandt et al. 1998; Cr - Ganguly et al. 2007 ( $m=-0.1)$; Fe-Mg (open square) - Klügel (2001); Fe-Mg (stars) - ter Heege et al. (2006) $(m=0.15)$. Although the oxygen fugacity dependence was not explicitly investigated for Fe-Mg (Ganguly and Tazzoli 1994), we have used the dependence $(m=0.17)$ reported by Stimpfl et al. (2005). The regression line for the data of ter Heege et al. (2006) must only be considered as indicative because of the very few available data. It suggests, however, similar activation energy to that for $\mathrm{Mg}$ from Schwandt et al. (1998) and for Fe-Mg from Ganguly and Tazzoli (1994).

c) Anisotropy of diffusion in clinopyroxenes (crystallographic axes are indicated in brackets): $\mathrm{Ca}^{1}$ - Dimanov et al. (1996), Dimanov and Jaoul (1998); Ca - Dimanov and Ingrin (1995); Fe - Azough and Freer (2000); $\mathrm{Mg}^{2}-$ Gasc et al. (2006); $\mathrm{Mg}^{4}$ and $\mathrm{Ca}^{2}-$ Zhang et al. (2010). For the data showing anisotropy, diffusion is fastest along the $c$-axis. Extrinsic, intrinsic and transitional diffusion regimes (denoted by $\mathrm{Ca}-$ Extr, Ca-Intr, Ca-Trans) are reported for Ca (Dimanov et al. 1996; Dimanov and Jaoul 1998; Dimanov and Ingrin 1995). Diffusion of Ca and Fe in synthetic crystals (labeled Syn) is shown to be slower than in natural materials.

d) Anisotropy of diffusion in orthopyroxenes (crystallographic axes are indicated in brackets): Mg - Schwandt et al. (1998); Cr - Ganguly et al. (2007. Diffusion along the $c$-axis is the fastest. The regressions of the original data of Ganguly et al. (2007) are indicated by dotted-dashed lines, but the authors recommended the regressions indicated by solid- and dotted lines. 

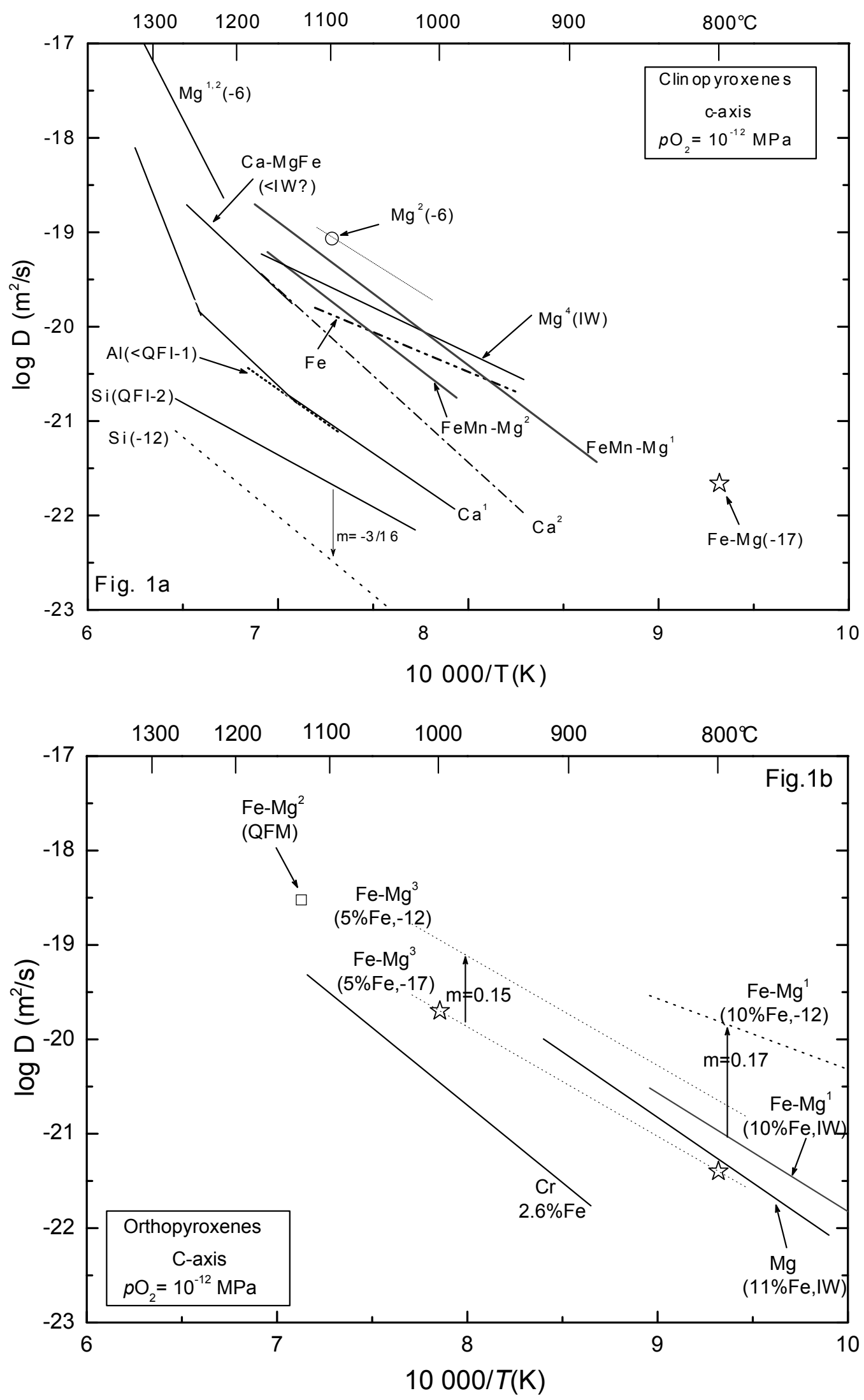

Figures 1a and 1b. See caption on facing page. 

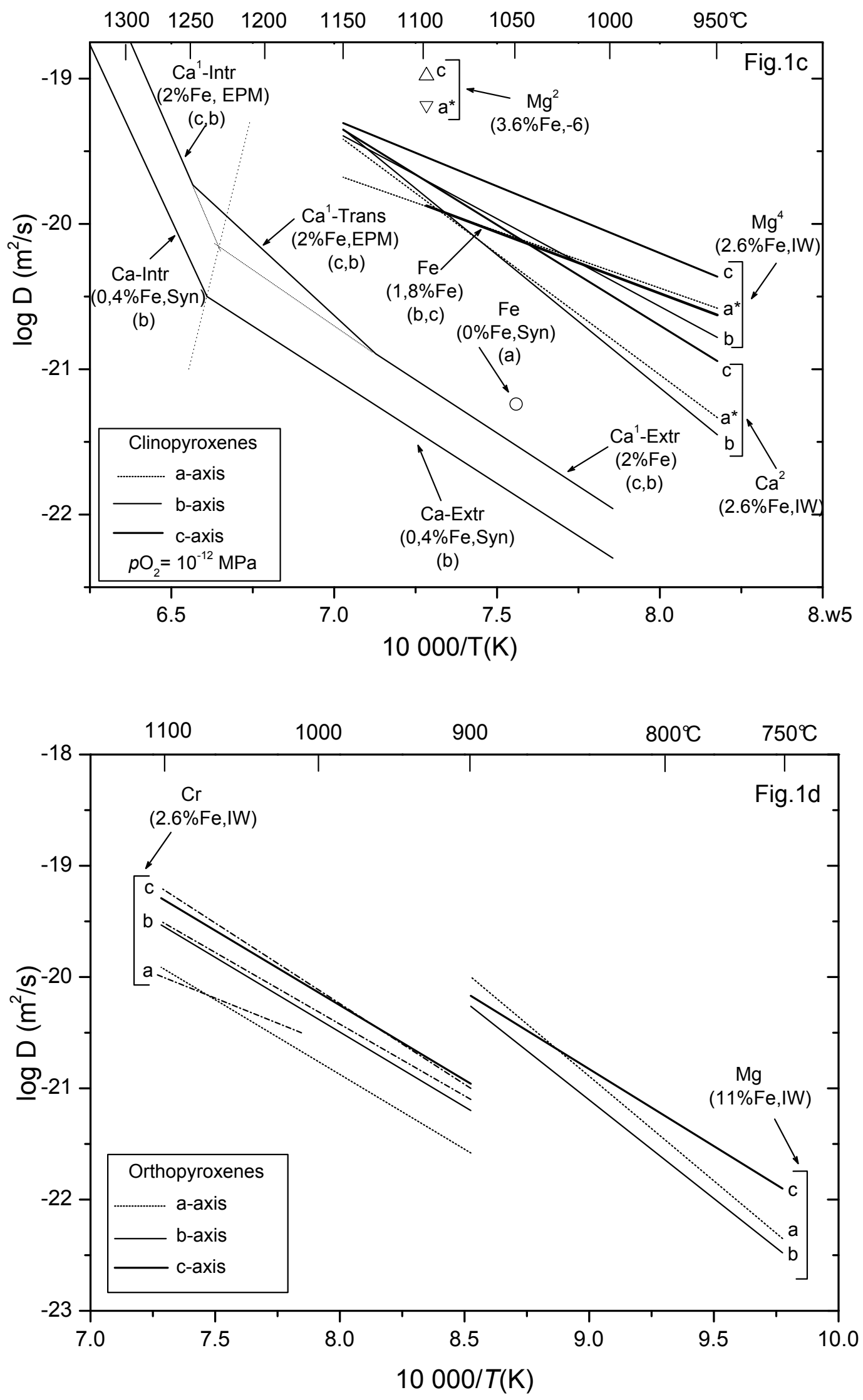

Figures 1c and 1d. See caption on previous page. 


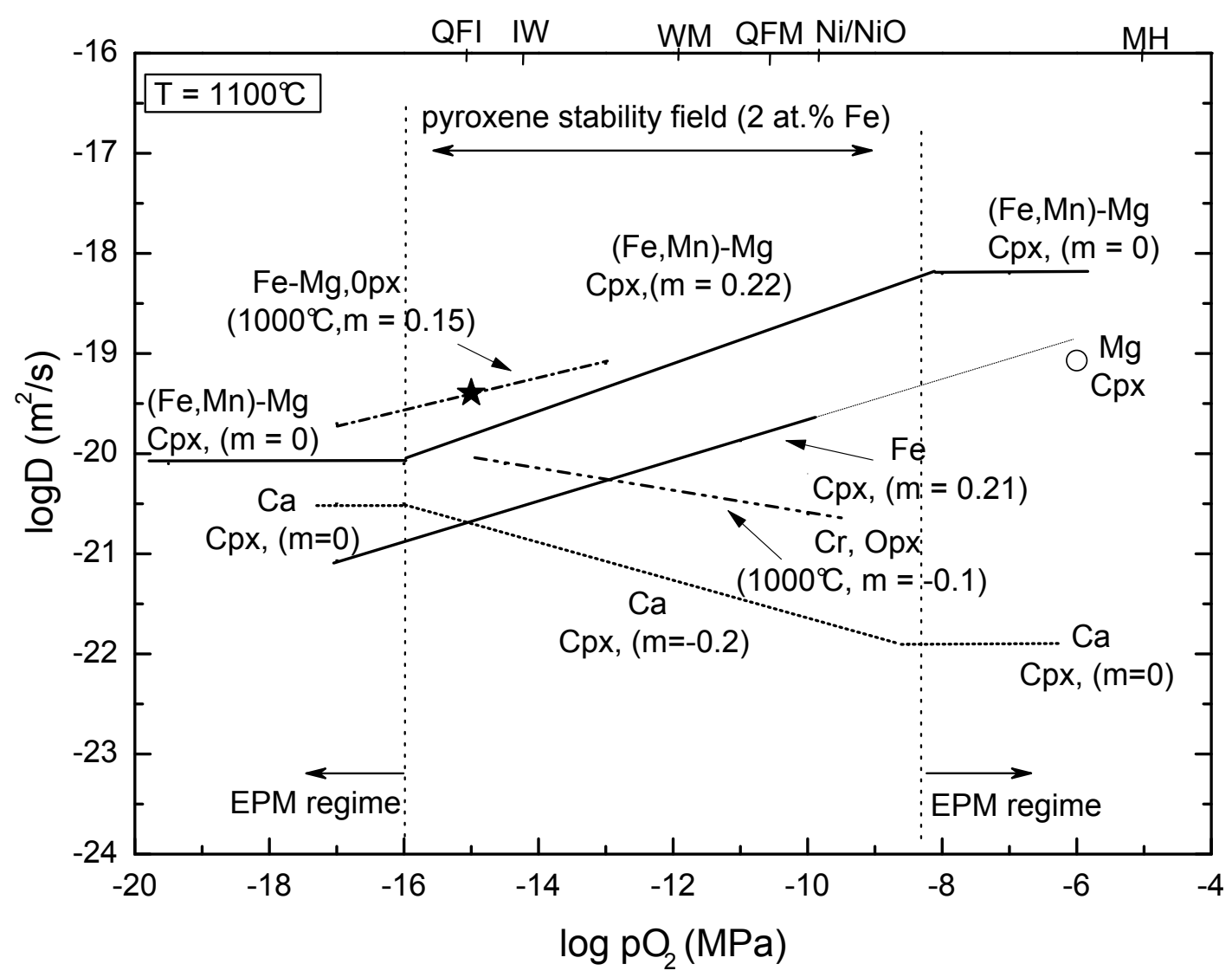

Figure 2. Oxygen fugacity dependence of diffusion coefficients for major cations in iron-bearing pyroxenes. Data are reported for $T=1100{ }^{\circ} \mathrm{C}$. On the top axis are the $p \mathrm{O}_{2}$ values imposed by the major solid buffers QFI, IW, WM, QFM and $\mathrm{MH}$ at $1100^{\circ} \mathrm{C}$. Between $p \mathrm{O}_{2}=10^{-16} \mathrm{MPa}$ and $p \mathrm{O}_{2}=10^{-8} \mathrm{MPa}$ ironbearing clinopyroxene $(2$ at $\% \mathrm{Fe}$ ) is in its stability field-i.e., in equilibrium with oxygen-which fixes the $\mathrm{Fe}^{2+} / \mathrm{Fe}^{3+}$ ratio and point defect populations (see text for additional discussion). Beyond the stability field limits, the clinopyroxene presents EPM (early partial melting, which is the exsolution of silica microdroplets, see text for further information), which prevents the oversaturation of point defects. Within the stability field, diffusion in diopside (Cpx) of Fe (Azough and Freer 2000) and (Fe,Mn)-Mg interdiffusion (Dimanov and Wiedenbeck 2006) exhibit a positive dependence on $\mathrm{pO}_{2}$, indicating vacancy mechanisms. In contrast, diffusion of $\mathrm{Ca}$ in diopside (Dimanov et al. 1996) and of $\mathrm{Cr}$ in enstatite (Ganguly et al. 2007) exhibit a negative dependence on $\mathrm{pO}_{2}$ in the stability field, indicating interstitial mechanisms. Beyond the stability field limits $p \mathrm{O}_{2}$ dependencies vanish. $\mathrm{Mg}$ diffusion in diopside (Gasc et al. 2006) is also reported, and the data correspond to Fe diffusion after extrapolation to higher oxygen fugacity. In enstatite (Opx), interdiffusion of Fe- $\mathrm{Mg}$ (ter Heege et al. 2006) shows a positive $\mathrm{pO}_{2}$-dependence and the data correspond closely to the data of Ganguly and Tazzoli (1994) when extrapolated to higher temperatures.

defects. This interpretation was supported by the so called premelting phenomenon, which was observed during calorimetric investigations of diopside and other silicates (Richet and Fiquet 1991; Richet et al. 1994), and which manifests itself by an anomalous increase of heat capacity when approaching the melting point. Premelting is usually attributed to intrinsic (thermal) point defects, cation disordering, phase transitions, or sublattice melting (Ubbelohde 1978). Dimanov and Ingrin (1995) showed that the enthalpy excess associated with the anomalous increase of heat capacity may be compared to the formation enthalpy of Ca Frenkel defects and related to the observed enhancement of Ca self-diffusion above $\sim 1240{ }^{\circ} \mathrm{C}$. Hence, the authors attributed diopside premelting to a sort of $\mathrm{Ca}$ disorder among M2 and interstitial sites. The authors calculated that close to the melting point, the Ca-Frenkel defect concentrations may be as high as a few mole percent, which in turn is the basis for sub-lattice melting. Their suggestion that dominant $\mathrm{Ca}$ Frenkel type defects are responsible for the intrinsic diffusion 
regime (or premelting regime) was later corroborated by Pacaud et al. (1999) and Ingrin et al. (2001), who measured oxygen self-diffusion in the same synthetic Fe-free diopside and did not detect any diffusional enhancement in the premelting regime, thus precluding Schottky type defects as dominant.

Dimanov et al. (1996) used natural iron-bearing diopside single crystals with different iron contents and measured ${ }^{44} \mathrm{Ca}$ diffusion along the $c$ - and $b$-axes. Specimens were annealed between $1000^{\circ} \mathrm{C}$ and $1250^{\circ} \mathrm{C}$, under controlled oxygen fugacity, between $0.021 \mathrm{MPa}$ (air) and $10^{-18} \mathrm{MPa}$. Diffusion profiles were analyzed by RBS. As observed earlier for Sr diffusion by Sneeringer et al. (1984), Ca diffusion was found to be isotropic over the investigated temperature range and to be faster in natural than in synthetic crystals (Fig. 1c). For iron contents $X_{\mathrm{Fe}}$ between 0.004 and 0.025 , Ca diffusion rates were found to depend on Fe content, described by the relationship $\left(X_{\mathrm{Fe}}\right)^{0.24}$. The authors reported two distinct diffusion regimes, with a transition temperature $\left(T_{\mathrm{c}}\right)$ ranging between $1100{ }^{\circ} \mathrm{C}$ and $1150{ }^{\circ} \mathrm{C}$, depending on $\mathrm{pO}_{2}$. (Figs. 1a, 1c, 2) The authors noticed that above $T_{\mathrm{c}}$, diopside exhibits the early partial melting (EPM, see below) phenomenon, the precipitation of small $(<\sim 100 \mathrm{~nm})$ silica droplets within the diopside crystal, which occurs in response to over-saturation of extrinsic cation vacancies related to the Fe oxidation state, and hence to $\mathrm{pO}_{2}$ (Raterron and Jaoul 1991; Jaoul and Raterron 1994). In the EPM regime, Ca selfdiffusion is characterized by an activation energy of $E_{\mathrm{a}}=396 \pm 38 \mathrm{~kJ} / \mathrm{mol}$, and is independent of $p \mathrm{O}_{2}$. Below $T_{\mathrm{c}}$, in the EPM-free regime, Ca self-diffusion has a lower activation energy, $E_{\mathrm{a}}=264 \pm 33 \mathrm{~kJ} / \mathrm{mol}$, and varies as $\left(p \mathrm{O}_{2}\right)^{-0.14}$ between $p \mathrm{O}_{2}=10^{-17}-10^{-7} \mathrm{MPa}$. Based on their observations and the point defect model (see below) refined by Jaoul and Raterron (1994), Dimanov et al. (1996) proposed an interstitial mechanism for Ca self-diffusion. As noted later by several authors (Cherniak 1998a; Zhang et al. 2010), the data of Dimanov et al. (1996) do not strongly appear to support a change of diffusion regime; given the experimental scatter the entire dataset may also be fitted by a single linear relation rather than two distinct Arrhenius lines. However, Dimanov et al. (1996) could discriminate between the two distinct regimes on the basis of a statistically sound data set (77 independent experimental data points), analyzed with two different data inversion procedures. One of the inversions was based on the Bayesian probabilistic approach (Weber and Taupin 1995; Taupin 1998), while the other was a classical least-squares non-linear inversion (Sotin and Poirrier 1984). Both procedures could provide the complete fitting parameter set $\left(D_{0}, m, E_{\mathrm{a}}\right)$, the corresponding errors, and statistical analysis of the residuals, in order to evaluate the adequacy of the fitting model. In particular, the presence of two diffusion regimes was indicated by a bi-modal distribution of residuals when performing a least-squares fit based on a single diffusion regime. In addition to the purely statistical aspect, the authors also considered that the observed change of $p \mathrm{O}_{2}$ dependence justifies data analysis in terms of two different regimes, because this implicitly indicates either a change of diffusion mechanism, or at least a different dominant reaction for formation of point defects.

Preliminary work by Stimpfl et al. (2003) and the more recent and extensive study of Zhang et al. (2010) reported results for Ca self-diffusion in diopside. Both studies were performed in the same laboratory and are based on similar experimental procedures and analytical techniques, but given the greater scope of the investigation of Zhang et al. (2010), this study supersedes the findings of Stimpfl et al. (2003) (J. Ganguly, personal communication). ${ }^{44} \mathrm{Ca}$ enriched $\mathrm{CaO}$ thin films were deposited by thermal evaporation onto oriented single crystals containing $~ 2.5$ at $\%$ Fe. The diffusion experiments were performed between $950-1150{ }^{\circ} \mathrm{C}$, in a dry environment, with $\mathrm{CO} / \mathrm{CO}_{2}$ gas mixtures adjusted to buffer the system at an oxygen fugacity equivalent to the IW buffer. Zhang et al. (2010) reported a lower activation energy $\left(E_{\mathrm{a}}=264 \pm 23 \mathrm{~kJ} / \mathrm{mol}\right)$ and faster diffusion rates for diffusion along the $c$-axis, while diffusivities along the $a^{*}$ - and $b$-axes were comparable (Fig. 1c). Diffusion along the $c$-axis was about half an order of magnitude faster at $950{ }^{\circ} \mathrm{C}$, but due to the difference in activation energies for the different orientations the diffusion anisotropy vanishes above $1050{ }^{\circ} \mathrm{C}$, which is in good agreement with the observations of Dimanov et al. (1996) and Dimanov and Jaoul (1998), who reported isotropic diffusion along 
the $c$ - and $b$-axes above $1000{ }^{\circ} \mathrm{C}$. However, the diffusion rates reported by Zhang et al. (2010) are about 1.5 orders of magnitude faster than those reported by Dimanov et al. (1996) and Dimanov and Jaoul (1998). Zhang et al. (2010) highlighted the discrepancies between their results and those of Dimanov et al. (1996), but noted the relatively good agreement between their results and the high pressure $\mathrm{Ca}-(\mathrm{Mg}, \mathrm{Fe})$ interdiffusion data of Brady and McCallister (1983), after providing corrections to compare with findings of the latter study to account for the effects of pressure and non-ideal mixing. However, the corrections may be called into question because they were performed with different activation volumes (varying between $4-7 \mathrm{~cm}^{3} / \mathrm{mol}$, Zhang et al. 2010), and because they do not account for the differences in oxygen fugacity among the studies. Indeed, the high temperature (1100-1200 $\left.{ }^{\circ} \mathrm{C}\right)$ and pressure $(2.5 \mathrm{GPa})$ data of Brady and McCallister (1983), might correspond to lower oxygen fugacity than the IW conditions of Zhang et al. (2010); experiments run under graphite-buffered conditions in piston-cylinder apparatus have been recognized to differ substantially from what would be expected for a pure C-CO buffer (Holloway et al. 1992; Hirschmann et al. 2008; Médard et al. 2008). For example, Médard et al. (2008) report that the potential range of conditions varies from C-CO to four orders of magnitude lower. Similarly, Zhang et al. (2010) do not adequately compare their results with those from Dimanov et al. (1996) and those for Fe diffusion from Azough and Freer (2000), because the data of Zhang et al. (2010) correspond to an oxygen fugacity that varies with temperature (between $\sim 10^{-17}-10^{-13} \mathrm{MPa}$, i.e., along the IW buffer), while the data of Dimanov et al. (1996) and of Azough and Freer (2000) correspond to fixed oxygen fugacities (of 10 $10^{-12}$ MPa and $10^{-14} \mathrm{MPa}$, respectively). Both Dimanov et al. (1996) and Azough and Freer (2000) demonstrated marked effects of oxygen fugacity, so corrections to account for differences in $p \mathrm{O}_{2}$ are critical for direct comparison. In general, diffusion data obtained at oxygen fugacity conditions which vary with temperature (such as with a solid buffer) present only an apparent activation energy, because the variation of point defect populations, and hence of diffusion rates, are not solely determined by temperature. However in natural systems, for example the cooling of a self-buffered natural assemblage, oxygen fugacity will vary, and correspondingly the populations of extrinsic point defects will vary so diffusion rates are affected as well. Hence for geological applications it may be convenient and useful to present diffusion data under conditions that correspond to solid buffers. But it is important to recognize that an apparent activation energy determined under such conditions corresponds to behavior under the given buffer and does not represent the thermal activation of the diffusion process itself. The latter can only be determined at fixed $p \mathrm{O}_{2}$, when populations of extrinsic point defects are independent of temperature. Therefore, comparison of different data sets might only be fairly performed at comparable thermodynamic conditions, either along the same oxygen fugacity buffer, or at a fixed oxygen fugacity. This type of comparison is illustrated in Figure 1a, where all diffusion data for major cations in pyroxenes were recalculated to $p \mathrm{O}_{2}=10^{-12} \mathrm{MPa}$, for cases where dependence on oxygen fugacity was investigated and quantified. For instance, since Zhang et al. (2010) did not report EPM, we corrected their data according to the $p \mathrm{O}_{2}$ exponent $m=-3 / 16$, which is the theoretical value calculated by Jaoul and Raterron (1994) in the EPM-free regime, and is also close to the experimental values $(m=-0.18$, Dimanov et al. 1996; $m=-0.19$, Dimanov and Jaoul 1998). The data of Zhang et al. (2010) fall in much better agreement with the previously published data of Dimanov et al. (1996) after this correction (Fig. 1). However, because the samples and the experimental techniques employed in these studies are different, it is not surprising that some differences may remain.

Dimanov and Jaoul (1998) further investigated Ca self-diffusion in natural iron-bearing diopside under controlled oxygen fugacity, and at temperatures up to $1320^{\circ} \mathrm{C}$ (i.e., $30^{\circ}$ below the nominal melting point). As in the work of Dimanov and Ingrin (1995), they observed two distinct diffusion regimes, characterized by activation energies of $284 \pm 10 \mathrm{~kJ} / \mathrm{mol}$ and $1006 \pm 75 \mathrm{~kJ} / \mathrm{mol}$ below and above $T=1230 \pm 15^{\circ} \mathrm{C}$, respectively (Fig. 1a, 1c). In the lower temperature regime, Ca self-diffusion was proportional to $\left(\mathrm{pO}_{2}\right)^{-0.19 \pm 0.03}$. Following their previous studies (Dimanov 
and Ingrin 1995; Dimanov et al. 1996), the lower temperature, $p \mathrm{O}_{2}$ dependent diffusion regime was interpreted as an extrinsic one, while the higher temperature regime was interpreted in terms of intrinsic diffusion and premelting conditions, as was previously proposed for synthetic Fe-poor diopside (Dimanov and Ingrin 1995). On the basis of their work, Dimanov and Jaoul (1998) alternatively suggested that the $\mathrm{pO}_{2}$ independent diffusion regime, characterized by an intermediate activation energy $E_{\mathrm{a}}=396 \pm 38 \mathrm{~kJ} / \mathrm{mol}$ between $\sim 1150{ }^{\circ} \mathrm{C}$ and $1250{ }^{\circ} \mathrm{C}$ (Dimanov et al. 1996) may actually represent a transitional mixed mode between extrinsic and intrinsic regimes (Fig. 1c). Based on the crystal structure and diffusional isotropy the authors also suggested that in both regimes Ca self-diffusion might involve the well-known M3 (distorted octahedron) interstitial sites, located in the octahedral layers, but also new octahedral interstitial sites that the authors identified within the tetrahedral layers and termed M4.

In summary: i) when point defect concentrations are determined by the Fe oxidation state, Ca extrinsic self-diffusion operates by an interstitial mechanism, in which the activation energy does not depend on low Fe concentrations $(<2.5$ at $\%)$; ii) when point defect concentrations are essentially thermally activated, Ca-Frenkel type defects are dominant, and hence Ca intrinsic self-diffusion still operates by an interstitial mechanism involving M3 and newly recognized M4 interstitial sites; iii) owing to the interstitial mechanism, Ca diffusion is isotropic at temperatures above $1000{ }^{\circ} \mathrm{C}$, but could become anisotropic at lower temperatures, due to a somewhat lower activation energy for diffusion along the $c$-axis; v) $\mathrm{Ca}$ is the slowest-diffusing octahedral cation and is therefore a kinetically limiting species.

Iron. Azough and Freer (2000) measured ${ }^{54} \mathrm{Fe}$ tracer diffusion along the $\mathrm{b}$ and $c$-axis directions in synthetic Fe-free single crystals of diopside and natural diopside containing 1.8 at $\%$ Fe. Diffusion couples were produced by deposition of thick films (0.1-0.2 $\mu \mathrm{m})$ of Fe citrate gel, obtained by mixing and heating ${ }^{54} \mathrm{Fe}$ enriched iron chloride and citric acid, on oriented, polished and chemically cleaned diopside samples. Subsequent annealing for 2 hours at 1050 ${ }^{\circ} \mathrm{C}$ in a reducing atmosphere resulted in crystallization of the gel, ensuring good interfacial contact, evidenced by the significant enrichment in $\mathrm{Ca}, \mathrm{Mg}$ and $\mathrm{Si}$. Diffusion couples were placed in Pt crucibles, with diffusion experiments performed at room pressure at temperatures between $950-1100{ }^{\circ} \mathrm{C}$, with oxygen fugacity controlled by flowing $\mathrm{H}_{2} / \mathrm{CO}_{2}$ gas mixtures. An activation energy for diffusion was determined at a fixed $p \mathrm{O}_{2}=10^{-14} \mathrm{MPa}$, and the dependence of Fe diffusion on oxygen fugacity was determined at $1050^{\circ} \mathrm{C}$ between $p \mathrm{O}_{2}=10^{-11} \mathrm{MPa}$ and $10^{-17} \mathrm{MPa}$. After the longer experimental anneals the composition of the deposited surface layer approached that of diopside. Diffusion profiles, extending over $\sim 0.1-0.6 \mu \mathrm{m}$, were acquired by SIMS. The data were analyzed with different analytical solutions to the diffusion equation, with thin, thick or infinite surface source boundary conditions, depending on the comparison between diffusion lengths and thicknesses of surface films; film thickness was determined with SIMS prior to diffusion anneals. The different solutions resulted in diffusion coefficients spanning an order of magnitude, yielding pre-exponential factors within a factor of $\sim 5$ and similar activation energies. Their recommended Fe diffusion coefficient was taken as the mean of the two most reliable analytical treatments.

As in the case of Ca (Dimanov et al. 1996), Fe diffusion rates in the natural diopside were found to be effectively the same parallel to the $c$ and $b$ axes (Fig. 1c), and to depend on $p \mathrm{O}_{2}$ (Fig. 2). Between $p \mathrm{O}_{2}=10^{-11}-10^{-17} \mathrm{MPa}$ diffusion of $\mathrm{Fe}$ in the natural (iron-bearing) diopside crystals at $1050{ }^{\circ} \mathrm{C}$ was determined to be proportional to $\left(p \mathrm{O}_{2}\right)^{0.229 \pm 0.036}$. Based on this observation and on the previous work of Jaoul and Raterron (1994) and Dimanov et al. (1996) the authors proposed a vacancy mechanism for Fe diffusion in diopside. From results of atomistic simulations of vacancy formation in diopside (Azough et al. 1998) the authors inferred that the low activation energy $\left(E_{\mathrm{a}}=162 \pm 35 \mathrm{~kJ} / \mathrm{mol}\right.$ obtained at $\left.p \mathrm{O}_{2}=10^{-14} \mathrm{MPa}\right)$ was representative of the migration energy for vacancy related extrinsic diffusion. Fe diffusion at $1050{ }^{\circ} \mathrm{C}$ in the iron-free synthetic samples was approximately one order of magnitude slower than in the natural crystals (Fig. 1c). 
Magnesium self-diffusion. Mg self-diffusion in diopside at ambient pressure was measured with NRA by the group of Olivier Jaoul (Pacaud 1999; Gasc et al. 2006). In these studies ${ }^{26} \mathrm{Mg}$-enriched synthetic diopside was deposited as a thin film $(\sim 50 \mathrm{~nm})$ by RF sputtering onto polished and chemically cleaned iron-bearing ( 3.6 at $\% \mathrm{Fe})$ natural diopside and the iron-poor synthetic diopside single crystals used by Dimanov and Ingrin (1995). Natural samples oriented for diffusion along the $a^{*}$ - and $c$-axes were annealed at $T=1100{ }^{\circ} \mathrm{C}$. Synthetic samples, oriented for diffusion along the $a$-, $b$ - and $c$-axes, were annealed at $T=1200-1300{ }^{\circ} \mathrm{C}$. An oxygen fugacity $p \mathrm{O}_{2}=10^{-6} \mathrm{MPa}$ was controlled by flowing Ar. Diffusion profiles were analyzed by the nuclear reaction ${ }^{26} \mathrm{Mg}(\mathrm{p}, \gamma)^{27} \mathrm{Al}$; diffusion profiles extended up to $150 \mathrm{~nm}$.

Consistent with the findings for diffusion of Ca (Dimanov et al. 1996, Dimanov and Jaoul 1998) and Fe (Azough and Freer 2000), no obvious anisotropy was observed for the synthetic samples at the investigated temperatures. The limited data for natural diopside also suggest little anisotropy (Fig. 1c). The Mg diffusion coefficients in the synthetic diopside samples $\left(D_{\mathrm{Mg}}=7.8 \times 10^{-19}-4.2 \times 10^{-18} \mathrm{~m}^{2} / \mathrm{s}\right.$ at $T=1300{ }^{\circ} \mathrm{C}$ and $D_{\mathrm{Mg}}=3.6 \times 10^{-19}-4.2 \times 10^{-19} \mathrm{~m}^{2} / \mathrm{s}$ at $\left.T=1200{ }^{\circ} \mathrm{C}\right)$ and in natural samples $\left(D_{\mathrm{Mg}}=6.03 \times 10^{-20}-1.4 \times 10^{-19} \mathrm{~m}^{2} / \mathrm{s}\right.$ at $\left.T=1100{ }^{\circ} \mathrm{C}\right)$ proved to be substantially higher (about two orders of magnitude) than those for calcium in the same materials (Dimanov and Ingrin 1995; Dimanov et al. 1996; Dimanov and Jaoul 1998). As previously observed for calcium (Dimanov et al. 1996) and for iron (Azough and Freer 2000), Mg is significantly faster in natural iron-bearing diopside than in synthetic iron-free or iron-poor material. Combining the limited data sets of Pacaud (1999) and Gasc et al. (2006) one can obtain an activation energy of $E_{\mathrm{a}}=748 \pm 87 \mathrm{~kJ} / \mathrm{mol}$ for $\mathrm{Mg}$ self-diffusion in synthetic diopside between $T=1200-1300^{\circ} \mathrm{C}$. This value is much higher than proposed by Azough and Freer (2000) for extrinsic vacancy-mediated diffusion, but it is consistent with the findings of Dimanov and Ingrin (1996) for Ca self-diffusion in the intrinsic regime $\left(E_{\mathrm{a}}=950 \mathrm{~kJ} / \mathrm{mol}\right.$, above $T \sim 1230{ }^{\circ} \mathrm{C}$ ), where Ca-Frenkel defects dominate. The combined results of Pacaud (1999) and Gasc et al. (2006) suggest that the Mg sublattice may also be affected by the premelting regime.

In an abstract in 2003, Stimpfl et al. reported preliminary results of $\mathrm{Mg}$ self-diffusion in diopside, measuring isotopic exchange between diopside and ${ }^{26} \mathrm{Mg}$-enriched $\mathrm{MgO}$ thin films, with the films deposited by thermal evaporation onto oriented diopside single crystals. Diffusion experiments were performed at $0.1 \mathrm{MPa}$ under conditions near the IW buffer, and diffusion profiles were measured by SIMS. This preliminary work has been superseded by a more comprehensive study of Mg diffusion (Zhang et al. 2010) from the same laboratory. Zhang et al. (2010) measured diffusion along the three crystallographic axes, between 950$1150{ }^{\circ} \mathrm{C}$ at $0.1 \mathrm{MPa}$, and with $p \mathrm{O}_{2}$ near the IW buffer, controlled using $\mathrm{CO}-\mathrm{CO}_{2}$ gas mixtures. As in the case of their Ca diffusion results, Zhang et al. (2010) observed that Mg diffusion along $c$-axis was somewhat faster than along $a^{*}$ - and $b$-axes (Fig. 1c). The activation energy for $\mathrm{Mg}$ self-diffusion along the three crystallographic axes was found to vary between $150 \pm 22$ $\mathrm{kJ} / \mathrm{mol}$ and $231 \pm 23 \mathrm{~kJ} / \mathrm{mol}$. These values correspond reasonably well to those measured by Azough and Freer (2000) for Fe self-diffusion $\left(E_{\mathrm{a}}=162 \pm 35 \mathrm{~kJ} / \mathrm{mol}\right)$ and their estimates for $\mathrm{Mg}$ self-diffusion $\left(E_{\mathrm{a}}=214 \mathrm{~kJ} / \mathrm{mol}\right)$ based on their previously published atomistic simulations of vacancy mediated mechanisms (Azough et al. 1998).

In Figures 1a and 1c, it can be seen that the Mg diffusion data of Gasc et al. (2006) obtained at $1100^{\circ} \mathrm{C}$ are within half an order of magnitude of the recent $\mathrm{Mg}$ diffusion data of Zhang et al. (2010) when extrapolated down to their temperature range $\left(900-1000{ }^{\circ} \mathrm{C}\right)$ with the activation energy $(214 \mathrm{~kJ} / \mathrm{mol})$ proposed by Azough and Freer (2000). However, this agreement may be fortuitous since the studies were not performed under the same conditions of oxygen fugacity. The numerical and experimental findings of Azough et al. (1998) and Azough and Freer (2000) indicate that vacancy related mechanisms might be favorable for both $\mathrm{Fe}$ and $\mathrm{Mg}$ diffusion. For these mechanisms the hypothetical oxygen fugacity exponent of the $\mathrm{Mg}$ diffusion coefficient should be positive, as it is in the case of Fe diffusion. If the differences in oxygen fugacities 
among data sets are considered in order to directly compare the data at an intermediate $p \mathrm{O}_{2}$, the diffusivities of Gasc et al. (2006) obtained at high oxygen fugacity $\left(p \mathrm{O}_{2}=10^{-6} \mathrm{MPa}\right)$ should be lowered, while those of Zhang et al. (2010) obtained at low oxygen fugacity (IW conditions) should be raised. Unfortunately, since the dependence on oxygen fugacity of $\mathrm{Mg}$ diffusion in diopside was not investigated in any of the extant studies, it is difficult to quantify the appropriate corrections.

(Fe,Mn)-Mg and Fe-Mg interdiffusion. Dimanov and Sautter (2000) and Dimanov and Wiedenbeck (2006) investigated (Fe,Mn)-Mg interdiffusion along the $c$ axis in natural diopside single crystals $\left(X_{\mathrm{Fe}} \sim 0.03\right)$. In both studies the diffusion couples were prepared by RF-sputtering of ferro-johannsenite (Mn-rich hedenbergite) thin $(<50 \mathrm{~nm})$ films onto polished and chemically cleaned oriented iron-bearing diopside samples. Iron and manganese surface films contained $\mathrm{Fe} /(\mathrm{Fe}+\mathrm{Mn}+\mathrm{Mg}) \sim 0.48$. Diffusion couples were placed in sintered diopside crucibles and annealing was performed at ambient pressure, temperatures between $900-1240{ }^{\circ} \mathrm{C}$, and at low oxygen fugacities controlled between $p \mathrm{O}_{2}=10^{-7}-10^{-19} \mathrm{MPa}$ by either $\mathrm{CO} / \mathrm{CO}_{2}$ (Dimanov and Wiedenbeck 2006), or Ar- $\mathrm{H}_{2} / \mathrm{Ar}-\mathrm{H}_{2} \mathrm{O}$ (Dimanov and Sautter 2000) gas mixtures. Dimanov and Sautter (2000) determined the diffusion profiles of Fe and Mn (ranging in length from 30 to $350 \mathrm{~nm}$ ) by both RBS and SIMS, while Dimanov and Wiedenbeck (2006) used only SIMS. Fe and $\mathrm{Mn}$ from the surface layer exchanged with $\mathrm{Mg}$ from the diopside substrate. As M2 sites were saturated with calcium in both the substrate and the surface layer, the exchange involved essentially only the M1 sublattice. During this pseudo-binary (Fe,Mn)-Mg interdiffusion process, Fe and Mn diffused at similar rates. Diffusion profiles were successfully evaluated with concentration-independent diffusion coefficients and a thin source solution to the diffusion equation. However, in all experiments Dimanov and Sautter (2000) used the same gas mixture to set oxygen fugacity, resulting in temperature-dependent oxygen fugacity (see previous sections). They noted that if the diffusion mechanism is vacancy-related the reported activation energy ( $406 \pm 64 \mathrm{~kJ} / \mathrm{mol})$ might be overestimated.

Dimanov and Wiedenbeck (2006) continued the study of Dimanov and Sautter (2000), focusing on the effects of oxygen fugacity. They investigated both EPM-present and EPM-free regimes, at temperatures between $1000-120{ }^{\circ} \mathrm{C}$ and $p \mathrm{O}_{2}=10^{-7}-10^{-19} \mathrm{MPa}$. As shown in Figure 2, at both high and extremely low oxygen fugacities EPM was observed and the interdiffusion process was $\mathrm{pO}_{2}$ independent. In an intermediate regime, where diopside is in equilibrium with respect to point defect concentrations and is EPM-free, the interdiffusion coefficient depends on $\mathrm{OO}_{2}$ with an exponent $m=0.22 \pm 0.02$, which is very similar to that reported by Azough and Freer (2000) for Fe self-diffusion. Dimanov and Wiedenbeck (2006) found that in the EPMfree regime, at fixed $p \mathrm{O}_{2}=10^{-14} \mathrm{MPa}$, the activation energy is $E_{\mathrm{a}}=297 \pm 31 \mathrm{~kJ} / \mathrm{mol}$, which is substantially lower than the previously reported value (Dimanov and Sautter 2000). However, in Figure 1a it can be seen that the data of Dimanov and Sautter (2000) and Dimanov and Wiedenbeck (2006) are in reasonably good agreement both in terms of magnitude of diffusivities and activation energy after $p \mathrm{O}_{2}$ corrections are made to the former dataset. Both datasets still differ by about half an order of magnitude, but this moderate discrepancy may result from the different analytical techniques (e.g., SIMS versus RBS). Some difference may also result from the fact that Dimanov and Wiedenbeck (2006) controlled oxygen fugacity with dry $\mathrm{CO} / \mathrm{CO}_{2}$ gas mixtures, while Dimanov and Sautter (2000) employed $\mathrm{Ar}-\mathrm{H}_{2} / \mathrm{Ar}-\mathrm{H}_{2} \mathrm{O}$ mixtures, in which hydrogen was present. It has been shown (Hier-Majumder et al. 2004; Demouchy et al. 2007) that hydrogen incorporation within the crystal structure is accommodated by iron reduction and concomitant point defect formation, resulting in the enhancement of cation diffusion in ironbearing silicates and oxides.

Figure 1a also shows that in the range $900-1100{ }^{\circ} \mathrm{C}$ the (Fe,Mn)-Mg interdiffusion rates (Dimanov and Sautter 2001; Dimanov and Wiedenbeck 2006) and self-diffusion rates of Fe (Azough and Freer 2000) and Mg (Gasc et al. 2006; Zhang et al. 2010) are all within less than an order of magnitude. In contrast, Ca diffusion rates (Dimanov et al. 1996; Dimanov and 
Jaoul 1998; Zhang et al. 2010) are substantially lower, which confirms that Ca is the kinetically limiting species among octahedral cations.

In comparison with other silicates, the diffusion rates in diopside are unusually slow for interdiffusion processes involving Fe and Mg. Dimanov and Sautter (2000) observed that as well as being comparatively slow, all diffusion rates for major cations in diopside reported thus far are also closely grouped (within less than 3 orders of magnitude, see Fig. 1a), while cation diffusion rates at similar conditions in olivines and garnets and much more widely spread. The authors argued that this behavior reflects a strong crystal-electrochemical coupling between the octahedral and tetrahedral sublattices, with many divalent and trivalent cations able to occupy all of the different crystal sites present in clinopyroxenes. Conversely, in olivine and garnets, octahedral and tetrahedral sublattices are virtually independent in terms of cation occupancy; hence the species occupying octahedral sites diffuse much faster than those occupying tetrahedral sites. Dimanov and Sautter (2000) further argued that due to this crystal-chemical coupling, clinopyroxenes should be diffusionally unreactive, and hence their compositional re-equilibration should also involve net transfer reactions (e.g., exsolution, dissolution-precipitation) rather than purely diffusional exchange with surrounding phases. This is potentially of great importance when modeling compositional re-equilibration in natural assemblages assuming only diffusion controlled kinetics.

Dimanov and Wiedenbeck (2006) also compared the data from previous studies on transport properties (electrical conductivity, single crystal creep and cation diffusion) in diopside versus oxygen fugacity. Based on their data and previous work, the established point defect model for iron-bearing diopside of Jaoul and Raterron (1994) was strengthened and further extended to the case of $\mathrm{Fe}$ - and Mn-bearing diopside. The authors also showed that at $1000-1150{ }^{\circ} \mathrm{C}$ and very low oxygen fugacity (below QFI), irrespective of the diffusion mechanism considered, the diffusion rates of the major octahedral cations $(\mathrm{Ca} ; \mathrm{Fe} ; \mathrm{Fe}, \mathrm{Mn}-\mathrm{Mg})$ tend to be grouped within less than an order of magnitude (Fig. 2). Conversely, the diffusion rates of the same species strongly diverge at oxidizing conditions, which is due to the opposite dependences of interstitial and vacancy mediated mechanisms on oxygen fugacity. Hence, for cation exchange involving both interstitial and vacancy mechanisms, for example $\mathrm{Ca}-(\mathrm{Fe}, \mathrm{Mg})$ exchange, important compositional effects are expected to appear primarily at high oxygen fugacities.

Recent preliminary investigations of Fe-Mg interdiffusion in iron-rich diopside $\left(\mathrm{Di}_{95} \mathrm{Hd}_{5}\right)$ were reported by Chakraborty et al. (2008). Thin films $(20-50 \mathrm{~nm})$ of iron-rich olivine $\left(\mathrm{Fo}_{30} \mathrm{Fa}_{70}\right)$ were deposited by laser ablation onto oriented diopside samples. Samples were annealed at 800$1000{ }^{\circ} \mathrm{C}$ under flowing $\mathrm{CO} / \mathrm{CO}_{2}$ controlling $\mathrm{pO}_{2}=10^{-17} \mathrm{MPa}$. Fe-Mg interdiffusion between olivine films and diopside substrates along $c$-axis was measured by RBS. A single datum was reported at $800{ }^{\circ} \mathrm{C}$ and yielded $D_{\mathrm{Fe}-\mathrm{Mg}}=2.2 \times 10^{-22} \mathrm{~m}^{2} / \mathrm{s}$, which is at least one and half orders of magnitude higher than data from Dimanov and Sautter (2000) and Dimanov and Wiedenbeck (2006) extrapolated to lower temperatures (Fig. 1a). It is unfortunately impossible to further comparatively discuss these data due to different experimental conditions and lack of details provided in the abstract of Chakraborty et al. (2008).

Ca-Mg interdiffusion. Except for the early study of Brady and McCallister (1983), where the authors evaluated the pseudo-binary $\mathrm{Ca}-(\mathrm{Fe}, \mathrm{Mg}$ ) interdiffusion coefficient (see the "Pioneering Approaches" section) from the kinetics of lamellar homogenization, there has not been to date any direct measurement of $\mathrm{Ca}-\mathrm{Mg}$ interdiffusion rates in pyroxenes. However, Zhang et al. (2010) measured both $\mathrm{Ca}$ and $\mathrm{Mg}$ self-diffusion coefficients under the same experimental conditions (see previous sections), and hence they could model the Ca$\mathrm{Mg}$ exchange process. The authors used the formalism of Brady and McCallister (1983), where $\mathrm{Ca}-\mathrm{Mg}$ interdiffusion is described as a serial process, depending on $\mathrm{Ca}-$ and $\mathrm{Mg}$ selfdiffusion coefficients, the corresponding element fractions, and a thermodynamic factor (TF), which accounts for the non-ideality of mixing of $\mathrm{Ca}$ and $\mathrm{Mg}$, in relation to the large pyroxene 
solvus. Brady and McCallister (1983) and Zhang et al. (2010) demonstrated that TF has a quite substantial impact on the Ca-Mg interdiffusion rates. For instance, Zhang et al. (2010) show that without accounting for the TF the calculated $\mathrm{Ca}-\mathrm{Mg}$ interdiffusion coefficients are very similar for moderate variations in diopside content. When the TF was considered, the interdiffusion coefficients differed substantially both in magnitude and activation energy for the same compositions. For example, the authors calculated that at $1100{ }^{\circ} \mathrm{C}$ the activation energy was increased from $252 \mathrm{~kJ} / \mathrm{mol}$ to $427 \mathrm{~kJ} / \mathrm{mol}$, while the magnitude of the interdiffusion coefficient decreased by an order of magnitude when the diopside component fraction decreased from 0.8 to 0.7. These considerations, together with the fact that $\mathrm{Ca}-$ and $\mathrm{Mg}$ self-diffusion show temperature dependent anisotropy (Zhang et al. 2010), may be of fundamental importance when modeling $\mathrm{Ca}-\mathrm{Mg}$ and $\mathrm{Ca}-(\mathrm{Fe}, \mathrm{Mg})$ interdiffusion processes in natural assemblages.

\section{Diffusion in synthetic versus natural crystals}

It is worthwhile to recall some systematic observations from the studies reported in the previous sections. As general rule it seems that cation diffusion is always substantially faster in natural, iron-bearing crystals than in pure synthetic ones. In the studies of Azough and Freer (2000), Dimanov et al. (1996), Pacaud (1999) and Gasc et al. (2006) it appears that Fe, Ca and $\mathrm{Mg}$ self-diffusion coefficients at temperatures above $1000{ }^{\circ} \mathrm{C}$ were found to be half an order to an order of magnitude faster in natural iron-bearing diopside $(\sim 2-3$ at $\% \mathrm{Fe})$ than in pure synthetic iron-free (or iron-poor) diopside. Similar observations are noted for trace elements, as Sr diffusion in diopside (Sneeringer et al. 1984) and for other silicates such as olivine, where it was observed that $\mathrm{Mg}$ diffusion in San Carlos olivine was substantially faster than in pure synthetic forsterite (Chakraborty et al. 1994).

It may be generally stated that, except if they are specifically doped, synthetic materials always contain much lower concentrations of any kind of impurities, and hence of any related point defects. Similarly, synthetic crystals are also virtually free of higher order crystalline defects (free dislocations, dislocation arrays and sub-grains) related to the sometimes complex thermo-mechanical histories of the natural crystals; these extended defects may act as shortcut diffusion pathways. For these reasons it appears reasonable to observe lower diffusion rates in synthetic, pure crystals than in natural minerals which inherently contain numerous types and higher concentrations of crystalline defects.

\section{Major element cation diffusion in orthopyroxenes}

From the beginning of the 1990s to date a few studies have investigated major cation diffusion in enstatite. These were also motivated by the interest in interpreting petrogenetic and cooling histories of pyroxene bearing assemblages, as well by the need to constrain the closure temperatures of the well-known orthopyroxene-garnet geothermometer, based on FeMg exchange (Ganguly et al. 1994; Pattison and Bégin 1994).

$\boldsymbol{F e}-\mathbf{M g}$ interdiffusion. Ganguly and Tazzoli (1994) made the first indirect estimates of Fe$\mathrm{Mg}$ interdiffusion rates in orthopyroxenes on the basis of experimentally determined kinetics of Fe and $\mathrm{Mg}$ fractionation between non-equivalent M1 and M2 sites (Besancon 1981; Saxena et al. 1987; Anovitz et al. 1988). Ganguly and Tazzoli (1994) interpreted the rate constants of Fe-Mg order-disorder, or crystal site exchange reactions, in terms of intracrystalline Fe- $\mathrm{Mg}$ interdiffusion. Considering enstatite crystallography and nearly ideal mixing properties of $\mathrm{Fe}$ and $\mathrm{Mg}$, the authors assumed an equivalence of interdiffusion rate constants and order-disorder rate constants at the microscopic level. They further argued that the overall Fe-Mg exchange rate constant might represent essentially an average of microscopic rate constants along the $c$ - and $b$-crystallographic directions. The authors also assumed that the Fe-Mg interdiffusion coefficients along the $c$ - and $b$-directions might be comparable, and directly related to the macroscopic order-disorder rate constants. Experiments were carried out at temperatures between 500-800 ${ }^{\circ} \mathrm{C}$; in some of the experiments oxygen fugacity was controlled by a gas mixture of $\mathrm{H}_{2}$ and $\mathrm{CO}_{2}$ 
within $\sim 0.5-0.8 \log$ units above that of the IW buffer, while in other experiments it was defined by vacuum conditions in sealed silica capsules. The iron contents of the enstatite crystals ranged between 0.13 and 0.49 . Rate constants, and hence diffusivities, increased with iron content, but the activation energy for diffusion was constant $\left(E_{\mathrm{a}}=241 \pm 8 \mathrm{~kJ} / \mathrm{mol}\right)$. More recently, Stimpfl et al. (2005) addressed the effect of oxygen fugacity on Fe-Mg order-disorder kinetics and reported an oxygen fugacity exponent $m \sim 1 / 6(m=0.17)$. Figure $1 \mathrm{~b}$ shows the interdiffusion data (for $10 \% \mathrm{Fe}$ and IW conditions) originally obtained by Ganguly and Tazzoli (1994) and the corresponding data recalculated for a fixed $p \mathrm{O}_{2}=10^{-12} \mathrm{MPa}$ with $m=0.17$.

Klügel (2001) estimated the Fe-Mg interdiffusion rates in iron-rich orthopyroxene from comparative analysis of chemical zoning in olivine and orthopyroxene in natural harzburgite xenoliths. The author observed Fe-Mg zoning in both olivine and orthopyroxene that he interpreted as diffusional exchange between the xenoliths and surrounding mafic, silicaundersaturated melt. He estimated temperatures between $1050-1200{ }^{\circ} \mathrm{C}$ and QFM buffered oxygen fugacity. From the olivine zoning and the known Fe-Mg interdiffusion coefficients he retrieved the diffusion times, which were used to calculate $\mathrm{Fe}-\mathrm{Mg}$ interdiffusion rates from the orthopyroxene zoning. He reported $D_{\mathrm{Fe}-\mathrm{Mg}}=3 \times 10^{-19} \mathrm{~m}^{2} / \mathrm{s}$ at $T=1130{ }^{\circ} \mathrm{C}$ and QFM-buffered conditions and found good agreement with the ( $\mathrm{Fe}, \mathrm{Mn})-\mathrm{Mg}$ interdiffusion data in diopside (Dimanov and Sautter 2000) and the Fe-Mg interdiffusion data for orthopyroxene from Ganguly and Tazzoli (1994), when the latter are extrapolated to higher temperatures (Fig. 1b).

More recently, preliminary investigations of $\mathrm{Fe}-\mathrm{Mg}$ interdiffusion in iron-rich orthopyroxene $\left(\mathrm{En}_{90} \mathrm{Fs}_{10}\right)$ were reported by ter Heege et al. (2006). Thin films $(20-50 \mathrm{~nm})$ of iron-rich olivine $\left(\mathrm{Fo}_{30} \mathrm{Fa}_{70}\right)$ were deposited by laser ablation onto oriented orthopyroxene samples. Samples were annealed at $800-1000{ }^{\circ} \mathrm{C}$ under flowing $\mathrm{CO} / \mathrm{CO}_{2}$ controlling $p \mathrm{O}_{2}$ to $10^{-}$ ${ }^{17}-10^{-13} \mathrm{MPa}$. Fe-Mg interdiffusion between olivine films and orthopyroxene substrates along the $c$-axis was measured by RBS. Reported interdiffusion coefficients were $D_{\mathrm{Fe}-\mathrm{Mg}}=4 \times 10^{-22}$ $\mathrm{m}^{2} / \mathrm{s}$ to $2 \times 10^{-20} \mathrm{~m}^{2} / \mathrm{s}$ at temperatures of $800{ }^{\circ} \mathrm{C}$ to $1000{ }^{\circ} \mathrm{C}$ and $p \mathrm{O}_{2}=10^{-17} \mathrm{MPa}$. At $800{ }^{\circ} \mathrm{C}$, the data are in relatively good agreement (within half an order of magnitude) with the previously estimated Fe-Mg interdiffusion rates from Ganguly and Tazzoli (1994). ter Heege et al. (2006) also reported that the interdiffusion rates at $1000{ }^{\circ} \mathrm{C}$ decreased by a factor of 4 when oxygen fugacity decreased from $10^{-13}$ to $10^{-17} \mathrm{MPa}$, thus suggesting a vacancy related mechanism. The very limited data provide only a rough estimate of the oxygen fugacity exponent, $m=$ 0.15, which is consistent with the findings of Stimpfl et al. (2005), who studied the effect of oxygen fugacity on Fe-Mg order-disorder rates in orthopyroxene and found $m$ between 1/5.5 and 1/6.5. These values agree with the general framework of the point defect model of Jaoul and Raterron (1994), which can be similarly applied to clinopyroxene or to orthopyroxene with low Fe content. The data of ter Heege et al. (2006) and of Ganguly and Tazzoli (1994) are still in relatively good agreement when both data sets are recalculated to the same oxygen fugacity (Fig. 1b). Unfortunately additional comparison and discussion remains speculative due to the lack of details and the very limited data provided in the abstract of ter Heege et al. (2006).

Magnesium self-diffusion. Schwandt et al. (1998) experimentally determined magnesium self-diffusion coefficients in iron-rich orthopyroxene $\left(X_{\mathrm{Fe}} \sim 0.11\right)$, with centimeter-sized crystals oriented to study diffusion along the $a$-, $b$ - and $c$-axes. The polished samples were pre-annealed for 24 hours at temperature and oxygen fugacity conditions corresponding to the experimental conditions for diffusion, and thin layers (100-200 nm) of ${ }^{25} \mathrm{Mg}$-enriched $\mathrm{MgO}$ were deposited onto the pre-annealed substrates by thermal evaporation in high vacuum. Diffusion experiments were performed at temperatures between $750-900{ }^{\circ} \mathrm{C}$, at oxygen fugacity equivalent to the IW buffer, controlled by $\mathrm{CO}-\mathrm{CO}_{2}$ gas mixtures, and diffusion profiles measured by SIMS. The effects of composition and oxygen fugacity were not investigated. Although the surface films were relatively thin, the diffusion profiles could be modeled by thick source solutions. $\mathrm{Mg}$ diffusion coefficients were found to be comparable, irrespective of the crystallographic 
direction of diffusion. However, the authors speculated that the observed isotropy of diffusion may only correspond to the experimental conditions, and, in spite of the large uncertainties due to limited data and a restricted temperature range for experiments, the authors argued that the activation energy for diffusion along the $c$-axis is consistently lower $\left(E_{\mathrm{a}}=265 \pm 66 \mathrm{~kJ} / \mathrm{mol}\right)$ than for diffusion along the $b$-axis $\left(E_{\mathrm{a}}=339 \pm 77 \mathrm{~kJ} / \mathrm{mol}\right)$ and the $c$-axis $\left(E_{\mathrm{a}}=360 \pm 52 \mathrm{~kJ} / \mathrm{mol}\right)$. The data were found to be in relatively good agreement with the previous estimates of Fe-Mg interdiffusion rates by Ganguly and Tazzoli (1994). In extrapolation to higher temperatures, both data sets are also in relatively good agreement with the Fe-Mg interdiffusion rates estimated from naturally zoned assemblages by Klügel (2001).

Chromium. Recently, Ganguly et al. (2007) determined Cr diffusion coefficients in iron bearing natural orthopyroxene $\left(X_{\mathrm{Fe}} \sim 0.026\right)$ in order to constrain closure temperatures for application of the ${ }^{53} \mathrm{Mn}-{ }^{53} \mathrm{Cr}$ chronometer in understanding early solar-system processes. The authors investigated diffusion parallel to the $a$-, $b$-, and $c$-axes. Temperatures ranged between $900{ }^{\circ} \mathrm{C}$ and $1100{ }^{\circ} \mathrm{C}$, and $\mathrm{pO}_{2}$, corresponding to that of the IW buffer and up to 4.5 orders of magnitude above, was controlled by $\mathrm{CO}-\mathrm{CO}_{2}$ gas mixtures. The authors indicated that in these conditions $\mathrm{Cr}$ is likely in the +3 valence state. Oriented samples were polished and pre-annealed at conditions similar to those of the diffusion experiments in order to heal polishing damage and to set point defect concentrations. Thin Cr films $(\sim 50 \mathrm{~nm})$ were deposited onto samples by thermal evaporation under high vacuum. Diffusion profiles, typically several tens of nm, were obtained by SIMS depth profiling. Two analytical solutions were applied to retrieve diffusion coefficients. The authors considered either infinite or finite sources of diffusant, with the former model providing the best fits. $\mathrm{Cr}$ was assumed to diffuse within the octahedral sub-lattice alone. Diffusion was found to be slightly anisotropic, with the fastest rates along the $c$-axis and the slowest rates along the $a$-axis. Fits to the data for experiments buffered at IW yield an activation energy of $237 \pm 19 \mathrm{~kJ} / \mathrm{mol}$ and pre-exponential factor $2.62 \times 10^{-11} \mathrm{~m}^{2} / \mathrm{s}\left(\log D_{0}=-10.58 \pm 0.67\right)$ for diffusion parallel to $b$, and an activation energy of $277 \pm 14 \mathrm{~kJ} / \mathrm{mol}$ and pre-exponential factor $3.87 \times 10^{-10} \mathrm{~m}^{2} / \mathrm{s}\left(\log D_{0}=-9.41 \pm 0.35\right)$ for diffusion parallel to the $c$-axis. The activation energy for diffusion along the $a$-axis could not be adequately constrained, but Ganguly et al. (2007) suggested that the activation energies are likely to be similar for all the crystallographic directions. They proposed the mean value of $257 \pm 12 \mathrm{~kJ} / \mathrm{mol}$, which was used to reprocess the data to obtain the pre exponential factors of $7.41 \times 10^{-11} \mathrm{~m}^{2} / \mathrm{s}\left(\log D_{0}=-10.13 \pm 0.39\right)$ for diffusion parallel to the $a$-axis, $1.78 \times 10^{-10} \mathrm{~m}^{2} / \mathrm{s}\left(\log D_{0}=-9.75 \pm 0.78\right)$ for diffusion parallel to $b$, and $3.10 \times 10^{-10} \mathrm{~m}^{2} / \mathrm{s}\left(\log D_{0}=-9.51 \pm 0.56\right)$ for diffusion parallel to the $c$-axis.

Ganguly et al. (2007) investigated the effects of $p \mathrm{O}_{2}$ for diffusion parallel to $c$ at $950{ }^{\circ} \mathrm{C}$ and $1050{ }^{\circ} \mathrm{C}$. They observed a decrease of diffusion rates by a factor of 2 to 3 for an increase in $\log p \mathrm{O}_{2}$ from IW to IW +4.5 , and hence an oxygen fugacity exponent $m \sim-0.07$ to -0.1 . A decrease in diffusion coefficients with increasing oxygen fugacity indicates an interstitial mechanism as for Ca in diopside (Dimanov et al. 1996), but the low value of the oxygen fugacity exponent appears inconsistent with the previously reported point defect model for clinopyroxene (Jaoul and Raterron 1994; Dimanov and Wiedenbeck 2006), where $m=-3 / 16$ for an interstitial mechanism. The authors proposed an alternative point defect model, which also predicted a much higher $p \mathrm{O}_{2}$ dependence $(m \sim-2 / 3)$ than observed $(m \sim-0.07$ to -0.1$)$. Given this discrepancy they suggested a mixed mode for $\mathrm{Cr}$ diffusion involving both vacancy and interstitial mechanisms.

\section{Pyroxene point defect chemistry}

As reported in the previous sections, diffusion data for many major cations in both clinoand ortho-pyroxenes exhibit pronounced dependences on oxygen fugacity, with $m \sim 0.1$ 0.22. Similar observations are reported for diffusion of rare earths and $\mathrm{Pb}$ in clinopyroxenes (Van Orman et al. 2001; Cherniak 1998a, 2001), as well as for Pb diffusion in orthopyroxene (Cherniak 2001). The influence of oxygen fugacity is also evidenced in creep (Jaoul and 
Raterron 1994) and electrical conductivity (Duba et al. 1973, 1976; Huebner and Voigt 1988), and is a fundamental control of transport properties of pyroxenes. In comparison with olivine (Smyth and Stocker 1975; Nakamura and Schmalzried 1983, Hirsh and Shankland 1991; Tsai and Dieckmann 2002), however, fewer models of point defect chemistry have been developed for iron-bearing pyroxenes (Huebner and Voigt 1988). The present section summarizes the best developed point defect model for iron bearing clinopyroxene (Jaoul and Raterron 1994). As Nakamura and Schmalzried (1983) proposed for fayalite, Jaoul and Raterron (1994) proposed that for Fe-bearing diopside (described as $\mathrm{MeSiO}_{3}$, where $\mathrm{Me}$ stands for $\mathrm{Ca}, \mathrm{Mg}$ or $\mathrm{Fe}$ ) in equilibrium with gaseous oxygen, the dominant extrinsic point defects are cation vacancies and electron holes in the valence band, while the oxygen sub-lattice is considered a perfect framework. In the standard point defect notation of Kröger and Vink (1956) the vacancies are $\mathrm{V}^{\prime \prime}{ }_{\text {Me }}$ and $\mathrm{V}^{\prime \prime \prime \prime}{ }_{\mathrm{Si}}$, and the electron holes are $\mathrm{h}^{\bullet}$. The subscript indicates the vacant crystallographic site and the superscript represents the charge deficiency of the point defect. A prime (') denotes a negative charge excess, a dot $(\bullet)$ represents a positive one, while $\times$ stands for normal charge.

When a system is open to oxygen alone (i.e., other component activities are not buffered), increasing oxygen fugacity results in adsorption of oxygen atoms at the sample surface. These may be incorporated in the crystal structure by the formation of new, but incomplete diopside molecules. In these molecules all cation sites are vacant. Their charge deficiency is compensated by electron holes localized on substitutional $\mathrm{Fe}$, written as $\mathrm{Fe}_{\mathrm{Me}}$ (i.e., $\mathrm{Fe}^{3+}$ located on the octahedral M1 and/or M2 site). The latter are also called small polarons. Conversely, lowering oxygen fugacity leads to oxygen desorption from the sample surface, resulting in the reduction of $\mathrm{Fe}^{3+}$, with a concomitant annihilation of cation vacancies. In this model, cation vacancies and small polarons are the majority point defects.

However, Raterron and Jaoul (1991), and Doukhan et al. (1993) report that, depending on oxygen fugacity and temperature, but considerably below the nominal melting point, small amounts $(<<1 \mathrm{vol} \%)$ of partially molten phase is exsolved as tiny droplets within the host diopside. At the beginning of this phenomenon, called EPM (early partial melting), the droplets are only a few tens of nm large and composed of nearly pure silica, although with time and increasing temperature these grow and their composition progressively evolves, draining impurities $(\mathrm{Fe}, \mathrm{Al})$ and $\mathrm{Ca}$ from the surrounding matrix.

Jaoul and Raterron (1994) proposed that the formation of major point defects has certain limits, beyond which the vacancy-supersaturated diopside tends to stabilize its crystalline structure by silica exsolution, and hence the onset of EPM. The model has two concurrent relations for point defect formation equilibria:

$$
\begin{gathered}
6 \mathrm{Fe}_{\mathrm{Me}}^{\times}+\mathrm{Me}_{\mathrm{Me}}^{\times}+\mathrm{Si}_{\mathrm{Si}}^{\times}+\frac{3}{2} \mathrm{O}_{2} \leftrightarrow \mathrm{MeSiO}_{3}+\mathrm{V}_{\mathrm{Me}}^{\prime \prime}+\mathrm{V}_{\mathrm{Si}}^{\prime \prime \prime \prime}+6 \mathrm{Fe}_{\mathrm{Me}}^{\cdot} \\
2 \mathrm{Fe}_{\mathrm{Me}}^{\times}+\mathrm{Me}_{\mathrm{Me}}^{\times}+\mathrm{SiO}_{2}+\frac{1}{2} \mathrm{O}_{2} \leftrightarrow \mathrm{MeSiO}_{3}+\mathrm{V}_{\mathrm{Me}}^{\prime \prime}+2 \mathrm{Fe}_{\mathrm{Me}}^{\bullet}
\end{gathered}
$$

The first reaction represents either the formation of new diopside molecules, plus cation vacancies which are charge balanced by ferric iron (to the right), or oxygen desorption accompanied by vacancy annihilation and reduction of ferric to ferrous iron (to the left). This operates alone, within the limits of the stability field of diopside plus gaseous oxygen. But if the equilibrium is displaced enough to the right so that the concentrations of cation vacancies become higher than allowed by the second equilibrium condition, then reaction (2) starts operating to the left. This represents consumption of octahedral vacancies and reduction of ferric to ferrous iron through desorption of oxygen and formation of silica. Reactions (1) and (2) can be written more concisely as: 


$$
\begin{gathered}
6 \mathrm{Fe}_{\mathrm{Me}}^{\times}+\frac{3}{2} \mathrm{O}_{2} \leftrightarrow 3 \mathrm{O}_{\mathrm{O}}^{\times}+\mathrm{V}_{\mathrm{Me}}^{\prime \prime}+\mathrm{V}_{\mathrm{Si}}^{\prime \prime \prime \prime}+6 \mathrm{Fe}_{\mathrm{Me}}^{\cdot} \\
2 \mathrm{Fe}_{\mathrm{Me}}^{\times}+\mathrm{SiO}_{2}+\frac{1}{2} \mathrm{O}_{2} \leftrightarrow 3 \mathrm{O}_{\mathrm{O}}^{\times}+\mathrm{Si}_{\mathrm{Si}}^{\times}+\mathrm{V}_{\mathrm{Me}}^{\prime \prime}+2 \mathrm{Fe}_{\mathrm{Me}}^{\cdot}
\end{gathered}
$$

Any such chemical solid state reaction must obey three conservation rules: (i) the conservation of matter, (ii) the respect for electroneutrality, and (iii) the conservation of the ratio of anion to cation sites. For the $\mathrm{MeSiO}_{3}$ diopside one has Me:Si:O = 1:1:3. Expressed differently, the reaction must create or annihilate entire molecules in the crystallographic sense, though these can be incomplete in the chemical sense.

Jaoul and Raterron (1994) showed that the concentrations of major point defects (cation vacancies and small polarons) related to reaction (1) vary as $\left(\mathrm{pO}_{2}\right)^{3 / 16}$. Conversely, the minority point defects (interstitial cations) show a $p \mathrm{O}_{2}$ dependence with exponent $m=-3 / 16$. In the following we will derive the $\mathrm{pO}_{2}$ dependence of major point defects associated with reaction (1) alone, i.e., in EPM absent conditions. The reader is referred to Jaoul and Raterron (1994) for further details of conditions involving reaction (2), i.e., in cases where EPM is present.

The majority point defects involved in the chemical reaction (1) satisfy the charge neutrality condition.

$$
4\left[\mathrm{~V}_{\mathrm{Si}}^{\prime \prime \prime \prime}\right]+2\left[\mathrm{~V}_{\mathrm{Me}}^{\prime \prime}\right]=\left[\mathrm{Fe}_{\mathrm{Me}}^{\cdot}\right]
$$

where the brackets represent site fractions (which are actually identical to mole fractions for cations in diopside written as $\mathrm{MeSiO}_{3}$ ). The mass action law associated with the chemical reaction (1) is:

$$
\left[\mathrm{V}_{\mathrm{Si}}^{\prime \prime \prime \prime}\right] \cdot\left[\mathrm{V}_{\mathrm{Me}}^{\prime \prime \prime}\right] \cdot\left[\mathrm{Fe}_{\mathrm{Me}}^{\cdot}\right]^{6}=K_{1} x_{\mathrm{Fe}}^{6} p \mathrm{O}_{2}^{3 / 2}
$$

where $x_{\mathrm{Fe}}$ (atomic fraction $\mathrm{Fe} /(\mathrm{Ca}+\mathrm{Mg}+\mathrm{Fe})$ ) is nearly the $\mathrm{Fe}$ mole fraction $\left[\mathrm{Fe}^{x}{ }_{\mathrm{Me}}\right]$ (because the number of $\mathrm{Fe}^{3+}$ is negligible as compared with $\left.\mathrm{Fe}^{2+}\right) . K_{1}=\exp \left(-Q_{1} / R T\right)$ is the equilibrium constant for the reaction (1) and $Q_{1}$ is the (standard state) Gibbs free energy of the reaction. We note that in reaction (1), considering an ideal solid solution, the activity of the components $\mathrm{FeSiO}_{3}$ and $\mathrm{MeSiO}_{3}$ are assumed to be respectively $x_{\mathrm{Fe}}$ and 1 , which is reasonable since the overall Fe concentration in diopside is low.

The system is incompletely defined if only two reactions govern the concentrations of three major point defects. Non-stoichiometry of pseudo-ternary systems is completely determined if one introduces two parameters describing departures from stoichiometry between anions and cations and between octahedral cations and tetrahedral cations (Nakamura and Schmalzried 1983). These two parameters are approximated by Jaoul and Raterron (1994) as functions of cation vacancy concentration, assuming that the oxygen lattice forms a perfect framework, as follows:

$$
\begin{aligned}
& \bar{\xi}=\frac{n_{\mathrm{Si}}}{n_{\mathrm{Si}}+n_{\mathrm{Me}}}-\frac{1}{2} \approx \frac{1}{4}\left(\left[\mathrm{~V}_{\mathrm{Me}}^{\prime \prime}\right]-\left[\mathrm{V}_{\mathrm{Si}}^{\prime \prime \prime \prime}\right]\right) \\
& \bar{\eta}=\frac{n_{\mathrm{O}}}{n_{\mathrm{Si}}+n_{\mathrm{Me}}}-\frac{3}{2} \approx \frac{3}{4}\left(\left[\mathrm{~V}_{\mathrm{Me}}^{\prime \prime}\right]+\left[\mathrm{V}_{\mathrm{Si}}^{\prime \prime \prime \prime}\right]\right)
\end{aligned}
$$

where $n_{i}$ represents the number of moles of a species $i$ in the pyroxene system.

It is assumed that diopside has some initial departure from stoichiometry; however this parameter is not directly measurable. Reaction (1) shows that, with respect to oxygen exchange between diopside and its surrounding environment, octahedral and tetrahedral cation vacancies 
are both created or annihilated at the same rate. Thus, the initial state of octahedral to tetrahedral cation non-stoichiometry remains preserved. Hence, for convenience, it is possible to consider the simplest case and take the initial cationic ratio Si:Me as equal to 1 (i.e., the initial octahedralto tetrahedral cation departure from stoichiometry is zero). It follows that all cationic vacancies are related to reaction (1) and obey the relationship:

$$
\left[\mathrm{V}_{\mathrm{Si}}^{\prime \prime \prime \prime}\right]=\left[\mathrm{V}_{\mathrm{Me}}^{\prime \prime \prime}\right]
$$

Combining Equations (3) and (7) allows us to rewrite Equation (4) and to obtain the expression of the concentration of cation vacancies and oxidized iron as a function of $p \mathrm{O}_{2}$

$$
\left[\mathrm{V}_{\mathrm{Me}}^{\prime \prime}\right] \propto\left[\mathrm{V}_{\mathrm{Si}}^{\prime \prime \prime \prime}\right] \propto\left[\mathrm{Fe}_{\mathrm{Me}}^{\cdot}\right] \propto K_{1}^{1 / 8} p \mathrm{O}_{2}^{3 / 16}
$$

The model of Jaoul and Raterron (1994) provides a valuable description of the influence of point defects on transport properties of Fe-bearing diopside. For instance, Equation (8) shows that the concentrations of cation vacancies vary as $\left(p \mathrm{O}_{2}\right)^{m}$ with $m=3 / 16 \approx 0.188$, which is in very good agreement with the experimental observations for electrical conductivity (Huebner and Voigt 1988) and cation diffusion (Dimanov et al. 1996; Azough and Freer 2000; Cherniak 2001; Dimanov and Wiedenbeck 2006).

\section{Diffusion of minor and trace elements in pyroxene}

Along with major element constituents, diffusion of a range of minor and trace elements has been measured in pyroxene. These include $\mathrm{Li}$, useful in geospeedomtery and tracing weathering and aqueous alteration, and elements important in geochronology $(\mathrm{Pb}, \mathrm{Sr}, \mathrm{U}$ and Th) and as geochemical tracers, such as the rare earth elements. As in the case of major elements, dependence of diffusion on oxygen fugacity and other parameters can shed light on diffusion mechanisms, and has been explored in some of these studies. The findings of these investigations are discussed below and diffusion parameters for minor and trace elements are presented in Table A2.

Lithium. Li diffusion was measured in natural diopside (with $\sim 0.7$ at $\% \mathrm{Fe}$ ) by Coogan et al. (2005) as part of a study of Li partitioning between clinopyroxene and plagioclase undertaken in order to develop a lithium geospeedometer. Diffusion experiments were conducted in 1-atm furnaces with flowing $\mathrm{CO}-\mathrm{CO}_{2}$ gas to fix oxygen fugacity within the stability field of diopside and prevent oxidation of $\mathrm{Fe}^{+2} \cdot p \mathrm{O}_{2}$ was $10^{-11} \mathrm{~Pa}$ at $800-900{ }^{\circ} \mathrm{C}$ and $10^{-7} \mathrm{~Pa}$ at $1000-1100{ }^{\circ} \mathrm{C}$. The source of $\mathrm{Li}$ for diffusion experiments was a mixture of crushed San Carlos olivine, $\mathrm{Li}_{2} \mathrm{CO}_{3}$ (enriched in ${ }^{6} \mathrm{Li}$ ) and $\mathrm{Li}_{2} \mathrm{SiO}_{3}$ powders. The diopside crystals, cut normal to the [010] axis and polished, were annealed in alumina crucibles with the powder mixtures. ${ }^{6} \mathrm{Li}$ profiles were measured with SIMS. From four experiments performed (one each at 800, 900, 1000, and 1100 ${ }^{\circ} \mathrm{C}$ ), Coogan et al. (2005) obtained an activation energy of $258 \mathrm{~kJ} / \mathrm{mol}$ and pre-exponential factor of $2.9 \times 10^{-2} \mathrm{~m}^{2} / \mathrm{s}$. No uncertainties are reported, but these may be significant given the limited size of the dataset. Li diffusion in clinopyroxene is about 3 orders of magnitude slower than $\mathrm{Li}$ diffusion in plagioclase (Giletti and Shanahan 1997), but considerably faster than diffusion of most other elements in clinopyroxene.

Strontium. Sneeringer et al. (1984) measured Sr chemical diffusion in synthetic and natural diopside, using a variety of analytical techniques, including a ${ }^{85} \mathrm{Sr}$ radiotracer source and serial sectioning, and stable Sr tracers with RBS or SIMS depth profiling. This study was one of the first applications of the accelerator-based ion beam technique RBS to studies of diffusion in geological materials.

The radiotracer experiments were conducted with a natural diopside $(\sim 1$ at $\% \mathrm{Fe})$ and a synthetic diopside containing less than 0.1 at $\% \mathrm{Fe}$. The radiotracer was in the form of ${ }^{85} \mathrm{SrCl}_{2}$ in a dilute $\mathrm{HCl}$ solution and was deposited on sample surfaces (oriented to measure diffusion parallel to $c$ ); the tracer was dried and heated to $800{ }^{\circ} \mathrm{C}$ (a temperature considerably lower than 
the diffusion anneals) in flowing $\mathrm{N}_{2}$ gas to induce bonding of the tracer to the sample. Excess tracer was removed following this step, and diffusion anneals were conducted in 1-atm furnaces in flowing $\mathrm{N}_{2}$ gas. Samples were sequentially polished and diffusivities determined by evaluating residual activity as a function of depth from the initial sample surface. For the natural diopside over the temperature range $1200-1300{ }^{\circ} \mathrm{C}$, an activation energy of $406 \pm 71 \mathrm{~kJ} / \mathrm{mol}$ and preexponential factor of $5.4 \times 10^{-3} \mathrm{~m}^{2} / \mathrm{s}\left(\log D_{0}=-2.27\right)$ are reported. The details of the procedures used in fitting are not fully elaborated by Sneeringer et al. (1984), but it should be noted that in some cases reported Arrhenius parameters appear inconsistent with those that would be obtained given the tabulated diffusivities and uncertainties. For the synthetic diopside over the same temperature range, Sneeringer et al. (1984) report an activation energy of $456 \pm 75 \mathrm{~kJ} / \mathrm{mol}$ and pre-exponential factor of $2.5 \times 10^{-3} \mathrm{~m}^{2} / \mathrm{s}\left(\log D_{0}=-2.61\right)$. Diffusion in synthetic diopside is about 2 orders of magnitude slower than diffusion in natural diopside, and the activation energy for diffusion in the synthetic material is higher. The natural diopside used by Sneeringer et al. (1984) was found (through examination of etch pits) to have a dislocation density two orders of magnitude higher than the synthetic diopside. This higher vacancy concentration is likely associated with electron holes needed to charge balance $\mathrm{Fe}^{3+}$ and other impurities.

Experiments were also run with a stable $\mathrm{Sr}$ tracer at 1-atmosphere, conducted by applying the tracer solution to polished synthetic diopside, permitting it to dry, heating at low temperature on a hotplate, and placing the tracer-deposited sample face to face with another polished diopside section inside a Pt envelope. The experimental assembly was then annealed in air in 1-atm furnaces. Samples were analyzed with an ion microprobe, and diffusion was investigated in three crystallographic orientations. For transport along the $a$-axis, Sneeringer et al. (1984) report an activation energy of $452 \pm 42 \mathrm{~kJ} / \mathrm{mol}$ and pre-exponential factor of $6.4 \times 10^{-4} \mathrm{~m}^{2} / \mathrm{s}$ $\left(\log D_{0}=-3.19\right)$. For the $b$-axis, values reported are an activation energy of $565 \pm 38 \mathrm{~kJ} / \mathrm{mol}$ and pre-exponential factor of $1.2 \times 10^{1} \mathrm{~m}^{2} / \mathrm{s}\left(\log D_{0}=1.08\right)$, and for the $c$-axis an activation energy of $511 \pm 29 \mathrm{~kJ} / \mathrm{mol}$ and pre-exponential factor of $1.2 \times 10^{-1} \mathrm{~m}^{2} / \mathrm{s}\left(\log D_{0}=-0.92\right)$ are determined. These findings suggest that diffusion along the $a$-axis may be somewhat slower than diffusion along the $b$ and $c$ axes, but there is considerable overlap and scatter in the data and little evidence of strong anisotropy. Some of the samples analyzed by SIMS were also analyzed with Rutherford Backscattering Spectrometry (RBS). For these data, which measured diffusion parallel to $c$, an activation energy of $544 \pm 25 \mathrm{~kJ} / \mathrm{mol}$ and pre-exponential factor of 3.1 $\mathrm{m}^{2} / \mathrm{s}\left(\log D_{0}=0.49\right)$ were reported.

Sneeringer et al. (1984) also conducted experiments at high pressure (0.8-2 GPa) using solid-media piston-cylinder apparatus. Diffusion couples of polished synthetic diopside were used in experiments, with one half of the couple an undoped diopside and the other half doped with $\mathrm{Sr}$ and $\mathrm{Sm}$ in concentrations of $450 \mathrm{ppm}$ and $250 \mathrm{ppm}$ respectively. $\mathrm{Sr}$ and $\mathrm{Sm}$ profiles were obtained with an ion microprobe. The authors reported some difficulty in separating the halves of the diffusion couple and locating the interface between doped and undoped material, which may contribute to experimental uncertainty. The results for high-pressure experiments at $2 \mathrm{GPa}$ suggest pronounced anisotropy for $\mathrm{Sr}$ diffusion, with diffusion along the $c$-axis slower than diffusion along the $b$ - and $a$-axes. Diffusion along the $c$-axis was also found to have a higher activation energy for diffusion. For these data at $2 \mathrm{GPa}$, the Arrhenius parameters are $260 \pm 50 \mathrm{~kJ} / \mathrm{mol}$ and $1.7 \times 10^{-9} \mathrm{~m}^{2} / \mathrm{s}\left(\log D_{0}=-8.77\right)$ for diffusion along the $a$-axis, $381 \pm 84$ $\mathrm{kJ} / \mathrm{mol}$ and $5.2 \times 10^{-5} \mathrm{~m}^{2} / \mathrm{s}\left(\log D_{0}=-4.28\right)$ for diffusion along the $b$-axis, and $607 \pm 33 \mathrm{~kJ} /$ mol and $8.7 \times 10^{2} \mathrm{~m}^{2} / \mathrm{s}\left(\log D_{0}=2.94\right)$ for diffusion along the $c$-axis. For diffusion at $1.4 \mathrm{GPa}$ parallel to the $c$-axis, an activation energy of $728 \pm 134 \mathrm{~kJ} / \mathrm{mol}$ and pre-exponential factor $1.2 \times 10^{7} \mathrm{~m}^{2} / \mathrm{s}\left(\log D_{0}=7.08\right)$ are obtained. These data suggest anisotropy in activation volumes (with diffusion along the $c$-axis having the smallest values), and negative activation volumes (apparent faster diffusion at higher pressure), with values ranging from $-20.6 \mathrm{~cm}^{3} / \mathrm{mol}$ to $-2.3 \mathrm{~cm}^{3} / \mathrm{mol}$. However, Sneeringer et al. (1984) note that there was cracking of the samples (most likely during pressurization or depressurization of experiments) which could increase 
measured diffusivities. Diffusivities for $\mathrm{Sr}$ and $\mathrm{Sm}$ (discussed below) from the same specimens in these high-pressure experiments were for the most part similar in value, as were Arrhenius parameters, which suggests the possibility of influence of experimental artifacts on measured profile lengths and thus determinations of diffusivities.

Lead. $\mathrm{Pb}$ diffusion in a range of pyroxene compositions and under various $\mathrm{pO}_{2}$ conditions was measured by Cherniak (1998a, 2001). The sources of diffusant in these experiments were fused and finely ground mixtures of $\mathrm{PbS}$ powder and ground pyroxene of the same composition as the pyroxene samples. Experiments were run in 1-atm furnaces in sealed silica glass capsules with solid buffers (to buffer at QFM, IW or MH); a few experiments were "self-buffered", with only the sample and PbS-pyroxene source sealed in a silica glass capsule with no solid buffer. Rutherford Backscattering Spectrometry (RBS) was used to measure $\mathrm{Pb}$ diffusion profiles.

$\mathrm{Pb}$ diffusion in a near-end member diopside $(\sim 0.3$ at $\% \mathrm{Fe})$ under QFM-buffered conditions over the temperature range $800-1100{ }^{\circ} \mathrm{C}$ was described by an activation energy of $544 \pm 40 \mathrm{~kJ} /$ mol and pre-exponential factor of $4.03 \times 10^{2} \mathrm{~m}^{2} / \mathrm{s}\left(\log D_{0}=2.61 \pm 1.65\right)$ for diffusion normal to the (110) cleavage plane. For transport normal to (001), an activation energy of $512 \pm 23$ $\mathrm{kJ} / \mathrm{mol}$ and pre-exponential factor $2.17 \times 10^{1} \mathrm{~m}^{2} / \mathrm{s}\left(\log D_{0}=1.34 \pm 0.52\right)$ were determined; little anisotropy was evident comparing diffusion in these two orientations. A fit to both data sets yields the values $519 \pm 19 \mathrm{~kJ} / \mathrm{mol}$ for the activation energy and $4.40 \times 10^{1} \mathrm{~m}^{2} / \mathrm{s}\left(\log D_{0}=\right.$ $1.64 \pm 0.49)$ for the pre-exponential factor. The "self-buffered" data, from experiments with the PbS-diopside source and no solid buffer, yield a somewhat higher activation energy of $609 \pm 67$ $\mathrm{kJ} / \mathrm{mol}$ and larger pre-exponential factor of $5.38 \times 10^{4} \mathrm{~m}^{2} / \mathrm{s}\left(\log D_{0}=4.73 \pm 2.74\right)$ for diffusion normal to (110). The single datum for the (001) orientation under self-buffered conditions does not differ significantly from diffusivities found for (110).

Cherniak (1998a) also investigated $\mathrm{Pb}$ diffusion in a more Fe-rich clinopyroxene composition ( $\sim 40 \%$ diopside component; $\sim 5$ at $\% \mathrm{Fe}$ ). Over the temperature range $800-1050{ }^{\circ} \mathrm{C}$, for QFM-buffered experiments for diffusion normal to (110), an activation energy of $387 \pm 31$ $\mathrm{kJ} / \mathrm{mol}$ and pre-exponential factor of $2.20 \times 10^{-4} \mathrm{~m}^{2} / \mathrm{s}\left(\log D_{0}=-3.66 \pm 1.38\right)$ were obtained. Diffusivities from the "self-buffered" experiments for this pyroxene composition did not differ substantially from those for the QFM-buffered experiments; for these data the activation energy is $410 \pm 36 \mathrm{~kJ} / \mathrm{mol}$ and the pre-exponential factor is $1.90 \times 10^{-3} \mathrm{~m}^{2} / \mathrm{s}\left(\log D_{0}=-2.72 \pm 1.46\right)$.

Diffusion in the more iron-rich clinopyroxene is faster (by about half a log unit) and activation energy for diffusion lower than that for the near-end-member diopside. In the nearend-member diopside, $\mathrm{Pb}$ diffusivities under QFM-buffered and "self-buffered" conditions differ, but this is not the case for the Fe-rich clinopyroxene, for which they are quite similar. The latter observation suggests that the system containing the Fe-rich clinopyroxene may have a greater ability to buffer itself because of the higher Fe content of the source (since it contains ground clinopyroxene of the same composition as the sample). In contrast, the source used for the near-end-member diopside contains ground diopside of low Fe content, a material which likely has much poorer buffering capacity.

Additional work on $\mathrm{Pb}$ diffusion in pyroxene was conducted by Cherniak (2001), with investigation of diffusion in a chromian diopside, an augitic pyroxene, and a near-end member enstatite. The experimental and analytical approaches were similar to those of Cherniak's 1998 study, with sources of diffusant consisting of $\mathrm{PbS}$ powder and ground pyroxene (of the same type as the sample), source and sample contained in an open silica capsule which was sealed under vacuum with solid buffers (to buffer at QFM, IW, or MH) in an outer silica glass capsule. Prepared sample capsules were annealed in 1-atm furnaces, and $\mathrm{Pb}$ distributions in the pyroxene specimens were profiled by RBS.

For the QFM buffered experiments on the chromian diopside (transport normal to the (110) cleavage plane) over the temperature range $850-1050{ }^{\circ} \mathrm{C}$ an activation energy $351 \pm 36 \mathrm{~kJ} / \mathrm{mol}$ 
and pre-exponential factor $8.66 \times 10^{-7} \mathrm{~m}^{2} / \mathrm{s}\left(\log D_{0}=-6.06 \pm 1.49\right)$ were obtained. For transport parallel to $c$, an activation energy of $309 \pm 40 \mathrm{~kJ} / \mathrm{mol}$ and pre-exponential factor $2.00 \times 10^{-8}$ $\mathrm{m}^{2} / \mathrm{s}\left(\log D_{0}=-7.70 \pm 1.67\right)$ were determined. There appears little anisotropy when comparing diffusion in two orientations. Cherniak's (2001) fit to data for both orientations yields the values $336 \pm 27 \mathrm{~kJ} / \mathrm{mol}$ for the activation energy and $2.36 \times 10^{-7} \mathrm{~m}^{2} / \mathrm{s}\left(\log D_{0}=-6.63 \pm 1.10\right)$ for the pre-exponential factor.

For the augitic pyroxene, an activation energy of $372 \pm 15 \mathrm{~kJ} / \mathrm{mol}$ and pre-exponential factor of $3.78 \times 10^{-5} \mathrm{~m}^{2} / \mathrm{s}\left(\log D_{0}=-4.42 \pm 0.64\right)$ were found for transport normal to (110) under QFM-buffered conditions over the temperature range $850-1050{ }^{\circ} \mathrm{C}$.

Diffusion measurements on enstatite over the temperature range $850-1100{ }^{\circ} \mathrm{C}$ yielded an activation energy of $366 \pm 29 \mathrm{~kJ} / \mathrm{mol}$, and pre-exponential factor of $6.63 \times 10^{-7} \mathrm{~m}^{2} / \mathrm{s}\left(\log D_{0}=\right.$ $-6.18 \pm 1.18)$ for transport normal to (210) under QFM-buffered conditions.

As in the 1998 study, Cherniak (2001) found that $\mathrm{Pb}$ diffusion appears faster in more Fe-rich pyroxenes. Diffusivities in the augitic pyroxene are higher (by nearly an order of magnitude) than $\mathrm{Pb}$ diffusion in the $\mathrm{Cr}$ diopside. Dimanov et al. (1996) found a positive correlation between $\mathrm{Ca}$ diffusion rates and $\mathrm{Fe}$ content in diopside, with diffusion differing by nearly a log unit between diopsides having 0.4 and 2.4 at\% $\mathrm{Fe}$, when the data are normalized to constant $p \mathrm{O}_{2}$ and $T$. Activation energies for Ca diffusion in these diopsides were, however, found to be quite similar. In the case of $\mathrm{Pb}$ diffusion, comparable trends may broadly apply. Activation energies for $\mathrm{Pb}$ diffusion in these pyroxenes under QFM buffered conditions are also similar ( 390-350 kJ/mol), with the exception of the near end-member diopside, which has a higher value. (Fig. 3)

Since diffusion is controlled by defect chemistry, as discussed above, it is certainly likely that the differences in major and minor element concentrations and variations in defect populations between the pyroxenes will have significant effects on $\mathrm{Pb}$ transport rates. Investigation of the dependence of oxygen fugacity on diffusion can help to shed light on the involved diffusion mechanisms, thus Cherniak (2001) explored the relationship between Pb diffusion and oxygen fugacity, measuring diffusion under more oxidizing and more reducing ( $\mathrm{MH}$ and IW buffered) conditions than QFM for $\mathrm{Cr}$ diopside, augitic pyroxene and enstatite, and conducted comparable experiments on the diopside and Fe-rich clinopyroxene studied in the 1998 work. Cherniak (2001) found a positive dependence of $\mathrm{Pb}$ diffusion rates on $p \mathrm{O}_{2}$ for all of the pyroxene compositions investigated. This is clearly shown in Figure 4, where values for $\log D_{\mathrm{Pb}}$ at constant temperature $\left(1000{ }^{\circ} \mathrm{C}\right.$ for the enstatite, $950{ }^{\circ} \mathrm{C}$ for other pyroxenes) for these pyroxene compositions are plotted as a function of $\log \mathrm{pO}_{2}$. The slopes of these lines are similar, ranging from 0.141 to 0.203 , and these values of the exponent $m$ where $D \propto\left(p \mathrm{O}_{2}\right)^{m}$, are presented in Table A2. Comparison of the Arrhenius relation for $\mathrm{Pb}$ diffusion in near end-member diopside under "selfbuffered" conditions (Cherniak 1998a) with diffusivities found under controlled buffered conditions suggests that the "self-buffered" system (with its relatively iron-poor natural diopside) is more reducing than QFM, in contrast to the conclusion drawn in Cherniak (1998a).

Interestingly, the exponential term for diopside is 0.19 , which is in good agreement with the value $+3 / 16$ determined from point defect models for diffusion mechanisms controlled by cation vacancies (Jaoul and Raterron 1994). Despite differences in major and minor element concentrations and variations in defect populations among these pyroxenes, the similarities in $\mathrm{pO}_{2}$ dependence on $\mathrm{Pb}$ diffusion rates suggest a common controlling defect mechanism, likely vacancy-controlled (octahedrally coordinated vacancies) mechanism for $\mathrm{Pb}$ diffusion in pyroxene. This is in contrast to the finding of Dimanov et al. (1996) for Ca diffusion, in which a negative dependence on $p \mathrm{O}_{2}$ was determined for natural $\mathrm{Fe}$ bearing $(\sim 2$ at $\% \mathrm{Fe})$ diopside, suggesting diffusion controlled by an interstitial mechanism.

These dependences of $D$ on $p \mathrm{O}_{2}$ can also be used to obtain activation energies for diffusion at constant $p \mathrm{O}_{2}$ (rather than under the conditions imposed by the solid buffers, for which $p \mathrm{O}_{2}$ 

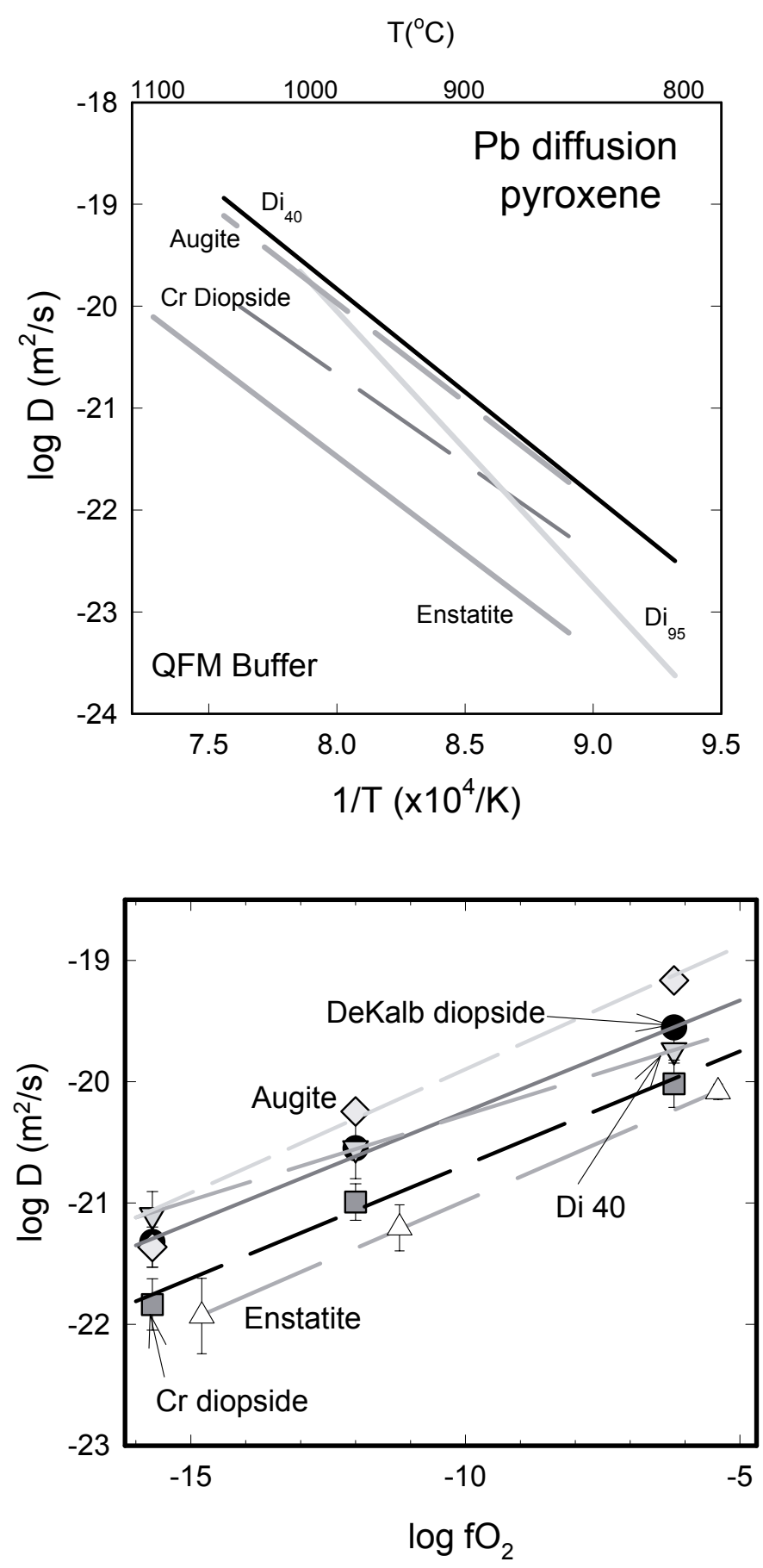

Figure 3. Summary of $\mathrm{Pb}$ diffusion data for pyroxene for experiments buffered at QFM. $\mathrm{Pb}$ diffusion is generally faster in more Fe-rich pyroxene, while diffusion in enstatite is slower than in the clinopyroxene compositions investigated. Data from Cherniak (1998a, 2001).

Figure 4. Dependence of $\mathrm{Pb}$ diffusion on $p \mathrm{O}_{2}$ for various pyroxene compositions, measured at $1000{ }^{\circ} \mathrm{C}$ for enstatite and 950 ${ }^{\circ} \mathrm{C}$ for other compositions. In all cases, there is a positive dependence of diffusion coefficients on $\mathrm{pO}_{2}$, with exponents $m$ ranging from 0.141 to 0.203 (Table A2), where $D \propto\left(p \mathrm{O}_{2}\right)^{m}$. This dependence is consistent with a vacancy controlled mechanism for $\mathrm{Pb}$ diffusion. Data from Cherniak (2001).

varies with temperature) as was done for major elements in Figure 1. If the diffusivities are normalized to a constant $p \mathrm{O}_{2}$ of $1 \times 10^{-12} \mathrm{MPa}$, we obtain activation energies of $417 \mathrm{~kJ} / \mathrm{mol}$ for diffusion parallel to $c$ in the near end-member diopside, $294 \mathrm{~kJ} / \mathrm{mol}$ for diffusion in the Fe-rich clinopyroxene (for diffusion normal to (110)), $275 \mathrm{~kJ} / \mathrm{mol}$ for the augitic pyroxene, and 259 $\mathrm{kJ} / \mathrm{mol}$ for the $\mathrm{Cr}$ diopside (for diffusion normal to (110). These values are lower than those determined for diffusion under QFM-buffered conditions. However, it should be emphasized that in self-buffered natural assemblages, $p \mathrm{O}_{2}$ will generally vary with temperature rather than being of fixed value, so Arrhenius relations determined for conditions corresponding to solid buffers may better describe the temperature dependence of diffusion in geologic systems. 


\section{Rare earth elements.}

Diopside. Sneeringer et al. (1984) measured Sm diffusion in synthetic diopside $(<0.1$ at $\% \mathrm{Fe}$ ) at pressures from 0.8-2.0 GPa using solid-media piston-cylinder apparatus. Diffusion couples of polished synthetic diopside were used in experiments, with one half of the couple an undoped diopside and the other half material doped with $\mathrm{Sr}$ and $\mathrm{Sm}$ in concentrations of 450 ppm and 250 ppm, respectively. Samples were analyzed with ion microprobe. As noted above when describing the Sr diffusion results from this study, the authors report some difficulty in separating the halves of the couple and locating the interface between doped and undoped diopside. The results for high-pressure experiments at $2 \mathrm{GPa}$ suggest pronounced anisotropy for Sm diffusion, with diffusion along the $c$-axis slower than diffusion along the $a$-axis. Diffusion in the $c$ direction was also found to have a higher activation energy for diffusion. For the $2 \mathrm{GPa}$ data, Sneeringer et al. (1984) report Arrhenius parameters of $197 \pm 50 \mathrm{~kJ} / \mathrm{mol}$ and $1.2 \times 10^{-11}$ $\mathrm{m}^{2} / \mathrm{s}\left(\log D_{0}=-10.92\right)$ for diffusion along the $a$-axis, and $590 \pm 96 \mathrm{~kJ} / \mathrm{mol}$ and $1.4 \times 10^{2} \mathrm{~m}^{2} / \mathrm{s}$ $\left(\log D_{0}=2.15\right)$ for diffusion along the $c$-axis. For diffusion at $1.4 \mathrm{GPa}$ in the $c$ direction, an activation energy of $628 \pm 71 \mathrm{~kJ} / \mathrm{mol}$ and pre-exponential factor $2.5 \times 10^{3} \mathrm{~m}^{2} / \mathrm{s}\left(\log D_{0}=3.40\right)$ was determined; for $0.8 \mathrm{GPa}$ values reported were an activation energy of $239 \pm 46 \mathrm{~kJ} / \mathrm{mol}$ and pre-exponential factor $1.9 \times 10^{-10} \mathrm{~m}^{2} / \mathrm{s}\left(\log D_{0}=-9.72\right)$. From the data along the $c$-axis they find positive activation volumes $\left(0.3-6.6 \mathrm{~cm}^{3} / \mathrm{mol}\right)$, but note that the large uncertainties in these determinations permit few definitive statements about whether activation volume is small approaching zero, negative, or positive. Cracking of the samples (most likely during pressurization or depressurization of experiments), as noted above, could increase apparent profile lengths from high-pressure experiments, and the effect of experimental artifacts may lead to the similarities in diffusivities for $\mathrm{Sr}$ and $\mathrm{Sm}$ measured on the same samples. As a consequence of these limitations and the potential that these experimental artifacts may result in overestimates of Sm diffusivities, the REE diffusivities of Van Orman et al. (2001), to be discussed next, are considered more reliable measurements.

Van Orman et al. (2001) measured diffusion of five rare-earth elements (La, Ce, $\mathrm{Nd}, \mathrm{Dy}$ and $\mathrm{Yb}$ ) in natural diopside (with $0.70 \mathrm{wt} \% \mathrm{FeO}$ ). The rare-earth elements were deposited in a dilute nitric acid solution on the surfaces of polished pre-annealed diopside samples (cut normal to (001)); the solution was then dried, leaving a rare-earth oxide film. Most experiments were run in 1-atm furnaces in Pt capsules, using $\mathrm{CO}_{2}-\mathrm{H}_{2}$ gas mixtures to control oxygen fugacity near the QFM buffer. A few experiments were conducted in solid-media piston-cylinder pressure vessels to investigate $\mathrm{Ce}$ and $\mathrm{Yb}$ diffusion at higher pressures; these were run at pressures from 1.3 to $2.5 \mathrm{GPa}$, using graphite or noble metal capsules to contain the samples. Analyses of REE profiles from all experiments were performed with SIMS.

From the $0.1 \mathrm{MPa}$ experiments over temperatures ranging between 1050 and $1300{ }^{\circ} \mathrm{C}$, Van Orman et al. (2001) obtain Arrhenius relations for diffusion of the five rare earth elements along the $c$-axis (Fig. 5), and observe systematic dependence of diffusion coefficients on REE ionic radius, with the diffusivity of $\mathrm{Yb} \sim 3$ times faster than $\mathrm{Dy}, \sim 20$ times faster than $\mathrm{Nd}$ and $\sim 35$ times faster than La. Measured activation energies for diffusion range from 411-496 kJ/ $\mathrm{mol}\left(411 \pm 12 \mathrm{~kJ} / \mathrm{mol}\right.$ for $\mathrm{Yb}, 461 \pm 41 \mathrm{~kJ} / \mathrm{mol}$ for Dy, $496 \pm 77 \mathrm{~kJ} / \mathrm{mol}$ for $\mathrm{Nd}, 463 \pm 31 \mathrm{~kJ} \mathrm{~mol}^{-1}$ for Ce, and $466 \pm 78 \mathrm{~kJ} / \mathrm{mol}$ for $\mathrm{La}$ ), with pre exponential factors of $2.29 \times 10^{-5} \mathrm{~m}^{2} / \mathrm{s} ; 4.90 \times 10^{-4}$ $\mathrm{m}^{2} / \mathrm{s} ; 1.12 \times 10^{-3} \mathrm{~m}^{2} / \mathrm{s} ; 7.94 \times 10^{-5} \mathrm{~m}^{2} / \mathrm{s} ; 6.03 \times 10^{-5} \mathrm{~m}^{2} / \mathrm{s}$ for $\mathrm{Yb}, \mathrm{Dy}, \mathrm{Nd}, \mathrm{Ce}$ and La, respectively.

This trend is consistent with an elastic strain model for diffusion (Van Orman et al. 2001). The lighter rare earths with larger ionic radii cause greater lattice strain in diopside because they fit less well in M2 sites, and will diffuse more slowly. A similar trend has been observed for REE diffusion in zircon (Cherniak et al. 1997), with even more pronounced effects across the rare earth series, which may be attributable to the more rigid lattice of zircon and the greater mismatch between the REE and the lattice sites of $\mathrm{Zr}$ in zircon compared with sites for $\mathrm{Ca}$ in diopside. 


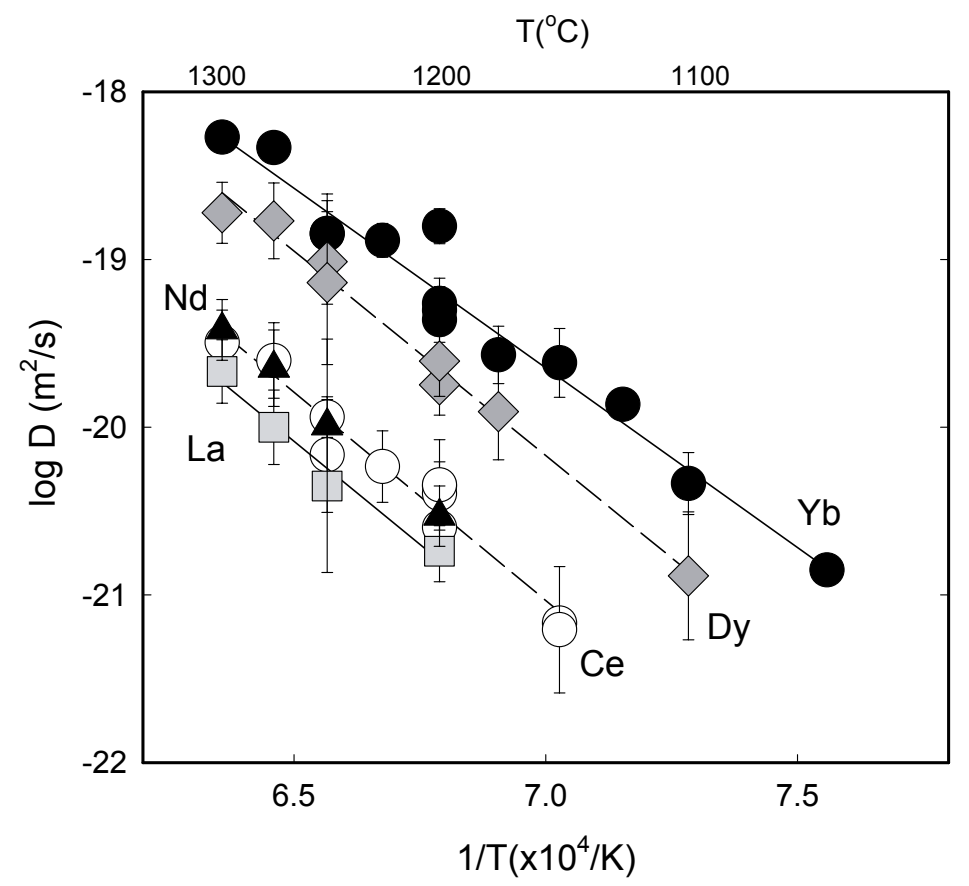

Figure 5. Arrhenius plot of diffusion of the REE in diopside, measured at $0.1 \mathrm{MPa}$ and at the QFM buffer by Van Orman et al. (2001). The data show a systematic dependence of REE diffusion on ionic radius, with the smaller heavy rare earth elements diffusing faster than the larger light rare earths.

Van Orman et al. (2001) performed one experiment on $\mathrm{Yb}$ diffusion at $1200{ }^{\circ} \mathrm{C}$ at an oxygen fugacity $4 \log$ units above QFM. The diffusion coefficient from this experiment was a factor of 3 higher than those from experiments run at the QFM buffer, indicating a positive dependence of $\mathrm{REE}^{+3}$ diffusion on $p \mathrm{O}_{2}$. In high-pressure experiments, a systematic difference between diffusivities was noted for samples annealed in contact with Pt or AuPd capsules and those in contact with graphite, with those annealed in noble metal capsules exhibiting lower diffusivities. The authors attributed this behavior to Fe loss to the noble metal capsules from the diopside. The loss of $\mathrm{Fe}^{3+}$ would be accompanied by the loss of associated M2 vacancies from the material, which would lead to slower diffusivities in cases where diffusion proceeds via a vacancy mechanism. In view of the complications in interpreting diffusion data given the varying conditions during the noble-metal capsule experiments, Van Orman et al. (2001) considered only the diffusivities obtained from experiments with graphite capsules. These data for Ce and $\mathrm{Yb}$ diffusion show a clear systematic trend of decreasing diffusivity with increasing pressure. Regressions with these data yield expressions of the form $D=D_{0} \exp \left(-\left(E_{\mathrm{a}}+P V\right) / R T\right)$, where $V$ is the activation volume for diffusion, to describe diffusion coefficients measured at temperatures from $1050-1450{ }^{\circ} \mathrm{C}$ and pressures ranging from $0.1 \mathrm{MPa}$ to $2.5 \mathrm{GPa}$. The parameters from these regressions are summarized in Table A3.

The activation volumes determined for $\mathrm{Ce}$ and $\mathrm{Yb}$ diffusion in diopside are higher than those for Mg-self-diffusion in olivine (Chakraborty et al. 1994) but similar to activation volumes of $8-10 \mathrm{~cm}^{3} / \mathrm{mol}$ for divalent cation diffusion in aluminosilicate garnet (Chakraborty and Rubie 1996; Ganguly et al. 1998). They are, however, not consistent with the negative activation volume and large apparent anisotropy of activation volume for $\mathrm{Sr}$ diffusion reported by Sneeringer et al. (1984); given the large amount of scatter in the Sneeringer et al. (1984) data and reported difficulty in retrieval of high-quality sample surfaces following high-pressure experiments, these apparent negative activation volumes may be an experimental artifact, as suggested by Van Orman et al. (2001).

The data for diffusion for Sm from Sneeringer et al. (1984) yield diffusivities about an order of magnitude faster than those of Van Orman et al. (2001) for Dy diffusion at 1 atmosphere. It would be expected, given the trend observed by Van Orman et al. (2001) of decreasing diffusivities with increasing REE ionic radii, that Sm would diffuse more slowly than Dy. In addition, 
the Sneeringer et al. (1984) experiments were run at higher pressures, so the positive activation volume determined by Van Orman et al. (2001) would lead to lower diffusivities at higher pressures, and further increase the differences between diffusivities of Dy at 1-atm vs. Sm at higher pressures. However, as noted above, experimental difficulties encountered in the Sneeringer et al. (1984) study may account for this apparent inconsistency between these datasets.

In diopside, a coupled substitution is required to balance $\mathrm{REE}^{+3}$ in exchange on the diopside M2 site. In the work of Van Orman et al (2001), REE concentrations in diopside in experiments are a few thousand ppm. No charge compensating species is present (e.g., $\mathrm{Na}$ or $\mathrm{Al}$ ) in the source, so the authors speculate that REE may be accommodated by an Eskola-type exchange, where charge balance occurs through creation of vacancies on M1 or M2 sites; potential mechanisms are discussed in their paper. The positive dependence of REE diffusion on oxygen fugacity suggests a vacancy mechanism, and if diffusion is governed by $\mathrm{M} 2$ vacancies, then diffusivities should have a proportional dependence on $\mathrm{pO}_{2}$ roughly equivalent to that expected from point defect models. The Van Orman et al. (2001) data suggest $m \cong 0.13$, a bit lower than 0.18 predicted by the point defect model. Cherniak (2001) observed a dependence of $\mathrm{Pb}$ diffusion on $p \mathrm{O}_{2}$ of $m \sim 0.18$ for diopside, and similar values for other pyroxene compositions. In contrast, Dimanov et al. (1996) found a negative dependence of Ca diffusion on $p \mathrm{O}_{2}$, with $m \cong-0.19$, suggesting that $\mathrm{Ca}$ diffuses via an interstitial mechanism. It appears that the energy required to jump to an M3 or M4 interstitial site is not that much different from the energy required for an M2 cation to move to an adjacent vacancy, and as a result the diffusion mechanism an ion prefers may be very sensitive to size and charge.

Enstatite. Rare earth element diffusion in enstatite has been studied by Cherniak and Liang (2007), who measured chemical diffusion coefficients of $\mathrm{La}, \mathrm{Nd}, \mathrm{Eu}, \mathrm{Gd}$, and $\mathrm{Yb}$ in natural near end member enstatite (with 0.2 at\% Fe). A summary of these data are shown in Figure 6. Along with an investigation of potential differences in diffusivities among the trivalent REE, this study also explored diffusion of divalent and trivalent Eu. Sources of diffusants were prereacted mixtures of synthetic enstatite powder and microcrystalline rare-earth aluminate garnet, with a single REE used in each set of experiments. Diffusion experiments were run in 1-atm furnaces, either with samples and source materials placed in Pt capsules and annealed in air, or in sealed silica glass capsules with an iron-wüstite (IW) solid buffer. Rutherford Backscattering Spectrometry (RBS) was used to measure REE diffusion profiles.

For Eu diffusion in air over the temperature range $1000-1200{ }^{\circ} \mathrm{C}$ for diffusion normal to (210), Cherniak and Liang (2007) obtained an activation energy for diffusion of $350 \pm 42$ $\mathrm{kJ} / \mathrm{mol}$ and pre-exponential factor of $1.70 \times 10^{-8} \mathrm{~m}^{2} / \mathrm{s}\left(\log D_{0}=-7.77 \pm 1.53\right)$. The Arrhenius parameters for Eu diffusion in enstatite, for diffusion normal to (210) from $850-1150{ }^{\circ} \mathrm{C}$ under IW-buffered conditions, are $384 \pm 29 \mathrm{~kJ} / \mathrm{mol}$ and $6.93 \times 10^{-6} \mathrm{~m}^{2} / \mathrm{s}\left(\log D_{0}=-5.16 \pm 1.18\right)$ for the activation energy and pre-exponential factor, respectively. Eu diffusion under IW-buffered conditions is more than an order of magnitude faster than Eu diffusion in air. It is likely that a large fraction of Eu becomes divalent under the more reducing conditions imposed by the IWbuffered experiments (e.g., Schreiber 1977), but Eu would be predominantly in the trivalent state for the diffusion experiments run in air.

Although the majority of REE diffusion experiments by Cherniak and Liang (2007) measured diffusion normal to (210) (this orientation, although not a major crystallographic direction, was chosen because of very pronounced cleavage along this plane in the enstatite specimens used in experiments), little evidence of anisotropy was observed in comparing Eu diffusivities normal to (001) and those normal to (210) for both the IW-buffered experiments and those run in air.

For diffusion of $\mathrm{Gd}$ in air over the temperature range $1000-1250{ }^{\circ} \mathrm{C}$, Cherniak and Liang (2007) obtained an activation energy for diffusion of $321 \pm 85 \mathrm{~kJ} / \mathrm{mol}$ and pre-exponential factor of $2.55 \times 10^{-9} \mathrm{~m}^{2} / \mathrm{s}\left(\log D_{0}=-8.59 \pm 3.08\right)$ for transport normal to (210). They present 


\section{$\mathrm{T}\left({ }^{\circ} \mathrm{C}\right)$}

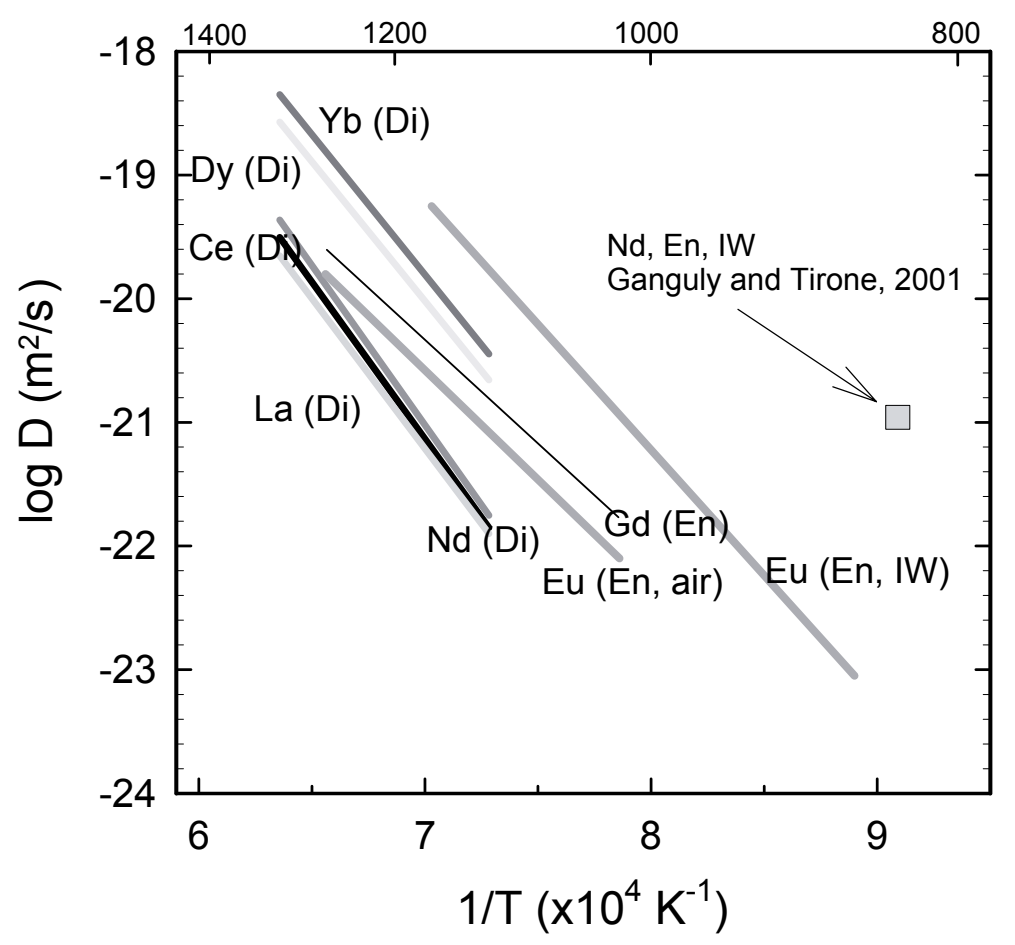

Figure 6. Summary of REE diffusion data for pyroxenes, showing the Arrhenius relations for Gd and Eu diffusion in enstatite from Cherniak and Liang (2007), the datum for Nd diffusion in enstatite from Ganguly and Tirone (2001) and Arrhenius relations for La, Ce, Nd, Dy and Yb diffusion in diopside from the study of Van Orman et al. (2001).

comparatively few Gd diffusion data, so uncertainties in Arrhenius parameters are large, but there is no significant difference between Gd diffusion in air and under IW-buffered conditions. Cherniak and Liang (2007) report that Nd and Gd behave similarly with no significant difference for diffusion in air or under buffered conditions. For both of these elements, where valence state does not change under the investigated $\mathrm{pO}_{2}$ conditions, measured diffusion coefficients for experiments run both in air and under IW-buffered conditions are comparable to those obtained for trivalent $\mathrm{Eu}$.

These findings, as well as measurements of $\mathrm{La}$ and $\mathrm{Yb}$ diffusion that yield diffusion coefficients similar to those of the other trivalent REE, suggest that diffusion of trivalent REE in enstatite is not greatly sensitive to ionic size, in contrast to observations for REE diffusion in diopside (Van Orman et al. 2001), where there is a systematic variation of rare earth element diffusion across the REE series, with the light rare earths with larger ionic radii diffusing more slowly than the smaller heavy rare earths (Fig. 7).

Measurements of $\mathrm{Pb}$ diffusion in enstatite (Cherniak 2001) indicate a positive dependence of diffusion on oxygen fugacity, suggesting that diffusion likely proceeds via a vacancy mechanism. Given the similarities in activation energies for $\mathrm{Pb}^{2+}(366 \mathrm{~kJ} / \mathrm{mol}$, Cherniak $2001)$ and $\mathrm{Eu}^{2+}(384 \mathrm{~kJ} / \mathrm{mol})$, it may be conjectured that Eu similarly diffuses via a vacancy mechanism, but because of the change in Eu valence state, a large range in $p \mathrm{O}_{2}$ could not be explored as was done for $\mathrm{Pb}^{2+}$ (Cherniak 2001) to confirm this. Van Orman et al. (2001) found a slightly weaker but still positive dependence on $p \mathrm{O}_{2}$ for the diffusion of $\mathrm{Yb}$ in diopside $(\sim \mathrm{a}$ factor of 3 increase for an increase of $4 \log$ units in $p \mathrm{O}_{2}$ ). The $\mathrm{Gd}$ diffusion measurements from Cherniak and Liang (2007), where diffusivities for experiments run in air and under IWbuffered conditions are similar, suggest that the $p \mathrm{O}_{2}$ dependence of REE diffusion in enstatite 
may be weaker than for $\mathrm{Pb}$, as long as the REE remain in the trivalent state. It is unclear why this is the case. The enstatite contains significant amounts of $\mathrm{Al}$ (larger than the total $\mathrm{Fe}$ concentration), and there is also abundant $\mathrm{Al}$ present in the source medium. If $\mathrm{Al}^{3+}$, rather than $\mathrm{Fe}^{3+}$, controls cation vacancy concentrations, this might account for the weak dependence on $p \mathrm{O}_{2}$. In addition, $\mathrm{Al}^{3+}$ (if substituting for $\mathrm{Si}^{4+}$ ) may be involved in coupled exchange to charge compensate $\mathrm{REE}^{3+}$ in substituting for $\mathrm{Mg}^{2+}$.

The behavior of Eu differs from that of the other REE investigated by Cherniak and Liang (2007). Although $\mathrm{Eu}^{2+}$ is considerably larger than $\mathrm{Eu}^{3+}$ (i.e., $1.25 \AA$ vs. $1.066 \AA$ in 8 -fold coordination, Shannon 1976), diffusivities appear more sensitive to cation charge than size, which is suggested by the extant cation diffusion data for enstatite, and also consistent with the strong charge dependence for cation diffusion observed in other minerals (e.g., zircon, feldspar, and apatite) and in molten silicates. The evidence from Cherniak and Liang (2007) suggests that diffusivities of $\mathrm{Nd}$ and $\mathrm{Gd}$ are not greatly affected by effects of differing oxygen fugacity on enstatite's defect chemistry, so the differences in diffusivities between the Eu experiments buffered at IW and those in air are most likely a result of the valence state of Eu. This is consistent with the observed $\mathrm{pO}_{2}$ dependence of Eu tracer diffusion in molten $\mathrm{CaMgSi}_{2} \mathrm{O}_{6}$, $\mathrm{NaAlSi}_{2} \mathrm{O}_{6}$, and $\mathrm{CaO}-\mathrm{MgO}-\mathrm{Al}_{2} \mathrm{O}_{3}-\mathrm{SiO}_{2}$ (Nakamura and Kushiro 1998; Liang et al. 2004).

In addition to the study of Cherniak and Liang (2007), results from a single diffusion experiment on REE diffusion in enstatite were reported by Ganguly and Tirone (2001). Ganguly and Tirone (2001) measured Nd diffusion in enstatite $\left(\mathrm{En}_{96} \mathrm{Fs}_{1}\right.$; from Sri Lanka) under IW buffered conditions at $827{ }^{\circ} \mathrm{C}$ by depositing a thin film of ${ }^{145} \mathrm{Nd}$ tracer on the sample surface, and annealing the sample in a 1-atm furnace with a flowing $\mathrm{CO}-\mathrm{CO}_{2}$ gas mixture to control oxygen fugacity; $\mathrm{Nd}$ was profiled following diffusion anneals with SIMS. They obtained a diffusion coefficient of $1.1 \times 10^{-21} \mathrm{~m}^{2} / \mathrm{s}$ at $827^{\circ} \mathrm{C}$ (Fig. 6). If the Arrhenius relation of Cherniak and Liang (2007) from results for trivalent REE is extrapolated to this temperature, a diffusivity more than three orders of magnitude smaller than the value obtained by Ganguly and Tirone (2001) is obtained. Interestingly, however, the diffusivity obtained by Ganguly and Tirone (2001) is similar to that for the diffusion of $\mathrm{Mg}^{2+}$ in enstatite (Schwandt et al. 1998). It is not clear why the discrepancy between these REE diffusion datasets exists, since the enstatite compositions in these studies are comparable, and some of the experiments were run under similar conditions of pressure and $p \mathrm{O}_{2}$. It is unlikely that the cause of the difference could be due to the protoenstatite-orthoenstatite transition (with the experiment of Ganguly and Tirone (2001) below the temperature of this transition, and experiments of Cherniak and Liang (2007) above it), given the findings of Cherniak (2001) and Cherniak and Liang (2007) and discussion

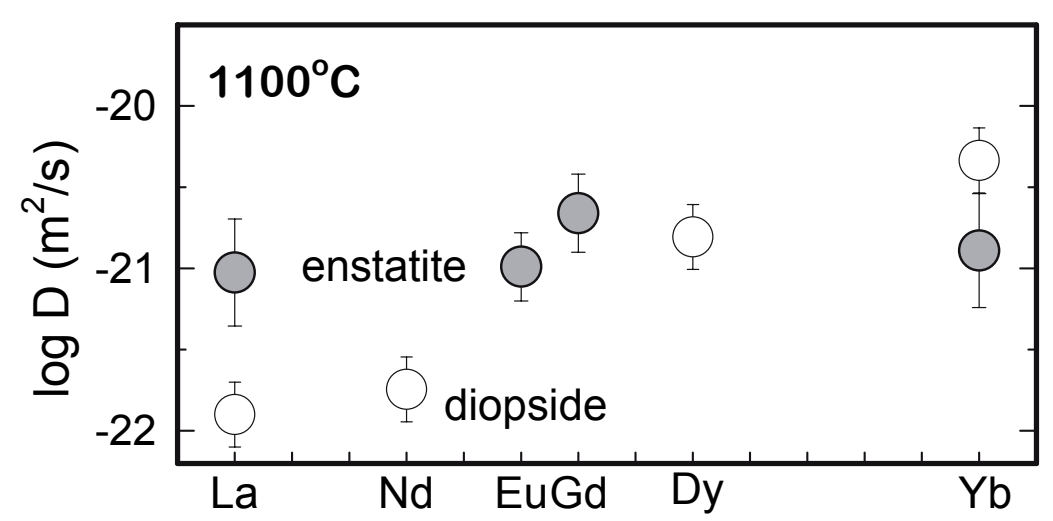

Figure 7. Comparison of diffusivities of the $\mathrm{REE}^{+3}$ in enstatite (filled circles) and diopside (open circles) at $1100{ }^{\circ} \mathrm{C}$, from the data and extrapolated Arrhenius relations of Cherniak and Liang (2007) and Van Orman et al. (2001). There is little evidence of dependence of REE diffusion in enstatite on REE ionic radius, in contrast with findings for REE diffusion in diopside. 
in later sections. Primary differences between these studies include the methods of introducing the REE source, the source compositions, and the depth-profiling techniques (ion probe vs. RBS). A likely explanation is that the datum of Ganguly and Tirone (2001) suffered from a mixing effect between the deposited source and the diffusion profile in SIMS depth profiling analysis (J. Ganguly, pers. commun.)

Comparison of REE diffusivities in enstatite and diopside. Diffusion of $\mathrm{La}, \mathrm{Nd}, \mathrm{Gd}$, and $\mathrm{Yb}$, and $\mathrm{Eu}$ in air (where it is trivalent) in enstatite is slower than diffusion of middle to heavy rare earths in diopside (Van Orman et al. 2001), but slightly faster than diffusion of the light rare earths $\mathrm{La}, \mathrm{Ce}^{3+}$, and $\mathrm{Nd}$ in diopside. The activation energies for $\mathrm{REE}^{3+}(411-496 \mathrm{~kJ} / \mathrm{mol})$ diffusion in diopside are higher than for $\operatorname{REE}^{3+}(321-350 \mathrm{~kJ} / \mathrm{mol})$ diffusion in enstatite; this is also true for $\mathrm{Pb}^{2+}$, where activation energies for diffusion are 544 and $366 \mathrm{~kJ} / \mathrm{mol}$ for near end member diopside and enstatite, respectively (Cherniak 2001).

These systematic variations and differences of REE diffusion in diopside and enstatite may, in part, be due to the differences in crystal chemistry between these pyroxenes. The M2 site of diopside is more flexible and is predominantly occupied by the large 8-fold coordinated cation $\mathrm{Ca}^{2+}$ (and $\mathrm{Na}^{1+}$ ), while the M2 site of enstatite is more rigid and is occupied by the small 6-fold coordinated $\mathrm{Mg}^{2+}$ (e.g., Cameron and Papike 1981). Further, in low-Ca pyroxene the M1 and M2 sites are more similar in size and show much less preference for ordering of $\mathrm{Mg}$ and $\mathrm{Fe}^{2+}$ than clinopyroxene (e.g., Cameron and Papike 1981). Although the smaller and less flexible M2 site of enstatite limits the uptake of large cations such as $\mathrm{Eu}^{2+}, \mathrm{Sr}^{2+}$, and the $\mathrm{REE}^{3+}$ into its structure compared with diopside, substitution of the 8-fold coordinated cations will lead to a significant distortion of the local M2 site, which may lower the activation energy for diffusion of the large cations in enstatite. This effect, if present, is likely to be stronger at low temperatures where lattice size or cation-oxygen distance is smaller or shorter than that at high temperatures. Clearly more experimental and theoretical work is needed to better understand the comparative mechanisms of cation diffusion in pyroxenes.

Uranium and thorium. In an early diffusion study, Seitz (1973) measured U diffusion in natural diopside by annealing crystals in a ${ }^{235} \mathrm{U}$-doped diopside-albite glass. U penetration into the crystals was evaluated by measuring fission track distributions, which yielded a diffusion coefficient at $1240{ }^{\circ} \mathrm{C}$ of $9.9 \times 10^{-17} \mathrm{~m}^{2} / \mathrm{s}$.

Van Orman et al. (1998) more recently investigated $U$ and Th diffusion in natural diopside (0.55 wt\% FeO) over the temperature range $1150-1300{ }^{\circ} \mathrm{C}$. The source of diffusant was a dilute nitric acid solution containing $\mathrm{U}$, Th and $\mathrm{Al}$, which was deposited on polished sample surfaces and dried. Diffusion anneals were conducted in 1-atm furnaces, with flowing $\mathrm{CO}_{2}-\mathrm{H}_{2}$ gas mixtures used to control oxygen fugacity to near the QFM buffer. Analyzes of $U$ and Th profiles were performed with SIMS. For Th, an activation energy of $356 \pm 26 \mathrm{~kJ} / \mathrm{mol}$ and preexponential factor of $1.70 \times 10^{-8} \mathrm{~m}^{2} / \mathrm{s}\left(\log D_{0}=-7.77 \pm 0.92\right)$ were obtained, and values for $\mathrm{U}$ were $418 \pm 28 \mathrm{~kJ} / \mathrm{mol}$ and $1.78 \times 10^{-6} \mathrm{~m}^{2} / \mathrm{s}\left(\log D_{0}=-5.75 \pm 0.98\right)$ for the activation energy of diffusion and pre-exponential factor, respectively. Diffusivities of $U$ and Th are similar, which is reasonable given their like charge ( $\mathrm{U}$ is likely in the tetravalent state under the conditions of the diffusion anneals) and similar size. No sign of early partial melting (EPM) was noted by Van Orman et al. (1998) in their experiments. Moreover, they argue that EPM is unlikely to have a great effect on cation diffusion since the precipitates that form in EPM are isolated and do not form an interconnected network that would provide fast diffusion paths.

The diffusion coefficient for $U$ from the measurements of Van Orman et al (1998) is four orders of magnitude slower than the determination of Seitz (1973) at $1240{ }^{\circ} \mathrm{C}$, which Van Orman et al (1998) suggest may be result of crystal growth in the U-doped diopside-anorthitealbite melt used in Seitz's (1973) experiments, which would lead to U incorporation into the samples due to processes other than simple volume diffusion. 


\section{Comparison of diffusion of cations in pyroxene}

Enstatite. Diffusion data for enstatite are summarized in Figure 8. Mg diffusion in enstatite (Schwandt et al. 1998) is about 3-4 orders of magnitude faster than Pb diffusion in enstatite (for systems buffered at IW), and about 2 orders of magnitude faster than $\mathrm{Eu}^{2+}$. The activation energies for diffusion of $\mathrm{Pb}, \mathrm{Eu}^{+2}$ and $\mathrm{Mg}$ are similar. However, the $\mathrm{Mg}$ diffusion experiments were run on an enstatite with higher Fe content $\left(\mathrm{En}_{88} \mathrm{Fs}_{12}\right)$ than that used by Cherniak (2001) and Cherniak and Liang (2007). Diffusion data from various studies of pyroxenes (e.g., Dimanov et al. 1996; Cherniak 1998a) suggest that diffusivities might be somewhat higher in more ironrich pyroxenes, but that activation energies for diffusion may be similar. However, the large differences in ionic radii between the divalent cations $\mathrm{Mg}$ and $\mathrm{Pb}$ (i.e., 0.89 and $1.29 \AA$ for $\mathrm{Mg}$ and $\mathrm{Pb}$, respectively; Shannon 1976), probably account to greater extent for these differences in diffusion rates than compositional differences. Marked differences in diffusion rates among trivalent rare earth elements have been noted for diopside (Van Orman et al. 2001), with diffusion coefficients systematically increasing with decreasing REE ionic radius, with similar trends noted for divalent and univalent cations in plagioclase (Giletti and Shanahan 1997; La Tourette and Wasserburg 1998). Ca-Mg interdiffusion rates, obtained through homogenization of pigeonite lamellae in diopside (Brady and McCallister 1983), lie near an up-temperature extrapolation of the Arrhenius relation for $\mathrm{Pb}$ diffusion in enstatite rather than that of self-diffusion of $\mathrm{Mg}$ (Schwandt et al. 1998). This observation is consistent with a diffusion process governed by exchange of $\mathrm{Pb}$ on $\mathrm{Mg}$ sites, with the large size differentials between $\mathrm{Mg}$ and $\mathrm{Pb}$ (and between $\mathrm{Ca}$ and $\mathrm{Mg}[1.29,1.12$, and $0.89 \AA$ in 8 -fold coordination for $\mathrm{Pb}, \mathrm{Ca}$ and $\mathrm{Mg}$, respectively; Shannon 1976]) as a factor contributing to sluggish diffusion. The trivalent REE (La, Nd, Eu, Gd and $\mathrm{Yb}$ ) diffuse more slowly than the divalent cations in enstatite, and these is, as noted in previous sections, little difference in diffusivities among the trivalent REE investigated.

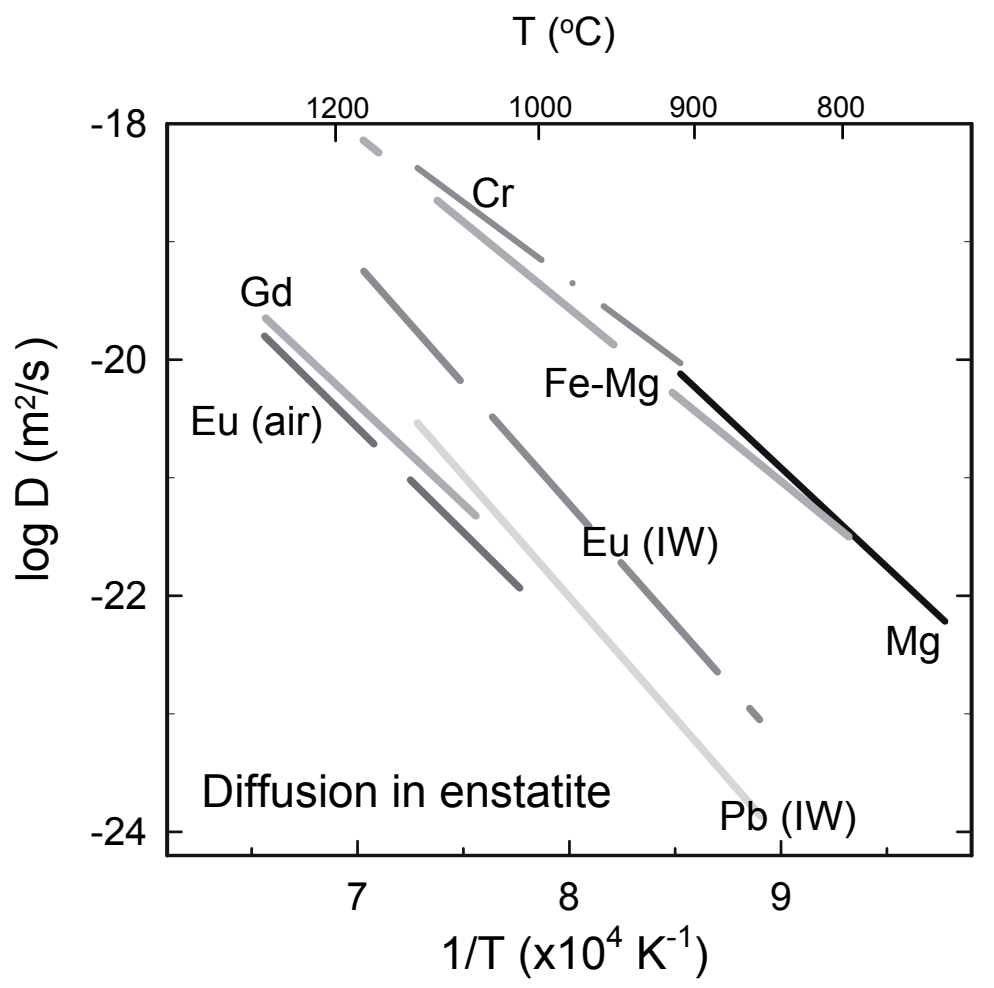

Figure 8. Diffusion of various cations in enstatite. Among the divalent cations $\left(\mathrm{Mg}, \mathrm{Pb}, \mathrm{Eu}^{+2}\right)$ there appears to be a trend of increasing diffusivity with increasing ionic radius. Sources for data: $\mathrm{Mg}-\mathrm{Schwandt}$ et al. (1998); Fe-Mg - Ganguly and Tazzoli (1994); Cr - Ganguly et al. (2007); Pb - Cherniak (2001); Eu, Gd Cherniak and Liang (2007). 
An additional consideration in diffusion studies of enstatite is the possibility that the orthoenstatite-protoenstatite transition may affect diffusion. Orthoenstatite ( $\mathrm{Pbca}$ structure) undergoes a structural inversion to protoenstatite (Pbcn structure) at about $985^{\circ} \mathrm{C}$ (Boyd and Schairer 1964; Smyth 1974); more recent studies (Yang and Ghose 1995; Choudhury et al. 1998) suggest that this transition may not occur until $1087^{\circ} \mathrm{C}$. The enstatite structures have different stacking sequences of alternating $\left[\mathrm{SiO}_{4}\right]$ tetrahedral and $\left[\mathrm{MO}_{6}\right]$ tetrahedral layers along the $a$-axis; the $\left[\mathrm{MgO}_{6}\right]$ octahedra are crystallographically distinct, with $\mathrm{M} 1$ smaller and more regular and M2 larger and more distorted. The ortho-proto transition, a displacivereconstructive phase transition, results in a decrease of the mean M2-O bond distance by $0.043 \AA$ and a highly distorted M2 octahedron in protoenstatite (Yang and Ghose 1995). The change in unit cell parameters (an increase in $c$ and decrease in $b$ ) in the transition is associated with unkinking of silicate chains; the increase in $a$ is a result of expansion of M2-O distances along $a$ along with an increase in out of plane tilting of silicate tetrahedra (Yang and Ghose 1995). Structural states of enstatite will depend on times and durations of both thermal pretreatments (if undertaken) and diffusion anneals. It is not clear how this transition will affect diffusivities in specific cases, but the measurements of REE (Cherniak and Liang 2007) and Pb (Cherniak 2001) diffusion in enstatite, which spanned the temperature range above and below the orthoenstatite-protoenstatite transition, showed little evidence of a change in diffusion rates for these elements in enstatite.

Diopside. Diffusion data for trace and minor elements in diopside are summarized in Figure 9, and presented with data for major elements in Figure 10. We first consider and compare diffusion data for divalent cations. The data for $\mathrm{Pb}$ diffusion in near end-member (DeKalb) and Cr diopsides under QFM-buffered conditions fall between down-temperature extrapolations from the diffusion data for $\mathrm{Sr}$ in natural and synthetic diopsides reported by Sneeringer et al. (1984), where diffusivities for synthetic (with low Fe content) and natural (1.5 wt $\% \mathrm{Fe}$ ) diopsides differed by two orders of magnitude. The natural specimens of Sneeringer et al. (1984) were annealed in nitrogen gas, while the synthetic specimens were annealed in air. The nitrogen atmosphere fixes the specimens at a constant (but unknown) oxygen fugacity, which the authors argue is probably higher than the ambient $p \mathrm{O}_{2}$ conditions during crystal formation. Thus, oxidation of $\mathrm{Fe}$ and formation of vacancies would likely result from the annealing of the natural specimens under these conditions.

The findings reported by Cherniak (2001) indicate a positive dependence of diffusion on $p \mathrm{O}_{2}$ for $\mathrm{Pb}$ in diopside; it may be the case that $\mathrm{Sr}$ diffusion has a similar dependence given its similar size and like charge. If the annealing conditions for the natural diopside in the Sneeringer et al. (1984) study are considered oxidizing, and the data are "normalized" to lower $p \mathrm{O}_{2}$ conditions using the dependence of $\mathrm{D}$ on $p \mathrm{O}_{2}$ derived for $\mathrm{Pb}$ diffusion in diopside by Cherniak (2001) (i.e., $m=0.19$ ), the family of curves shown in Figure 11 for MH, QFM, and IW buffered conditions is obtained. An up-temperature extrapolation from the Arrhenius relation for $\mathrm{Pb}$ diffusion in $\mathrm{Cr}$ diopside (experiments buffered at QFM) intersects the calculated QFM line. The DeKalb diopside line would lie somewhat above this (near $\mathrm{MH}$ ) by virtue of the very high activation energy $(544 \pm 40 \mathrm{~kJ} / \mathrm{mol}$, similar to the activation energy for $\mathrm{Sr}$ diffusion in the synthetic diopside [548 kJ/mol for the RBS-measured profiles of Sneeringer et al. 1984]). Interestingly, the calculated line for the most reducing conditions (i.e., IW), is nearly coincident with the line for Sr diffusion in the synthetic diopside. This agreement may be merely fortuitous, but perhaps indicates that a dominant factor influencing diffusion in pyroxenes is the change in defect chemistry (i.e., an increased vacancy concentration associated with electron holes needed to charge balance $\mathrm{Fe}^{+3}$; e.g., Buening and Buseck 1973) as consequence of the oxidation of Fe. Since ionic radii of $\mathrm{Sr}$ and $\mathrm{Pb}$ do not differ significantly (i.e., $1.29 \AA$ for $\mathrm{Pb}$ and $1.26 \AA$ for $\mathrm{Sr}$ in 8-fold coordination; Shannon 1976), similarities between $\mathrm{Sr}$ and $\mathrm{Pb}$ diffusion rates are unsurprising. Studies of $\mathrm{Sr}$ and Pb diffusion in feldspars (Cherniak and Watson 1992, 1994; Cherniak 1995) have also indicated comparable diffusivities for these cations. 

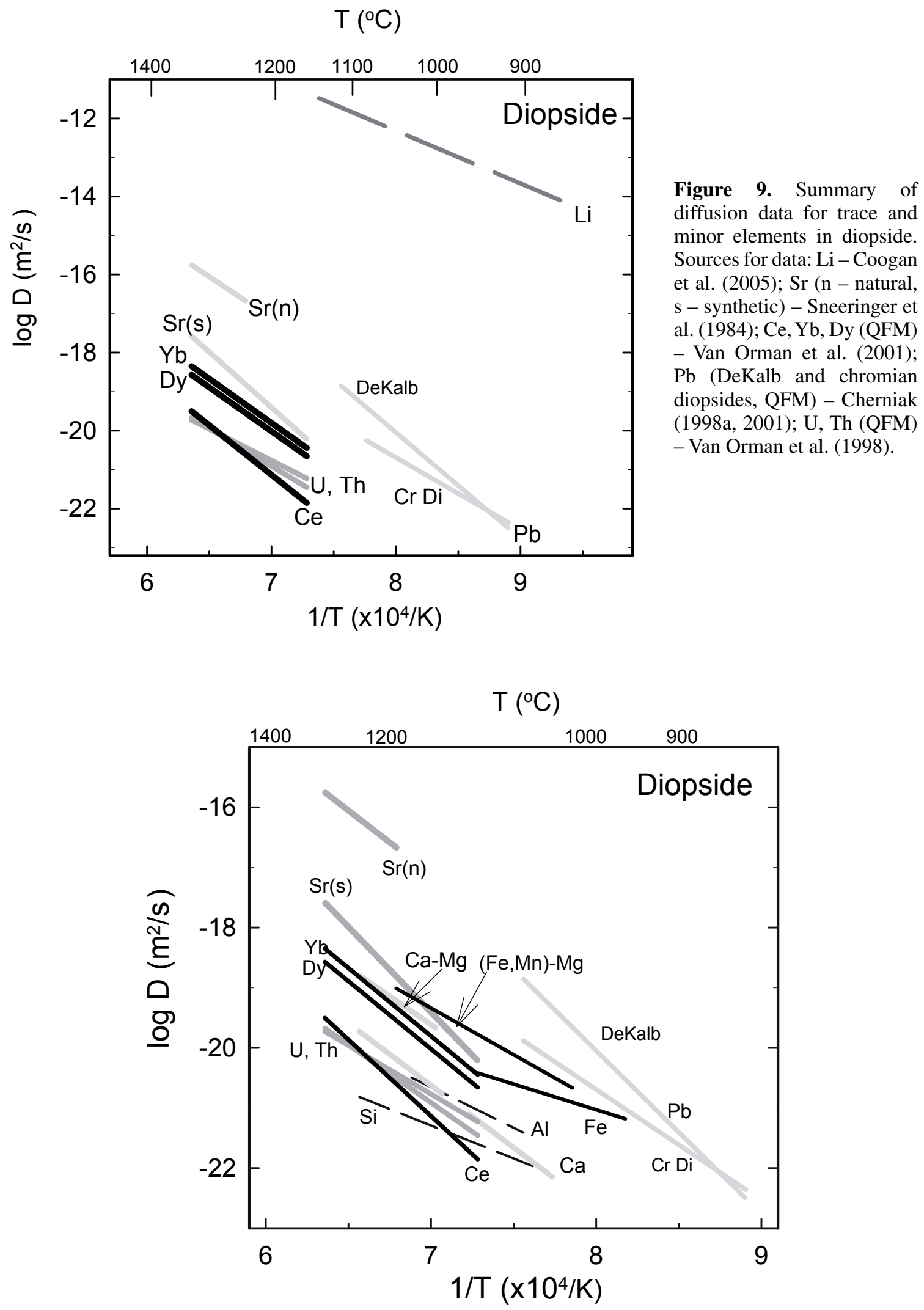

Figure 10. Diffusion data for major, trace and minor elements in diopside. Sources for data: $\mathrm{Ca}-\mathrm{Mg}-\mathrm{Brady}$ and McCallister (1983); (Fe,Mn)-Mg - Dimanov and Wiedenbeck (2006); Fe - Azough and Freer (2000); $\mathrm{Ca}\left(\mathrm{pO}_{2}=10^{-12} \mathrm{MPa}\right)-$ Dimanov et al. (1996); $\mathrm{Al}-$ Sautter et al. (1989); $\mathrm{Si}$ - Bejina and Jaoul (1996); $\mathrm{Sr}$ (n - natural, s - synthetic) - Sneeringer et al. (1984); Ce, Yb, Dy (QFM) - Van Orman et al. (2001); Pb (DeKalb and chromian diopsides, QFM) - Cherniak (1998a, 2001); U, Th (QFM) - Van Orman et al. (1998). 


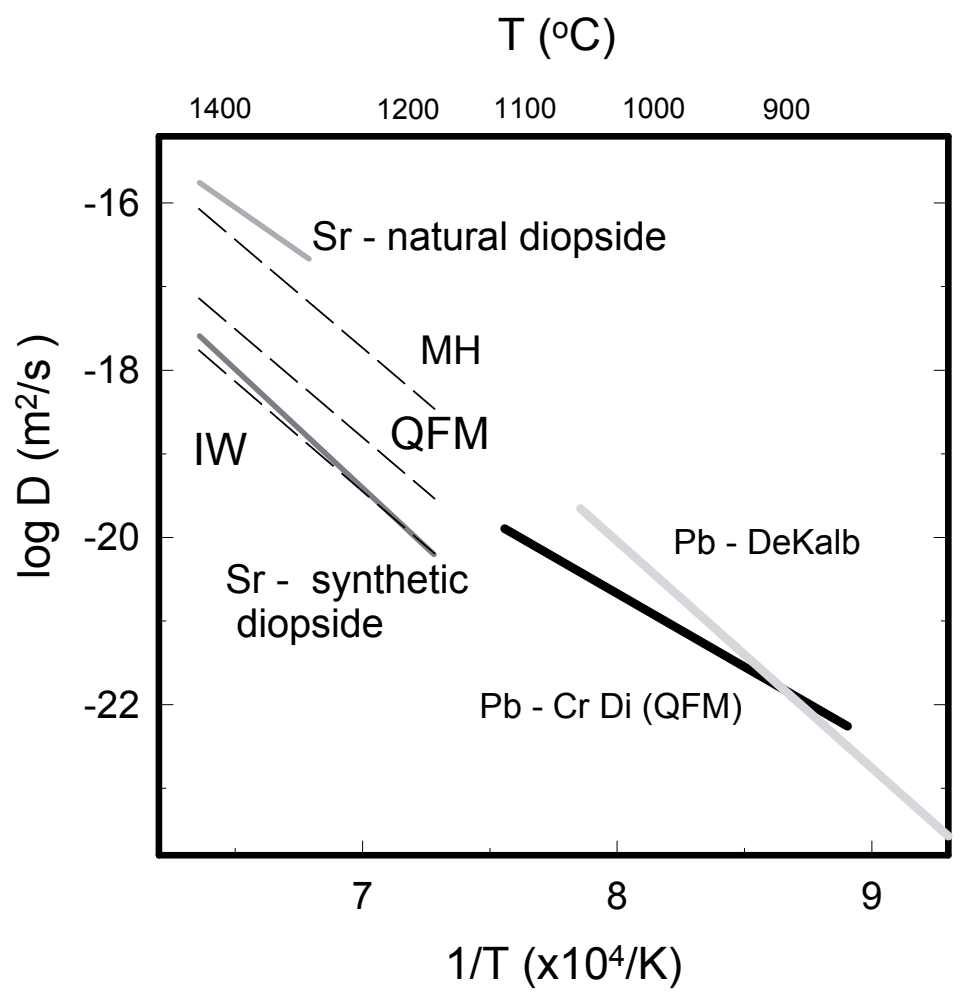

Figure 11. Potential effects of oxygen fugacity on $\mathrm{Sr}$ diffusion. The Arrhenius relation for the natural diopside in the Sneeringer et al. (1984) study is "normalized" to lower $p \mathrm{O}_{2}$ conditions using the dependence of $D$ on $p \mathrm{O}_{2}$ derived for $\mathrm{Pb}$ diffusion in diopside by Cherniak (2001) (i.e., $m=0.19$ ), producing the family of curves shown for MH, QFM, and IW buffered conditions (dashed lines). An up-temperature extrapolation from the diffusion data for $\mathrm{Pb}$ in $\mathrm{Cr}$ diopside (experiments buffered at QFM) intersects the calculated QFM line for Sr diffusion. The calculated line for the most reducing conditions (i.e., IW), is nearly coincident with the line for Sr diffusion in the synthetic diopside. This agreement may be merely fortuitous, but perhaps points to the importance of changes in defect chemistry in influencing diffusion in pyroxenes. See text for additional discussion.

Diffusion rates for the QFM buffered and the "self-buffered" Pb diffusion experiments on near end-member (DeKalb) diopside suggest that oxidation or reduction of multivalent minor elements may in some ways affect $\mathrm{Pb}$ transport (although $\mathrm{Pb}$ itself should remain in divalent state [e.g., Otto 1966]). Impurity levels tend to be much higher in natural samples (the diopside used by Cherniak (2001) has appreciable amounts of both $\mathrm{Na}$ and $\mathrm{Mn}$ ) and could influence diffusion. Effects would largely manifest themselves in elevated pre-exponential factors, as was found in the work of Dimanov et al. (1996) on Ca diffusion. Activation energies would likely be unaffected by the aforementioned factors in the extrinsic diffusion regime. The activation energy for $\mathrm{Sr}(607 \pm 33 \mathrm{~kJ} / \mathrm{mol})$ diffusion in synthetic diopside agrees within uncertainty with both buffered and self-buffered $\mathrm{Pb}$ diffusion results for diopside in the (110) orientation. $\mathrm{Ca}-$ $\mathrm{Mg}$ interdiffusion rates, obtained through homogenization of pigeonite lamellae in diopside (Brady and McCallister 1983), are about an order of magnitude slower than $\mathrm{Pb}$ diffusion data for diopside, but interdiffusion coefficients could vary by as much as an order of magnitude due to the large thermodynamic effect of non-ideal mixing on diffusion near a solvus (Brady and McCallister 1983; Zhang et al. 2010).

The most striking differences among diffusion rates of the divalent cations, however, may be noted when comparing results for Ca self-diffusion (Dimanov et al. 1996; Zhang et al. 2010) in natural Fe-bearing diopside with other findings. Ca diffusion is about one and half (Zhang et al. 2010) to more than two (Dimanov et al. 1996) orders of magnitude slower than $\mathrm{Pb}$ transport in the $\mathrm{Cr}$ diopside and DeKalb diopside. Based on point defect models and the observed $\mathrm{pO}_{2}$ 
dependence of Ca diffusion, Dimanov et al. 1996 advocate an interstitial mechanism for Ca transport. As it seems less likely that the much larger cations $\mathrm{Pb}$ and $\mathrm{Sr}(0.17$ and $0.14 \AA$ larger than Ca in 8-fold coordination, respectively; Shannon 1976) would be able to move through the lattice in this manner, diffusion rates and activation energies for $\mathrm{Ca}$ and other divalent cations might not be expected to be comparable. Dimanov et al. (1996) report an activation energy of $396 \pm 38 \mathrm{~kJ} / \mathrm{mol}$ for temperatures above $\sim 1150{ }^{\circ} \mathrm{C}$, and $264 \pm 33 \mathrm{~kJ} / \mathrm{mol}$ for temperatures below $1150{ }^{\circ} \mathrm{C}$. These activation energies are lower than that reported for $\mathrm{Pb}$ diffusion in diopside, but this is not inconsistent, as noted above, with the possibility of a different transport mechanism for $\mathrm{Pb}$ (and possibly $\mathrm{Sr}$ as well). Perhaps movement via the interstitial mechanism also accounts for the slower diffusion rate for $\mathrm{Ca}$ with respect to $\mathrm{Pb}$ and $\mathrm{Sr}$; if these species traveled via a similar diffusion mechanism it might be expected that $\mathrm{Ca}$ would diffuse more rapidly than both given its smaller size.

Diffusion of cations having higher valence states is slower than that of $\mathrm{Pb}$. The tetravalent cations U and Th (Van Orman et al. 1998), which likely substitute for Ca on M2 sites, diffuse several orders of magnitude more slowly than Pb. The trivalent REE (Van Orman et al. 2001), and especially the LREE with large ionic radii, also diffuse more slowly than $\mathrm{Pb}$. Pronounced decreases in diffusivities with higher cation charge have been noted in the feldspars (e.g., Giletti and Shanahan 1997; Giletti and Casserly 1994; Cherniak and Watson 1992, 1994; Foland 1974), zircon (Cherniak et al. 1997), and calcite (Cherniak 1997, 1998b). Silicon diffusion is also quite sluggish in diopside (Béjina and Jaoul 1996), consistent with observations made in other minerals, including olivine (Houlier et al. 1990; Dohmen et al. 2002), quartz (Cherniak 2003; Béjina and Jaoul 1996), and anorthite (Cherniak 2003). However, the activation energy for Si diffusion in diopside is relatively low $(211 \mathrm{~kJ} / \mathrm{mol})$ when compared with activation energies for diffusion of other cations, but, as noted by Béjina and Jaoul (1996), and earlier in this chapter, this value may represent an apparent activation energy, as experiments were not all performed at constant oxygen fugacity. Al diffusion in diopside at 1 atmosphere (Sautter et al. 1989; Jaoul et al. 1991) is also comparatively slow.

In sum, several factors may influence cation diffusion in clinopyroxenes. Variations in diffusion can be a consequence of the sites the ions occupy (tetrahedral vs. lower-energy M1 or M2 sites, or interstitial positions). Pyroxene composition has an influence, with higher diffusivities for more Fe-rich clinopyroxenes found for Ca (Dimanov et al. 1996), Sr (Sneeringer et al. 1984), and $\mathrm{Pb}$ (Cherniak 1998a, 2001). However, above about 1\% Fe, relatively large changes in Fe content appear to produce comparatively small changes in diffusivities (e.g., $\mathrm{Pb}$ diffusion in cpx with $17 \mathrm{wt} \% \mathrm{FeO}$ is up to half an order of magnitude faster than $\mathrm{Pb}$ diffusion in diopside with $\sim 1 \mathrm{wt} \% \mathrm{FeO}$ ), suggesting that cation diffusion rates are only reduced significantly when Fe content is quite low $(<\sim 1 \mathrm{wt} \%)$. It may be the case that cation vacancies associated with $\mathrm{Fe}^{3+}$ become saturated at relatively low $\mathrm{Fe}$ contents. Further, it appears that the energy required to jump to an M3 or M4 (e.g., Dimanov and Jaoul 1998) interstitial site is not that much different from the energy required for an M2 cation to move to an adjacent vacancy, and as a result the diffusion mechanism an ion prefers may be very sensitive to size and charge.

\section{DIFFUSION IN AMPHIBOLES AND MICAS}

The structures of amphiboles and micas are closely related to pyroxenes. Amphibole group minerals are common in metamorphic and igneous rocks, and in a broad range of pressuretemperature conditions. Micas fall into several distinct groups, and studies of diffusion have primarily focused on muscovite, biotite, and phlogopite. While micas and amphiboles are common minerals, and quantifying the diffusion behavior of cations and anions is important in applications of geochronology and geothermometry and in understanding metasomatic processes, there exist relatively few diffusion data for these minerals, which might be attributed to the difficulty in maintaining stability of hydroxyl-bearing phases under a broad range of 
experimental conditions, and, in the case of micas, of assessing potential anisotropy of diffusion in materials with platy geometries. Among early measurements were those of $\mathrm{K}, \mathrm{Sr}$ and $\mathrm{Rb}$ diffusion in biotite by Hofmann and Giletti (1970) and Hofmann et al. (1974), initially using bulk-exchange methods and later ion microprobe analysis to characterize diffusion. Two decades later, Brabander et al. (1995) and Brabander and Giletti (1995) measured F-OH interdiffusion in tremolite and $\mathrm{Sr}$ diffusion in tremolite and hornblende, respectively, developing methods to minimize the effects of dissolution-reprecipitation on sample surfaces during diffusion anneals. More recently, Hammouda and Cherniak (2000) circumvented the difficulty of dealing with hydroxyl-bearing phases by using synthetic fluorphlogopite, stable at elevated temperatures at 1-atm, for their Sr diffusion experiments. However, given the ubiquity of hydroxyl in most phlogopites found in nature, it should be stressed that results for diffusion in fluorphlogopite may have limited application to most geologic systems, although these data can provide useful constraints. In addition to the findings on cation and OH-F diffusion reported here, plotted in Figure 12, and summarized in Table A4, there have also been studies of $\mathrm{H}$ diffusion in micas (Graham 1981; Graham et al. 1984), oxygen diffusion in micas and hornblende (Fortier and Giletti 1991; Farver and Giletti 1985; Connolly and Muehlenbachs 1988; Giletti and Anderson 1975), and Ar diffusion in micas and amphibole (Giletti 1974; Giletti and Tullis 1977; Harrison 1981; Harrison et al. 1985, 2009; Baldwin et al. 1990; Grove and Harrison 1996).

\section{F-OH interdiffusion in tremolite}

Brabander et al (1995) measured F-OH interdiffusion in tremolite over the temperature range $500-800{ }^{\circ} \mathrm{C}$ and $200 \mathrm{MPa}$ pressure, with experiments conducted in cold-seal pressure vessels. Tremolite was exposed to F-poor (distilled water) or F-rich (created through reaction of $\mathrm{PdF}_{2}$ in the sample capsule) fluids in $\mathrm{Au}$ or Pt capsules, with $\mathrm{F}$ profiles measured by electron microprobe. A second set of experiments, which were analyzed with SIMS, used HF or CsF in aqueous solution to create the F-rich solution. The stability of crystal surfaces was maintained through the use of a silica-buffering assemblage (either quartz or forsterite + diopside +

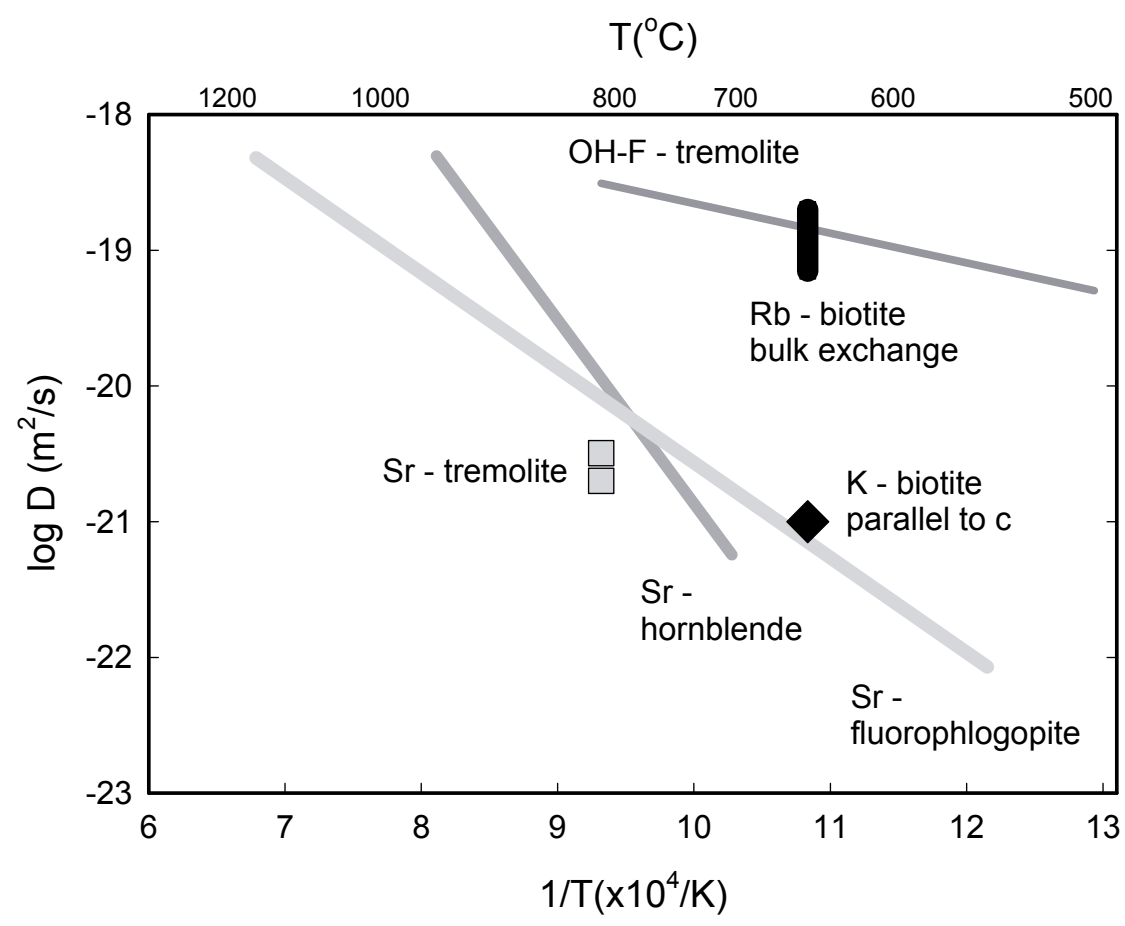

Figure 12. Diffusion in amphiboles and micas. Sources for data: $\mathrm{Sr}$ - fluorphlogopite: Hammouda and Cherniak (2000); Rb - biotite: Hofmann and Giletti (1970); K - biotite: Hofmann et al. (1974); Sr tremolite, hornblende: Brabander and Giletti (1995); OH-F - tremolite: Brabander et al. (1995). 
tremolite) in the fluid, with a double Pt capsule assembly used to contain sample, solid buffer and fluid. For diffusion parallel to $c$, an activation energy of $41 \pm 5 \mathrm{~kJ} / \mathrm{mol}$ and pre-exponential factor of $3.4 \times 10^{-17} \mathrm{~m}^{2} / \mathrm{s}\left(\log D_{0}=-16.46 \pm 0.36\right)$ were obtained. Diffusivities normal and parallel to $c$ agreed within experimental uncertainties, as did diffusivities for two tremolites of differing composition. This isotropy of diffusion is in contrast to results for $\mathrm{O}$ diffusion (Farver and Giletti 1985) where diffusion parallel to $c$ is 20 times faster than diffusion normal to $c$. Oxygen likely diffuses as molecular water, while fluorine and hydroxyl migrate as charged species.

However, it should be noted that in the study of Brabander et al. (1995) there was a difference of a factor of 5 between diffusivities from experiments conducted on cleaved surfaces and those on polished surfaces, with diffusion in experiments with cleaved surfaces the slower. This suggests that surface damage through polishing may contribute to apparent enhanced diffusivities, or reflects effects of the comparative instability of polished surfaces under the hydrothermal conditions of the experiments.

\section{Sr diffusion in tremolite and hornblende}

Brabander and Giletti (1995) measured Sr diffusion in hornblende and tremolite over the temperature range $700-960{ }^{\circ} \mathrm{C}$ at $200 \mathrm{MPa}$ pressure. Experiments were conducted with a quasihydrothermal technique designed to avoid the effects of solution-precipitation and consequent degradation of sample surfaces. A $\mathrm{SrCl}_{2}$ solution was evaporated on polished or cleaved sample surfaces and dried, and samples were sealed inside welded Au capsules; no free water was added to the capsules to avoid dissolution of the amphiboles, but a water fugacity high enough to maintain amphibole stability was created by diffusion of hydrogen through the walls of the noble metal capsule and water released through dehydration reactions on unpolished surfaces of the amphibole. Experiments at temperatures up to $800{ }^{\circ} \mathrm{C}$ were conducted in cold-seal pressure vessels, while those at higher temperatures were run in TZM pressure vessels with $\mathrm{Ar}-\mathrm{CH}_{4}$ gas as the pressure medium. Cold-seal experiments were buffered at $\sim \mathrm{Ni}-\mathrm{NiO}$ by the cold-seal vessel walls, and the TZM experiments were buffered at $\mathrm{Ni}-\mathrm{NiO}, \mathrm{MnO}-\mathrm{Mn}_{3} \mathrm{O}_{4}$ or magnetitewüstite using a double-capsule technique. Sr depth profiles in the amphiboles were measured with SIMS.

For diffusion in hornblende parallel to $c$, Brabander and Giletti (1995) obtain an activation energy of $260 \pm 12 \mathrm{~kJ} / \mathrm{mol}$ and pre-exponential factor of $4.9 \times 10^{-8} \mathrm{~m}^{2} / \mathrm{s}\left(\log D_{0}=-7.31 \pm 0.67\right)$. Experiments at $800{ }^{\circ} \mathrm{C}$ on two different natural tremolites (the former with a higher Fe content; 2.17 vs. $0.66 \mathrm{wt} \% \mathrm{FeO}$ ) yielded diffusivities (for transport parallel to $c$ ) of $3.2 \times 10^{-21}$ and $2.0 \times 10^{-21} \mathrm{~m}^{2} / \mathrm{s}$. Diffusion in tremolite at this temperature is a factor of 3-5 slower than in hornblende. There is little evidence of diffusional anisotropy for any of the amphiboles, as diffusivities parallel and normal to $c$ agree within experimental uncertainty. Sr diffusion appears relatively insensitive to oxygen fugacity in hornblende, as experiments buffered at $\mathrm{MnO}-\mathrm{Mn}_{3} \mathrm{O}_{4}$ and at magnetite-wüstite (with oxygen fugacities differing by $6 \times 10^{7}$ ) yield diffusivities agreeing with those for $\mathrm{Ni}-\mathrm{NiO}$ buffered experiments within a factor of 2 . This lack of dependence on $p \mathrm{O}_{2}$ suggests that $\mathrm{Sr}$ diffuses via a vacancy mechanism, and the differences in $\mathrm{Sr}$ diffusion among the amphiboles are attributed to the higher $\mathrm{Mg}$ to $\mathrm{Fe}$ and $\mathrm{Mn}$ ratio of the tremolite. The smaller ionic radius of $\mathrm{Mg}$ (in the $\mathrm{M} 2$ site) compared with these other divalent cations decreases the length of the M(4)-O bond, making these bonds more difficult to break and reducing the frequency of successful cation jumps to the M4 sites, which Sr is likely to occupy in substitution for $\mathrm{Ca}$.

Sr diffusion in tremolite is about 2 orders of magnitude slower than OH-F diffusion at $800{ }^{\circ} \mathrm{C}$, a variance that would likely increase with decreasing temperature because of the large differences in activation energies for diffusion between $\mathrm{Sr}$ and $\mathrm{OH}-\mathrm{F}$ diffusion. 


\section{Sr diffusion in fluorphlogopite}

Hammouda and Cherniak (2000) measured Sr diffusion in synthetic fluorphlogopite over the temperature range $550-1200{ }^{\circ} \mathrm{C}$. Sources for one set of experiments consisted of powder mixtures of oxides and fluorides in proportions of stoichiometric fluorphlogopite, with Sr added as a carbonate (with about $6000 \mathrm{wt}$ ppm $\mathrm{Sr}$ in the source mixture). A second set of experiments was conducted by depositing an aqueous $\mathrm{SrCl}_{2}$ solution on the sample surfaces (cleavage planes or growth surfaces) and drying the samples on a hotplate. 1-atm experiments with both sources were annealed in vertical tube furnaces in welded Pt capsules. Sr profiles were measured with RBS. Similar results were obtained for experiments run with the two sources, with an infinite source model used in determining diffusivities for both configurations. For the experiments with the surface-applied $\mathrm{SrCl}_{2}$ source, this solution was used because diffusion profiles were comparatively short, and high concentrations of the tracer remained on the sample surface throughout experiments. A few experiments at modest pressure $(28 \mathrm{MPa})$ were run using fastquench cold seal pressure vessels; these experiments used the powder source, with Pt capsules pressurized with Ar in the cold end of the cold-seal bomb prior to heating. For diffusion parallel to $c$, Hammouda and Cherniak (2000) obtained an activation energy of $136 \pm 3 \mathrm{~kJ} / \mathrm{mol}$ and preexponential factor of $2.7 \times 10^{-14} \mathrm{~m}^{2} / \mathrm{s}\left(\log D_{0}=-13.57\right)$. The 1 -atm and $28 \mathrm{MPa}$ experiments yielded similar results, but the pressure range was too narrow to establish whether there are any significant pressure effects on Sr diffusion.

Sr diffusivities for amphiboles and mica are within an order of magnitude over the temperature range in which experimental measurements overlap (Fig. 12), but the activation energy for Sr diffusion in fluorphlogopite is considerably smaller than that for hornblende (Brabander and Giletti 1995), which is in turn smaller than that for Sr diffusion in diopside (Sneeringer et al. 1984); these variations may be reflective of the influence on Sr transport of structural differences among these minerals.

\section{$K$ and $R b$ diffusion in biotite}

Hofmann and Giletti (1970) conducted experiments to measure isotopic exchange of $\mathrm{Rb}$, Sr and $\mathrm{K}$ between natural biotite and hydrothermal solutions doped with alkali chloride solutions enriched in ${ }^{41} \mathrm{~K}$ and ${ }^{87} \mathrm{Rb},{ }^{84} \mathrm{Sr}$, or ${ }^{85} \mathrm{Sr}$ and ${ }^{86} \mathrm{Rb}$. Experiments were run in cold-seal pressure vessels at $200 \mathrm{MPa}$ and temperatures ranging from $550-700{ }^{\circ} \mathrm{C}$. The relative weights and isotopic ratios in fluids and bulk samples were measured and diffusivities determined by using planar or cylindrical models and assuming that all exchange was due to diffusion. The experiments yielded a diffusivity for $\mathrm{Rb}$ in the range of $2 \times 10^{-19}$ to $7 \times 10^{-20} \mathrm{~m}^{2} / \mathrm{s}$ at $650{ }^{\circ} \mathrm{C}$, with a similar value for $\mathrm{K}$. There is considerable uncertainty in these determinations due to some evidence of dissolution. In addition, large uncertainties are inherent in bulk exchange experiments such as these, where profiles are not directly measured and assumptions are necessarily made in the modeling. Hofmann et al. (1974) continued these studies, using SIMS instead of bulk exchange methods in analyses. In this work they measured self-diffusion of potassium in biotite by inducing isotopic ${ }^{41} \mathrm{~K}$ exchange between the biotite and a ${ }^{41} \mathrm{~K}$-enriched hydrothermal alkali chloride solution at $650{ }^{\circ} \mathrm{C}$ and $200 \mathrm{MPa}$ pressure. $\mathrm{K}$ isotope profiles in the mica were measured following diffusion anneals. In the $c$ direction, a diffusion coefficient of $\mathrm{D}=1 \times 10^{-21} \mathrm{~m}^{2} / \mathrm{s}$ was determined, with diffusivities in the $a$ and $b$ directions greater than in the $c$ direction by 2 to 4 orders of magnitude. This large difference in $\mathrm{K}$ diffusion for different crystallographic orientations is consistent with the findings by Hofmann and Giletti (1970) for $\mathrm{Rb}$ diffusion, which are 2-3 orders of magnitude faster than $\mathrm{K}$ diffusion parallel to $c$. It might be assumed that the large alkali ions $\mathrm{K}$ and $\mathrm{Rb}$ would diffuse at similar rates, and with similar anisotropy. The bulk exchange method used by Hofmann and Giletti (1970) does not permit direct evaluation of such anisotropy, and diffusivities determined via this method would be biased toward the fastest diffusion directions. 


\section{ACKNOWLEDGMENTS}

We thank Jibamitra Ganguly for his thorough review of the manuscript, and Youxue Zhang for his editorial efforts for this chapter. We also gratefully acknowledge the legacy and career of Olivier Jaoul, who was one of the pioneering leaders in the study of diffusion in minerals, an exceptionally talented teacher, and a very motivated and motivating person.

\section{REFERENCES}

Anovitz LM, Essene EJ, Dunham WR (1988) Order-disorder experiments in orthopyroxenes: Implications for the orthopyroxene geospeedometer. Am Mineral 73:1060-1073

Azough F, Freer R (2000) Iron diffusion in single-crystal diopside. Phys Chem Miner 27:732-740

Azough F, Freer R, Wright K, Jackson R (1998) A computer simulation study of point defects in diopside and the self-diffusion of $\mathrm{Mg}$ and Ca by a vacancy mechanism. Mineral Mag 62:59-606

Baldwin SL, Harrison TM, Fitz Gerald JD (1990) Diffusion of ${ }^{40} \mathrm{Ar}$ in metamorphic hornblende. Contrib Mineral Petrol 105:691-703

Baxter EF (2010) Diffusion of noble gases in minerals. Rev Mineral Geochem 72:509-557

Béjina F, Jaoul O (1996) Silicon self-diffusion in quartz and diopside measured by nuclear micro-analysis methods. Phys Earth Planet Inter 97:145-162

Besancon JR (1981) Rate of cation ordering in orthopyroxenes. Am Mineral 66:965-973

Boyd FR, Schairer JF (1964) The system $\mathrm{MgSiO}_{3}-\mathrm{CaMgSi}_{2} \mathrm{O}_{6}$. J Petrol 5:275-309

Brabander DJ, Giletti BJ (1995) Strontium diffusion kinetics in amphiboles and significance to thermal history determination. Geochim Cosmochim Acta 59:2223-2238

Brabander DJ, Hervig RL, Jenkins DM (1995) Experimental determination of F-OH interdiffusion in tremolite and significance to fluorine-zoned amphiboles. Geochim Cosmochim Acta 59:3549-3560

Brady JB (1983) Intergranular diffusion in metamorphic rocks. Am J Sci 283 A:181-200

Brady JB, McCallister RH (1983) Diffusion data for clinopyroxenes from homogenization and self-diffusion experiments. Am Mineral 68:95-105

Buening DK, Buseck PR (1973) Fe-Mg lattice diffusion in olivine. J Geophys Res 78:6852-6862

Cameron M, Papike JJ (1981) Structural and chemical variations in pyroxenes. Am Mineral 66:1-50

Chakraborty S, Dohmen R, Müller T, Becker HW, ter Heege J (2008) Fe-Mg interdiffusion coefficients in clinopyroxene: Experimental determinations using nanoscale thin films. (abstr.) AGU Fall Meeting, San Francisco, CA, abstract \#MR21C-04

Chakraborty S, Farver JR, Yund RA, Rubie DC (1994) Mg tracer diffusion in synthetic forsterite and San Carlos Olivine as a function of $P, T$ and $f \mathrm{O}_{2}$. Phys Chem Miner 21:489-500

Chakraborty S, Rubie DC (1996) Mg tracer diffusion in aluminosilicate garnets at 750-850 degrees C, $1 \mathrm{~atm}$. and 1300 degrees C, 8.5 GPa. Contrib Mineral Petrol 122:406-414

Cherniak DJ (1995) Diffusion of lead in plagioclase and K-feldspar: an investigation using Rutherford Backscattering and resonant nuclear reaction analysis. Contrib Mineral Petrol 120:358-371

Cherniak DJ (1997) An experimental study of $\mathrm{Sr}$ and $\mathrm{Pb}$ diffusion in calcite, and implications for carbonate diagenesis and metamorphism. Geochim Cosmochim Acta 61: 4173-4179

Cherniak DJ (1998a) Pb diffusion in clinopyroxene. Chem Geol 150:105-117

Cherniak DJ (1998b) REE diffusion in calcite. Earth Planet Sci. Lett 160: 273-287

Cherniak DJ (2001) $\mathrm{Pb}$ diffusion in $\mathrm{Cr}$ diopside, augite, and enstatite, and consideration of the dependence of cation diffusion in pyroxene on oxygen fugacity. Chem Geol 177:381-397

Cherniak DJ (2003) Silicon self-diffusion in single-crystal natural quartz and feldspar. Earth Planet Sci Lett 214:655-668

Cherniak DJ, Hanchar JM, Watson EB (1997) Rare earth diffusion in zircon. Chem Geol 134:289-301

Cherniak DJ, Liang, Y (2007) Rare earth element diffusion in natural enstatite. Geochim Cosmochim Acta 71:1324-1340

Cherniak DJ, Watson EB (1992) A study of strontium diffusion in K-feldspar, Na-K feldspar and anorthite using Rutherford Backscattering Spectroscopy. Earth Planet Sci Lett 113:411-425

Cherniak DJ, Watson EB (1994) A study of strontium diffusion in plagioclase using Rutherford Backscattering Spectroscopy. Geochim Cosmochim Acta 58:5179-5190

Choudhury N, Ghose S, Chowdhury CP, Loong CK, Chaplot SL (1998) Lattice dynamics, Raman spectroscopy, and inelastic neutron scattering of orthoenstatite $\mathrm{Mg}_{2} \mathrm{Si}_{2} \mathrm{O}_{6}$. Phys Rev B 58:756-765

Connolly C, Muehlenbachs K (1988) Contrasting oxygen diffusion in nepheline, diopside and other silicates and their relevance to isotopic systematics in meteorites. Geochim Cosmochim Acta, 52:1585-1591

Coogan LA, Kasemann SA, Chakraborty S (2005) Rates of hydrothermal cooling of new oceanic upper crust derived from lithium-geospeedometry. Earth Planet Sci Lett 240:415-424 
Demouchy S, Mackwell SJ, Kohlstedt DL (2007) Influence of hydrogen on Fe-Mg interdiffusion in (Mg,Fe)O and implications for Earth's lower mantle. Contrib Mineral Petrol 154:279-289

Dimanov A, Dresen G (2005) Rheology of synthetic anorthite-diopside aggregates: implications for ductile shear zones. J Geophys Res 110:B07203, DOI:10.1029/2004JB003431

Dimanov A, Ingrin J (1995) Premelting and high-temperature diffusion of calcium in synthetic diopside: An increase of the cation mobility. Phys Chem Miner 22:437-442

Dimanov A, Jaoul O (1998) Calcium self-diffusion in diopside at high temperature: implications for transport properties. Phys Chem Miner 26:116-127

Dimanov A, Jaoul O, Sautter V (1996) Calcium self-diffusion in natural diopside single crystals. Geochim Cosmochim Acta 60:4095-4106

Dimanov A, Lavie MP, Dresen G, Ingrin J, Jaoul O (2003) Creep of polycrystalline anorthite and diopside. J Geophy. Res 108 (B1):2061, DOI:10.1029/2002JB001815

Dimanov A, Rybacki E, Wirth R, Dresen G (2007) Creep and strain-dependent microstructures of synthetic anorthite-diopside aggregates, J Struct Geol 29:1049-1069

Dimanov A, Sautter V (2000) "Average" interdiffusion of (Fe,Mn)-Mg in natural diopside. Eur J Mineral 12:749-760

Dimanov A, Wiedenbeck M (2006) (Fe,Mn)-Mg interdiffusion in natural diopside: effect of $p \mathrm{O}_{2}$. Eur J Mineral 18:705-718

Dodson MH (1973) Closure temperature in cooling geochronological and petrological systems. Contrib Mineral Petrol 40:259-274

Dodson MH (1986) Closure profiles in cooling systems. Mater Sci Forum 7:145-154

Dohmen R, Chakraborty S, Becker HW (2002) Si and O diffusion in olivine and implications for characterizing plastic flow in the mantle. Geophys Res Lett 29(21), doi 10.1029/2002GL015480

Doukhan N, Doukhan JC, Ingrin J, Jaoul O, Raterron P (1993) Early partial melting in pyroxenes. Am Mineral 78:1247-1257

Duba A, Boland J, Ringwood AE (1973) The electrical conductivity of pyroxene. J Geol 81:727-735

Duba A, Piwinskii AJ, Heard HC, Schock RN (1976) The electrical conductivity of forsterite, enstatite and albite. In: The Physics and Chemistry of Rocks and Minerals. Strens RGJ (ed) John Wiley \& Sons, London p 249-260

Farver JR (2010) Oxygen and hydrogen diffusion in minerals. Rev Mineral Geochem 72:447-507

Farver JR, Giletti BJ (1985) Oxygen diffusion in amphiboles. Geochim Cosmochim.Acta 49:1403-1411

Foland KA (1974) Alkali diffusion in orthoclase. In: Geochemical Transport and Kinetics. Hofmann AW, Giletti BJ, Yoder Jr HS, Yund RA (eds) Carnegie Institution of Washington Publication, 634, Carnegie Institution of Washington, Washington, DC, p 77-98

Fortier SM, Giletti BJ (1991) Volume self-diffusion of oxygen in biotite, muscovite, and phlogopite micas. Geochim Cosmochim Acta 55:1319-1330

Fraser DG, Lawless PJ (1978) Paleogeotherms: implication of disequilibrium in garnet lherzolite xenoliths. Nature 273:220-222

Freer R (1979) An experimental measurement of cation diffusion in almandine garnet. Nature 280:220-222

Freer R, Carpenter MA, Long JVP, Reed SJB (1982) "Null result" diffusion experiments with diopside: implications for pyroxene equilibria. Earth Planet Sci Lett 58:285-292

Ganguly J, Cheng W, Chakraborty S (1998) Cation diffusion in aluminosilicate garnets; experimental determination in pyrope-almandine diffusion couples. Contrib Mineral Petrol 131:171-180

Ganguly J, Dasgupta S, Cheng W, Neogi S (2000) Exhumation history of a section of the Sikkim Himalayas, India: records in the metamorphic mineral equilibria and compositional zoning of garnet. Earth Planet Sci Lett 183:471-486

Ganguly J, Ito M, Zhang X (2007) Cr diffusion in orthopyroxene; experimental determination, ${ }^{53} \mathrm{Mn}-{ }^{53} \mathrm{Cr}$ thermochronology, and planetary applications. Geochim Cosmochim Acta 71:3915-3925

Ganguly J, Tazzoli V (1994) $\mathrm{Fe}^{2+}$-Mg interdiffusion in orthopyroxene: Retrieval from the data on intracrystalline exchange reaction. Am Mineral 79:930-937

Ganguly J, Tirone M (2001) Relationship between cooling rate and cooling age of a mineral; theory and applications to meteorites. Meteoritics Planet Sci 36:167-175

Ganguly J, Yang, H, Ghose S (1994) Thermal history of mesosiderites: constraints from compositional zoning and Fe-Mg ordering in orthopyroxenes. Geochim Cosmochim Acta 48:2711-2723

Gasc J, Béjina F, Ingrin J (2006) Magnesium diffusion in diopside. 11th International Conference on Experimental Mineralogy, Petrology and Geochemistry

Gasparik T (1984) Experimentally determined stability of clinopyroxene + garnet + corundum in the system $\mathrm{CaO}-\mathrm{MgO} \mathrm{AlO}_{3}-\mathrm{SiO}_{2}$. Am Mineral 69:1025-1035

Gasparik T, Lindsley DH (1980) Phase equilibria at high pressure of pyroxenes containing monovalent and trivalent ions. Rev Mineral 7:309-339 
Giletti BJ (1974) Studies in diffusion; 1, Argon in phlogopite mica. In: Geochemical Transport and Kinetics. Carnegie Institution of Washington Publication 634. Hofmann AW, Giletti BJ, Yoder HS Jr., Yund RA (eds) Carnegie Institution of Washington, Washington, DC, p 107-115

Giletti BJ, Anderson TF (1975) Studies in diffusion; II, Oxygen in phlogopite mica. Earth Planet Sci Lett 28:225-233

Giletti BJ, Casserly JED (1994) Strontium diffusion kinetics in plagioclase feldspars. Geochim Cosmochim Acta 58:3785-3793

Giletti BJ, Shanahan TM (1997) Alkali diffusion in plagioclase feldspar. Chem Geol 139:3-20

Giletti BJ, Tullis J (1977) Studies in diffusion; IV. Pressure dependence of Ar diffusion in phlogopite mica. Earth Planet Sci Lett 35:180-183

Graham CM (1981) Experimental hydrogen isotope studies III: Diffusion of hydrogen in hydrous minerals, and stable isotope exchange in metamorphic rocks. Contrib Mineral Petrol 76:216-228

Graham CM, Harmon RS, Sheppard SMF (1984) Experimental hydrogen isotope studies: Hydrogen isotope exchange between amphibole and water. Am Mineral 69:128-138

Grove M, Harrison TM (1996) ${ }^{40}$ Ar* diffusion in Fe-rich biotite. Am Mineral 81:940-951

Hammouda T, Cherniak DJ (2000) Diffusion of Sr in fluorphlogopite determined by Rutherford backscattering spectrometry. Earth Planet Sci Lett 178:339-349

Harrison TM (1981) Diffusion of ${ }^{40} \mathrm{Ar}$ in hornblende. Contrib Mineral Petrol 178:324-331

Harrison TM, Celerier J, Aikman AB, Hermann J, Heizler MT (2009) Diffusion of ${ }^{40}$ Ar in muscovite. Geochim Cosmochim Acta 73:1039-1051

Harrison TM, Duncan I, McDougall I (1985) Diffusion of ${ }^{40} \mathrm{Ar}$ in biotite; temperature, pressure and compositional effects. Geochim Cosmochim Acta 49:2461-2468

Hier-Majumder S, Anderson IM, Kohlstedt DL (2004) Influence of protons on Fe-Mg interdiffusion in olivine. J Geophys Res 110, DOI: 10.1029/2004JB003292

Hirsch LM, Shankland TJ (1991) Equilibrium point-defect concentrations in MgO: understanding the mechanisms of conduction and diffusion and the role of Fe impurities. J Geophys Res 96:385-403

Hirschmann MM, Ghiorso MS, Davis FA, Gordon SM, Mukherjee S, Grove TL., Krawczynski, M, Medard E, Till CB (2008) Library of experimental phase relations (LEPR): a database and web portal for experimental magmatic phase equilibria data. Geochem Geophys Geosyst 9 (3), DOI:10.1029/2007GC001894

Hofmann AW, Giletti BJ (1970) Diffusion of geochronologically important nuclides in minerals under hydrothermal conditions. Eclogae Geologicae Helvetiae 63:141-150

Hofmann AW, Giletti BJ, Hinthorne JR, Andersen CA, Comaford D (1974) Ion microprobe analysis of a potassium self-diffusion experiment in biotite. Earth Planet Sci Lett 24:48-52

Hofmann AW, Hart SR (1978) An assessment of local and regional isotopic equilibrium in the mantle. Earth Planet Sci Lett 38:44-62

Holloway JR, Pan V, Gudmundson G (1992) High pressure fluid absent melting experiments in the presence of graphite: oxygen fugacity, ferric/ferrous ratio and dissolved $\mathrm{CO}_{2}$. Eur J Mineral 4:105-114

Houlier B, Cheraghmakani M, Jaoul O (1990) Silicon diffusion in San Carlos Olivine. Phys Earth Planet Inter 62:329-340

Huebner JS (1976) Diffusively rimmed xenocrysts in 77115. Lunar Planet Sci Conf 7:396-398

Huebner JS, Nord GL (1981) Assessment of diffusion in pyroxenes: what we do and do not know. Lunar Planet Sci XII, p 479-481

Huebner JS, Ross M, Hikling N (1975) Cooling history and significance of exsolved pyroxene in lunar noritic breccia 77215. Lunar Planet Sci Conf 6:408-410

Huebner JS, Voigt DE (1988) Electrical conductivity of diopside: Evidence for oxygen vacancies. Am Mineral 73:1235-1254

Ingrin J, Pacaud L, Jaoul O (2001) Anisotropy of oxygen diffusion in diopside. Earth Planet Sci Lett 192:347361

Jantzen CM (1984) On spinodal decomposition in Fe-free pyroxenes. Am Mineral 69:277-282

Jaoul O, Raterron P (1994) High-temperature deformation of diopside crystal. 3. Influences of $p \mathrm{O}_{2}$ and $\mathrm{SiO}_{2}$ precipitation. J Geophys Res 99:9423-9439

Jaoul O, Sautter V (1999) A new approach to geospeedometry based on the "compensation law". Phys Earth Planet Inter 110:95-114

Jaoul O, Sautter V, Abel F (1991) Nuclear microanalysis: a powerful tool for measuring low atomic diffusivity with mineralogical applications. In: Diffusion, Atomic Ordering and Mass Transport-Selected Topics in Geochemistry. Advances in Physical Geochemistry, Vol 8. Ganguly J (ed) Springer, New York, p 198-220

Joesten R (1991) Grain-boundary diffusion kinetics in silicate and oxide minerals. In: Diffusion, Atomic Ordering and Mass Transport-Selected Topics in Geochemistry. Advances in Physical Geochemistry, Vol 8. Ganguly J (ed) Springer, New York, p 345-395

Klügel A (2001) Prolonged reactions between harzburgite xenoliths and silica-undersaturated melt: implications for dissolution and Fe-Mg interdiffusion rates of orthopyroxene. Contrib Mineral Petrol 141:1-14 
Kröger FA (1964) The Chemistry of Imperfect Crystals. North Holland, Amsterdam

Kröger FA, Vink HJ (1956) Relations between the concentrations of imperfections in crystalline solids. In: Solid State Physics Advances in Research and Applications, Vol. 3. Seitz F, Turnbull D (eds) Academic Press, New York, p 307-435

Lasaga AC (1983) Geospeedometry: An Extension of Geothermometry. In: Kinetics and Equilibrium in Mineral Reactions, Vol 3. Saxena SK (ed) Springer, New York, p 81-114

Lasaga AC, Richardson SM, Holland HD (1977), The mathematics of cation diffusion and exchange between silicate minerals during retrogrde metamorphism. In: Saxena SK, Bhattachanji S (eds.), Energetics of Geochemical Processes, 353-388

LaTourrette T, Wasserburg GJ (1998) Mg diffusion in anorthite; implications for the formation of early solar system planetesimals. Earth Planet Sci Lett 158:91-108

Liang Y, Cherniak DJ, Morgan ZT, Hess PC (2004) $\mathrm{Eu}^{2+}$ and $\mathrm{REE}^{3+}$ diffusion in enstatite, diopside, anorthite, and a silicate melt: A database for understanding kinetic fractionation of REE in the lunar mantle and crust. In: Lunar Planet Sci XXXV. Lunar Planet. Inst, Houston. CD-ROM \#1894 (abstract)

Lindner R (1955) Studies on solid state reactions with radiotracers. J Chem Phys 23:410-411

McCallister RH (1978) The coarsening kinetics associated with exsolution in an iron-free clinopyroxene. Contrib Mineral Petrol 65:327-331

McCallister RH, Brady JB, Mysen BO (1979) Self-diffusion of calcium in diopside. Carnegie Institution of Washington Yearbook 78:574-577

McCallister RH, Nord G (1981) Subcalcic diopsides from kimberlites: Chemistry, exsolution microstruetures, and thermal history. Contrib Mineral Petrol 78:118-125

McCallum IS, O'Brien HE (1996) Stratigraphy of the lunar highland crust: Depths of burial of lunar samples from cooling-rate studies. Am Mineral 81:1166-1175

Médard E, McCammon CA, Grove TL (2008) Oxygen fugacity, temperature reproducibility and $\mathrm{H}_{2} \mathrm{O}$ content for nominally dry piston-cylinder experiments using graphite capsules. Am Mineral 93:1838-1844, DOI: 10.2138/am.2008.2842

Miyamoto M, Takeda H (1977) Evaluation of a crust model of eucrites from the width of exsolved pyroxene. Geochem J 11:161-169

Miyamoto M, Takeda H (1994) Evidence for excavation of deep crustal material of a Vesta-like body from Ca compositional gradients in pyroxene. Earth Planet Sci Lett 122:343-349

Nakamura A, Schmalzried H (1983) On the nonstoichiometry and point defects of olivine. Phys Chem Miner 10:27-37

Nakamura E, Kushiro I (1998) Trace element diffusion in jadeite and diopside melts at high pressures and its geochemical implication. Geochim Cosmochim Acta 62:3151-3160

Otto EM (1966) Equilibrium pressures of oxygen over oxides of lead at various temperatures. J Electrochem Soc 113:525-527

Pacaud L (1999) Mesure de l'autodiffusion de l'oxygène et du magnésium dans le diopside et applications. PhD Thesis, Université de Paris 11, Orsay, France

Pacaud L, Ingrin J, Jaoul O (1999) High-temperature diffusion of oxygen in synthetic diopside measured by nuclear reaction analysis. Mineral Mag 63:673-686

Pattison DRM, Begin NJ (1994) Zoning patterns in orthopyroxene and garnet in granulites: implications for geothermometry. J Metamorph Geol 12:387-410

Raterron P, Jaoul O (1991) .High-temperature deformation of diopside single crystal. 1. Mechanical data. J Geophys Res 96:14,277-14,286

Richet $\mathrm{P}$, Fiquet $\mathrm{G}$ (1991) High-temperature heat capacity and premelting of minerals in the system $\mathrm{MgO}-\mathrm{CaO}-$ $\mathrm{Al}_{2} \mathrm{O}_{3}-\mathrm{SiO}_{2}$. J Geophys Res 96:445-456

Richet P, Ingrin J, Mysen BO, Courtial P, Gillet P (1994) Premelting effects in minerals: an experimental study. Earth Planet Sci Lett 121:589-600

Rietmeijer FJM (1983) Inter-diffusion coefficients parallel to the $c$-axis in iron-rich clinopyroxenes calculated from microstructures. Contrib Mineral Petrol 83:169-176

Sautter V, Harte B (1988) Diffusion gradients in an eclogite xenolith from the Roberts Victor kimberlite pipe: (1) mechanism and evolution of garnet exsolution in $\mathrm{Al}_{2} \mathrm{O}_{3}$-rich clinopyroxene. J Petrol 29:1325-1358

Sautter V, Harte B (1990) Diffusion gradients in an eclogite xenolith from the Roberts Victor kimberlite pipe: (2) kinetics and implications for petrogenesis. Contrib Mineral Petrol 105:637-649

Sautter V, Jaoul O, Abel F (1989) Aluminium diffusion in diopside using the ${ }^{27} \mathrm{Al}(\mathrm{p}, \gamma)^{28} \mathrm{Si}$ nuclear reaction: preliminary results. Earth Planet Sci Lett 89:109-114

Saxena SK, Tazzoli V, Domeneghetti MC (1987) Kinetics of $\mathrm{Fe}^{2+}-\mathrm{Mg}$ distribution in aluminous orthopyroxenes. Phys Chem Miner 15:140-147

Schreiber HD (1977) Redox states of Ti, Zr, Hf, Cr, and Eu in basaltic magmas; an experimental study. In: Proceedings of the Eighth Lunar Science Conference. Pergamon Press, New York, NY, p 1785-1807

Schwandt CS, Cygan RT, Westrich HR (1998) Magnesium self-diffusion in orthoenstatite. Contrib Mineral Petrol 130:390-396 
Schwartz JM, McCallum IS (2005) Comparative study of equilibrated and unequilibrated eucrites: Subsolidus thermal histories of Haraiya and Pasamonte. Am Mineral 90:1871-1866

Seitz MG (1973) Uranium and thorium diffusion in diopside and fluorapatite. Year Book - Carnegie Institution of Washington 72:586-588

Shannon RD (1976) Revised effective ionic radii and systematic studies of interatomic distances in halides and chalcogenides. Acta Cryst A32: 751-767

Smyth DM, Stocker RL (1975) Point defects and non-stoichiometry in forsterite. Phys Earth Planet Inter 10: 183-192

Smyth JR (1974) Low orthopyroxene from a lunar deep crustal rock: a new pyroxene polymorph of space group P2 ${ }_{1}$ ca. Geophys Res Lett 1: 27-29

Sneeringer M, Hart SR (1978) Sr diffusion in diopside. EOS Trans Am Geophys Union 59:402

Sneeringer M, Hart SR, Shimizu N (1984) Strontium and samarium diffusion in diopside. Geochim Cosmochim Acta 48: 1589-1608

Sotin C, Poirrier JP (1984) Analysis of high temperature creep experiments by generalized nonlinear inversion. Mech Mater $3: 311-317$

Stanford RF, Huebner JS (1979) Reexamination of diffusion processes in 77115 and 77215 . Lunar Planet Sci $\mathrm{X}, \mathrm{p}$ 1052-1054

Stimpfl M, Ganguly J, Hervig R (2003) Ca and Mg tracer diffusion in diopside: experimental determination and application to cooling history of planetary samples. XXXIV Lunar Planet Sci Conf, League City, Texas. abstract no. 1497

Stimpfl M, Ganguly J, Molin G (2005) Kinetics of Fe ${ }^{2+}-\mathrm{Mg}$ order-disorder in orthopyroxene; experimental studies and applications to cooling rates of rocks. Contrib Mineral Petrol 150:319-334

Stocker RL (1978) Variation of electrical conductivity in enstatite with oxygen partial pressure: Comparison of observed and predicted behaviour. Phys Earth Planet Inter 17:34-40

Taupin D (1998) Probability estimations for fitted parameters - the EXPHER package. J Microscopy 190:19-27

ter Heege JH, Dohmen R, Becker H, Chakraborty S (2006) Experimental determination of Fe-Mg interdiffusion coefficients in orthopyroxene using pulsed laser ablation and nanoscale thin films. AGU Fall Meeting, San Francisco, CA. abstract \#MR21A-0004

Tsai TL, Dieckmann R (2002) Variation of the oxygen content and point defects in olivines, $\left(\mathrm{Fe}_{\mathrm{x}} \mathrm{Mg}_{1-\mathrm{x}}\right)_{2} \mathrm{SiO}_{4}$, $0.2 \leq \mathrm{x} \leq 1.0$. Phys Chem Miner 29:680-694

Ubbelohde AR (1978) The Molten State of Matter. John Wiley and Sons, New York

Van Orman JA, Grove TL, Shimizu N (1998) Uranium and thorium diffusion in diopside. Earth Planet Sci Lett 160:505-519

Van Orman JA, Grove TL, Shimizu N (2001) Rare earth element diffusion in diopside; influence of temperature, pressure, and ionic radius, and an elastic model for diffusion in silicates. Contrib Mineral Petrol 141:687703

Watson EB, Liang Y (1995) A simple model for sector zoning in slowly grown crystals; implications for growth rate and lattice diffusion, with emphasis on accessory minerals in crustal rocks. Am Mineral 80:1179-1187

Weber P, Taupin D (1995) EXPHER (EXperimental PHysics ERror analysis): a declaration language and a program generator for the treatment of experimental data. J Phys III 5(5):605-622

Weinbruch S, Müller WF (1995) Constraints on the cooling rates of chondrules from the microstructure of pyroxene and plagioclase. Geochim Cosmochim Acta 59:3221-3230

Weinbruch S, Müller WF, Hewins RH (2001) A transmission electron microscope study of exsolution and coarsening in iron-bearing clinopyroxene from synthetic analogues of chondrules. Meteoritics Planet Sci $36: 1237-1248$

Weinbruch S, Styrsa V, Müller WF (2003) Exsolution and coarsening in iron-free clinopyroxene during isothermal annealing. Geochim Cosmochim Acta 67:5071-5082

Yang H, Ghose S (1995) High temperature single crystal X-ray diffraction studies of the ortho-proto phase transition in enstatite, $\mathrm{Mg}_{2} \mathrm{Si}_{2} \mathrm{O}_{6}$ at $1360 \mathrm{~K}$. Phys Chem Miner 22:300-310

Yund RA, Tullis J (1991) Compositional changes of minerals associated with dynamic recrystallization. Contrib Mineral Petrol 108:346-355

Zhang X, Ganguly J, Ito M (2010) Ca-Mg diffusion in diopside: tracer and chemical inter-diffusion coefficients. Contrib Mineral Petrol 159:175-186, DOI: 10.10007/s00410-009-0422-5 


\begin{abstract}
APPENDIX
On the following pages, Tables A1-A4 contain the diffusion data and selected Arrhenius relations for the pyroxene, mica, and amphibole mineral phases discussed in this chapter.
\end{abstract}


Table A1. Diffusion data for major cations in pyroxenes where $D=D_{0}\left(p \mathrm{O}_{2}\right)^{m} \exp \left(n \cdot X_{\mathrm{Fe}}\right) \exp (-Q / R T)=D_{0}{ }^{\prime} \exp (-Q / R T)$.

\begin{tabular}{|c|c|c|c|c|c|}
\hline Mineral & Orientation & Species & $\begin{array}{c}\boldsymbol{T} \\
\left({ }^{\circ} \mathbf{C}\right)\end{array}$ & $\begin{array}{c}P \\
(\mathbf{M P a})\end{array}$ & $\begin{array}{c}p \mathrm{O}_{2} \\
(\mathrm{MPa})\end{array}$ \\
\hline $\begin{array}{l}\text { Cpx } \\
2.8 \% \mathrm{Fe}\end{array}$ & $\perp$ to $(001)$ & $\mathrm{Ca}-(\mathrm{Mg}, \mathrm{Fe})$ & $1150-1250$ & 2500 & $\mathrm{C}-\mathrm{O}_{2}$ \\
\hline $\begin{array}{l}\text { Diopside } \\
2.4 \% \mathrm{Fe}\end{array}$ & $\|$ to $c$ & Al-(Si,Mg?) & $1000-1180$ & 0.1 & $10^{-14}$ \\
\hline $\begin{array}{l}\text { Diopside } \\
1.8 \% \mathrm{Fe}\end{array}$ & $\|$ to $c$ & ${ }^{30} \mathrm{Si}$ & $1040-1250$ & 0.1 & $10^{-14}-10^{-17}$ \\
\hline $\begin{array}{l}\text { Diopside } \\
\text { Synthetic }\end{array}$ & $\|$ to $b$ & ${ }^{44} \mathrm{Ca}$ & $\begin{array}{l}1000-1242 \\
1242-1380\end{array}$ & $\begin{array}{l}0.1 \\
0.1\end{array}$ & $\begin{array}{l}10^{-7} \\
10^{-7}\end{array}$ \\
\hline $\begin{array}{l}\text { Diopsides } \\
0.4-2.4 \% \mathrm{Fe}\end{array}$ & $\|$ to $b, c$ & ${ }^{44} \mathrm{Ca}$ & $\begin{array}{l}1000-1130 \\
1130-1250\end{array}$ & $\begin{array}{l}0.1 \\
0.1\end{array}$ & $\begin{array}{l}10^{-7}-10^{-18} \\
0.02-10^{-18}\end{array}$ \\
\hline $\begin{array}{l}\text { Diopside } \\
2 \% \mathrm{Fe}\end{array}$ & $\|$ to $b, c$ & ${ }^{44} \mathrm{Ca}$ & $\begin{array}{l}1000-1230 \\
1230-1320\end{array}$ & $\begin{array}{l}0.1 \\
0.1\end{array}$ & $\begin{array}{l}10^{-11}-10^{-16} \\
10^{-13}-10^{-18}\end{array}$ \\
\hline $\begin{array}{l}\text { Diopside } \\
1.8 \% \mathrm{Fe} \\
\text { Synthetic }\end{array}$ & $\begin{array}{l}\| \text { to } b, c \\
\| \text { to } a\end{array}$ & ${ }^{54} \mathrm{Fe}$ & $\begin{array}{c}950-1100 \\
1050\end{array}$ & $\begin{array}{l}0.1 \\
0.1\end{array}$ & $\begin{array}{c}10^{-11}-10^{-16} \\
10^{-14}\end{array}$ \\
\hline $\begin{array}{l}\text { Diopside } \\
2.9 \% \mathrm{Fe}\end{array}$ & $\|$ to $c$ & $(\mathrm{Fe}, \mathrm{Mn})-\mathrm{Mg}$ & $900-1240$ & 0.1 & $10^{-13}-10^{-19}$ \\
\hline $\begin{array}{l}\text { Diopside } \\
2.9 \% \mathrm{Fe}\end{array}$ & $\|$ to $c$ & $(\mathrm{Fe}, \mathrm{Mn})-\mathrm{Mg}$ & $1000-1190$ & 0.1 & $10^{-7}-10^{-19}$ \\
\hline $\begin{array}{l}\text { Opx } \\
10-50 \% \mathrm{Fe}\end{array}$ & $\|$ to $b / c$ & $\mathrm{Fe}-\mathrm{Mg}$ & $500-800$ & 0.1 & IW \\
\hline $\begin{array}{l}\text { Enstatite } \\
11 \% \mathrm{Fe}\end{array}$ & $\begin{array}{l}\| \text { to } a \\
\| \text { to } b \\
\| \text { to } c\end{array}$ & ${ }^{25} \mathrm{Mg}$ & $750-900$ & 0.1 & IW \\
\hline $\begin{array}{l}\text { Enstatite } \\
2.6 \% \mathrm{Fe}\end{array}$ & $\begin{array}{l}\| \text { to } a \\
\| \text { to } b \\
\| \text { to } c\end{array}$ & $\mathrm{Cr}$ & $\begin{array}{c}1000-1100 \\
900-1100 \\
900-1100\end{array}$ & 0.1 & IW \\
\hline $\begin{array}{l}\text { Diopside } \\
\text { Synthetic }\end{array}$ & $\|$ to $a, b, c$ & ${ }^{26} \mathrm{Mg}$ & $1200-1300$ & 0.1 & 0.02 \\
\hline $\begin{array}{l}\text { Diopside } \\
\text { Natural } \\
3.6 \% \mathrm{Fe}\end{array}$ & $\|$ to $a^{*}, b$ & ${ }^{26} \mathrm{Mg}$ & $\begin{array}{c}1100 \\
1000-1100\end{array}$ & $\begin{array}{l}0.1 \\
0.1\end{array}$ & $\begin{array}{l}10^{-5} \\
10^{-5}\end{array}$ \\
\hline $\begin{array}{l}\text { Diopside } \\
1.8 \% \mathrm{Fe}\end{array}$ & $\begin{array}{l}\| \text { to } a^{*} \\
\| \text { to } b \\
\| \text { to c }\end{array}$ & ${ }^{44} \mathrm{Ca}$ & $950-1150$ & 0.1 & IW \\
\hline $\begin{array}{l}\text { Diopside } \\
1.8 \% \mathrm{Fe}\end{array}$ & $\begin{array}{l}\| \text { to } a^{*} \\
\| \text { to } b \\
\| \text { to } c\end{array}$ & ${ }^{26} \mathrm{Mg}$ & $950-1150$ & 0.1 & IW \\
\hline
\end{tabular}

$\dagger$ when possible, recalculated to $p \mathrm{O}_{2}=10^{-12} \mathrm{MPa}$

** Mg diffusion coefficient calculated from the data of Pacaud (1999) and Gasc et al. (2006).

*** Mg diffusion coefficient calculated from the data of Gasc et al. (2006) at $1100{ }^{\circ} \mathrm{C}$ and the activation energy $E_{\mathrm{a}}=214 \mathrm{~kJ} /$ mol from Azough and Freer (2000). 


\begin{tabular}{|c|c|c|c|c|c|}
\hline $\begin{array}{c}D_{0} \\
\left(\mathbf{m}^{2} / \mathbf{s}\right)\end{array}$ & $\begin{array}{l}\log D_{0}^{\prime} \\
\left(\mathbf{m}^{2} / \mathbf{s}\right) \dagger\end{array}$ & $\begin{array}{c}E_{\mathrm{a}} \\
(\mathrm{kJ} / \mathrm{mol})\end{array}$ & $m$ & $n$ & References \\
\hline $3.9 \times 10^{-7}$ & & $361 \pm 190$ & -- & -- & Brady and McCallister (1983) \\
\hline $2.11 \times 10^{-11}$ & & 273 & -- & -- & $\begin{array}{l}\text { Sautter et al. (1989), Jaoul et } \\
\text { al. (1991) }\end{array}$ \\
\hline $2.3 \times 10^{-14}$ & $\begin{array}{c}-13.6 \pm 4 \\
\text { (variable } p \mathrm{O}_{2} \text { ) }\end{array}$ & $211 \pm 110$ & -- & -- & Béjina and Jaoul (1996) \\
\hline $\begin{array}{c}1.58 \times 10^{-11} \\
2.5 \times 10^{12}\end{array}$ & $\begin{array}{c}-6.8 \pm 1 \\
16.4 \pm 2.9\end{array}$ & $\begin{array}{l}280 \pm 26 \\
951 \pm 87\end{array}$ & -- & -- & Dimanov and Ingrin (1995) \\
\hline $\begin{array}{l}7.04 \times 10^{-14} \\
2.38 \times 10^{-7}\end{array}$ & $\begin{array}{l}-10.96 \pm 1.3 \\
-6.14 \pm 1.4\end{array}$ & $\begin{array}{l}264 \pm 33 \\
396 \pm 38\end{array}$ & $\begin{array}{l}-0.14 \pm 0.01 \\
0\end{array}$ & $\begin{array}{l}55.3 \\
55.3\end{array}$ & Dimanov et al. (1996) \\
\hline $\begin{array}{l}2.63 \times 10^{-13} \\
5.62 \times 10^{14}\end{array}$ & $\begin{array}{l}-10.3 \pm 0.4 \\
18.75 \pm 2.46\end{array}$ & $\begin{array}{c}284 \pm 10 \\
1006 \pm 75\end{array}$ & $\begin{array}{l}-0.19 \pm 0.03 \\
0\end{array}$ & -- & Dimanov and Jaoul (1998) \\
\hline $\begin{array}{l}1.03 \times 10^{-11} \\
5.7 \times 10^{-22}\end{array}$ & $\begin{array}{l}-13.75 \pm 1.13 \\
-21.24 \pm 0.18\end{array}$ & $162 \pm 35$ & $0.23 \pm 0.04$ & -- & Azough and Freer (2000) \\
\hline $9.55 \times 10^{-5}$ & $\begin{array}{c}-4.02 \pm 0.32 \\
\left(\text { variable } p \mathrm{O}_{2}\right)\end{array}$ & $406 \pm 64$ & -- & -- & Dimanov and Sautter (2000) \\
\hline $1.62 \times 10^{-6}$ & $-8.43 \pm 0.32$ & $297 \pm 31$ & $0.22 \pm 0.02$ & -- & $\begin{array}{l}\text { Dimanov and Wiedenbeck } \\
\text { (2006) }\end{array}$ \\
\hline $2.88 \times 10^{-10}$ & $\begin{array}{l}-9.28(10 \% \mathrm{Fe}) \\
\left(\text { variable } p \mathrm{O}_{2}\right)\end{array}$ & $240 \pm 8$ & -- & 5.99 & Ganguly and Tazzoli (1994) \\
\hline $\begin{array}{c}1.1 \times 10^{-4} \\
6.93 \times 10^{-6} \\
4.34 \times 10^{-9}\end{array}$ & $\begin{array}{c}-3.96 \pm 2.48 \\
5.16 \pm 3.69 \\
-8.36 \pm 4.34\end{array}$ & $\begin{array}{l}360 \pm 52 \\
339 \pm 77 \\
265 \pm 66\end{array}$ & -- & -- & Schwandt et al. (1998) \\
\hline $\begin{array}{l}7.41 \times 10^{-11} \\
1.78 \times 10^{-10} \\
3.10 \times 10^{-10}\end{array}$ & $\begin{array}{c}-10.13 \pm 0.39 \\
-9.75 \pm 0.78 \\
-9.51 \pm 0.56\end{array}$ & $\begin{array}{l}257 \pm 12 \\
257 \pm 12 \\
257 \pm 12\end{array}$ & -0.09 & -- & Ganguly et al. (2007) \\
\hline $4.07 \times 10^{7}$ & $7.61 \pm 2.97$ & $748 \pm 87$ & -- & -- & $\begin{array}{l}\text { **Pacaud (1999), Gasc et al. } \\
\text { (2006) }\end{array}$ \\
\hline $\begin{array}{l}58 \times 10^{-20} \\
1.2 \times 10^{-11}\end{array}$ & $\begin{array}{l}-19.07 \pm 0.18 \\
-10.92\end{array}$ & 214 & -- & -- & $\begin{array}{l}\text { Gasc et al. (2006) } \\
* * * E_{\mathrm{a}} \text { from Azough and Freer } \\
(2000)\end{array}$ \\
\hline $\begin{array}{l}1.99 \times 10^{-8} \\
3.2 \times 10^{-7} \\
2.4 \times 10^{-10}\end{array}$ & $\begin{array}{l}-7.07 \pm 0.70 \\
-6.52 \pm 1.29 \\
-9.62 \pm 0.91\end{array}$ & $\begin{array}{l}319 \pm 18 \\
350 \pm 32 \\
265 \pm 23\end{array}$ & -- & -- & Zhang et al. (2010) \\
\hline $\begin{array}{l}6.76 \times 10^{-15} \\
1.23 \times 10^{-11} \\
1.44 \times 10^{-13}\end{array}$ & $\begin{array}{l}-14.17 \pm 0.49 \\
-10.91 \pm 0.93 \\
-12.84 \pm 0.68\end{array}$ & $\begin{array}{l}150 \pm 22 \\
231 \pm 23 \\
176 \pm 18\end{array}$ & -- & -- & Zhang et al. (2010) \\
\hline
\end{tabular}


Table A2. Arrhenius relations for trace and minor elements in pyroxenes, of the form $D=D_{0} \exp \left(-E_{\mathrm{a}} / R T\right)$.

\begin{tabular}{|c|c|c|c|c|}
\hline Mineral & Orientation & Species & $\begin{array}{c}\boldsymbol{T} \\
\left({ }^{\circ} \mathbf{C}\right)\end{array}$ & $\begin{array}{c}P \\
(\mathbf{M P a})\end{array}$ \\
\hline Diopside, 0.7 at $\% \mathrm{Fe}$ & [010] & $\mathrm{Li}$ & $800-1100$ & 0.1 \\
\hline Diopside, 0.3 at $\% \mathrm{Fe}$ & [110] & $\mathrm{Pb}$ & $800-1100$ & 0.1 \\
\hline Diopside, 0.3 at $\% \mathrm{Fe}$ & [001] & $\mathrm{Pb}$ & $800-1100$ & 0.1 \\
\hline Diopside, 0.3 at $\% \mathrm{Fe}$ & [110], [001] & $\mathrm{Pb}$ & $800-1100$ & 0.1 \\
\hline Clinopyroxene 5.4 at $\% \mathrm{Fe}$ & [110] & $\mathrm{Pb}$ & $800-1050$ & 0.1 \\
\hline Clinopyroxene 5.4 at $\% \mathrm{Fe}$ & [110] & $\mathrm{Pb}$ & $800-1050$ & 0.1 \\
\hline Cr diopside, 0.4 at $\% \mathrm{Fe}$ & [110] & $\mathrm{Pb}$ & $850-1050$ & 0.1 \\
\hline Cr diopside, 0.4 at $\% \mathrm{Fe}$ & {$[001]$} & $\mathrm{Pb}$ & $850-1050$ & 0.1 \\
\hline Augitic pyroxene, 1.2 at $\% \mathrm{Fe}$ & [110] & $\mathrm{Pb}$ & $850-1050$ & 0.1 \\
\hline Enstatite, 0.2 at $\% \mathrm{Fe}$ & [210] & $\mathrm{Pb}$ & $850-1100$ & 0.1 \\
\hline Diopside, 0.2 at $\% \mathrm{Fe}$ & [001] & $\mathrm{La}$ & $1200-1300$ & 0.1 \\
\hline Diopside, 0.2 at $\% \mathrm{Fe}$ & [001] & $\mathrm{Ce}$ & $1150-1450$ & 0.1 \\
\hline Diopside, 0.2 at $\% \mathrm{Fe}$ & [001] & $\mathrm{Nd}$ & $1200-1300$ & 0.1 \\
\hline Diopside, 0.2 at $\% \mathrm{Fe}$ & [001] & Dy & $1100-1300$ & 0.1 \\
\hline Diopside, 0.2 at $\% \mathrm{Fe}$ & [001] & $\mathrm{Yb}$ & $1050-1300$ & 0.1 \\
\hline Diopside, 1 at $\% \mathrm{Fe}$ & [001] & $\mathrm{Sr}$ & $1200-1300$ & 0.1 \\
\hline Diopside, $<0.1$ at $\% \mathrm{Fe}$ & [001] & $\mathrm{Sr}$ & $1200-1300$ & 0.1 \\
\hline Diopside,,$<0.1$ at $\% \mathrm{Fe}$ & [100] & $\mathrm{Sr}$ & $1150-1250$ & 0.1 \\
\hline Diopside, $<0.1$ at $\% \mathrm{Fe}$ & [010] & $\mathrm{Sr}$ & $1150-1250$ & 0.1 \\
\hline Diopside, $<0.1$ at $\% \mathrm{Fe}$ & [001] & $\mathrm{Sr}$ & $1100-1250$ & 0.1 \\
\hline Diopside, $<0.1$ at $\% \mathrm{Fe}$ & [001] & $\mathrm{Sr}$ & $1100-1250$ & 0.1 \\
\hline Diopside, $<0.1$ at $\% \mathrm{Fe}$ & [100] & $\mathrm{Sr}$ & $1100-1250$ & 2000 \\
\hline Diopside, $<0.1$ at $\% \mathrm{Fe}$ & {$[010]$} & $\mathrm{Sr}$ & $1100-1250$ & 2000 \\
\hline Diopside, $<0.1$ at $\% \mathrm{Fe}$ & [001] & $\mathrm{Sr}$ & $1100-1250$ & 2000 \\
\hline Diopside, $<0.1$ at $\% \mathrm{Fe}$ & [001] & $\mathrm{Sr}$ & $1150-1250$ & 1400 \\
\hline Enstatite, 0.2 at $\% \mathrm{Fe}$ & {$[210],[001]$} & $\mathrm{Eu}$ & $1000-1200$ & 0.1 \\
\hline Enstatite, 0.2 at $\% \mathrm{Fe}$ & {$[210],[001]$} & $\mathrm{Eu}$ & $850-1150$ & 0.1 \\
\hline Enstatite, 0.2 at $\% \mathrm{Fe}$ & [210] & $\mathrm{Gd}$ & $1000-1250$ & 0.1 \\
\hline Diopside, 0.2 at $\% \mathrm{Fe}$ & [001] & Th & $1150-1300$ & 0.1 \\
\hline Diopside, 0.2 at $\% \mathrm{Fe}$ & [001] & $\mathrm{U}$ & $1150-1300$ & 0.1 \\
\hline
\end{tabular}

*Arrhenius relations are for indicated oxygen fugacities. When dependence on $p \mathrm{O}_{2}$ has been investigated, a value for $m$, where $D \propto\left(p \mathrm{O}_{2}\right)^{m}$, is included. 


\begin{tabular}{|c|c|c|c|c|}
\hline$p \mathbf{O}_{2}^{*}$ & $\begin{array}{c}D_{0} \\
\left(\mathbf{m}^{2} / \mathbf{s}\right)\end{array}$ & $\log D_{0}$ & $\begin{array}{c}E_{\mathrm{a}} \\
(\mathrm{kJ} / \mathrm{mol})\end{array}$ & References \\
\hline $\begin{array}{c}10^{-17}\left(800-900^{\circ} \mathrm{C}\right) \\
10^{-13}\left(1000-1100^{\circ} \mathrm{C}\right)\end{array}$ & $2.9 \times 10^{-2}$ & -1.54 & 258 & Coogan et al. (2005) \\
\hline $\mathrm{QFM}(m=0.183 \pm 0.021)$ & $4.03 \times 10^{2}$ & $2.61 \pm 1.65$ & $544 \pm 40$ & Cherniak $(1998,2001)$ \\
\hline QFM & $2.17 \times 10^{1}$ & $1.34 \pm 0.52$ & $512 \pm 23$ & Cherniak $(1998,2001)$ \\
\hline "self-buffered" & $5.38 \times 10^{4}$ & $4.73 \pm 2.74$ & $609 \pm 67$ & Cherniak (1998) \\
\hline $\mathrm{QFM}(m=0.141 \pm 0.020)$ & $2.20 \times 10^{-4}$ & $-3.66 \pm 1.38$ & $387 \pm 31$ & Cherniak $(1998,2001)$ \\
\hline “self buffered" & $1.90 \times 10^{-3}$ & $-2.72 \pm 1.46$ & $410 \pm 36$ & Cherniak (1998) \\
\hline $\mathrm{QFM}(m=0.188 \pm 0.030)$ & $8.66 \times 10^{-7}$ & $-6.06 \pm 1.49$ & $351 \pm 36$ & Cherniak (2001) \\
\hline QFM & $2.00 \times 10^{-8}$ & $-7.70 \pm 1.67$ & $309 \pm 40$ & Cherniak (2001) \\
\hline $\mathrm{QFM}(m=0.203 \pm 0.014)$ & $3.78 \times 10^{-5}$ & $-4.42 \pm 0.64$ & $372 \pm 15$ & Cherniak (2001) \\
\hline $\mathrm{QFM}(m=0.200 \pm 0.019)$ & $6.63 \times 10^{-7}$ & $-6.18 \pm 1.18$ & $366 \pm 29$ & Cherniak (2001) \\
\hline QFM & $6.03 \times 10^{-5}$ & $-4.22 \pm 2.66$ & $466 \pm 78$ & Van Orman et al. (2001) \\
\hline QFM & $7.94 \times 10^{-5}$ & $-4.10 \pm 1.08$ & $463 \pm 31$ & Van Orman et al. (2001) \\
\hline QFM & $1.12 \times 10^{-3}$ & $-2.95 \pm 2.64$ & $496 \pm 77$ & Van Orman et al. (2001) \\
\hline QFM & $4.90 \times 10^{-4}$ & $-3.31 \pm 1.44$ & $461 \pm 41$ & Van Orman et al. (2001) \\
\hline $\mathrm{QFM} m=0.13$ & $2.29 \times 10^{-5}$ & $-4.64 \pm 0.42$ & $411 \pm 12$ & Van Orman et al. (2001) \\
\hline $\mathrm{N}_{2}$ gas & $5.4 \times 10^{-3}$ & -2.27 & $406 \pm 71$ & Sneeringer et al. (1984) \\
\hline $\mathrm{N}_{2}$ gas & $2.5 \times 10^{-3}$ & -2.61 & $456 \pm 75$ & Sneeringer et al. (1984) \\
\hline air & $6.4 \times 10^{-4}$ & -3.19 & $452 \pm 42$ & Sneeringer et al. (1984) \\
\hline air & $1.2 \times 10^{1}$ & 1.08 & $565 \pm 38$ & Sneeringer et al. (1984) \\
\hline air & $1.2 \times 10^{-1}$ & -0.92 & $511 \pm 29$ & Sneeringer et al. (1984) \\
\hline air & 3.1 & 0.49 & $544 \pm 25$ & Sneeringer et al. (1984) \\
\hline Buffered by piston cylinder assembly & $1.7 \times 10^{-9}$ & -8.77 & $260 \pm 50$ & Sneeringer et al. (1984) \\
\hline Buffered by piston cylinder assembly & $2.5 \times 10^{-5}$ & -4.28 & $381 \pm 84$ & Sneeringer et al. (1984) \\
\hline Buffered by piston cylinder assembly & $8.7 \times 10^{2}$ & 2.94 & $607 \pm 33$ & Sneeringer et al. (1984) \\
\hline Buffered by piston cylinder assembly & $1.3 \times 10^{7}$ & 7.08 & $728 \pm 134$ & Sneeringer et al. (1984) \\
\hline air & $1.70 \times 10^{-8}$ & $-7.77 \pm 1.53$ & $350 \pm 42$ & Cherniak and Liang (2007) \\
\hline IW & $6.93 \times 10^{-6}$ & $-5.16 \pm 1.18$ & $384 \pm 29$ & Cherniak and Liang (2007) \\
\hline air, IW & $2.55 \times 10^{-9}$ & $-8.59 \pm 3.08$ & $321 \pm 85$ & Cherniak and Liang (2007) \\
\hline QFM & $1.70 \times 10^{-8}$ & $-7.77 \pm 0.92$ & $356 \pm 26$ & Van Orman et al. (1998) \\
\hline QFM & $1.78 \times 10^{-6}$ & $-5.75 \pm 0.98$ & $418 \pm 28$ & Van Orman et al. (1998) \\
\hline
\end{tabular}




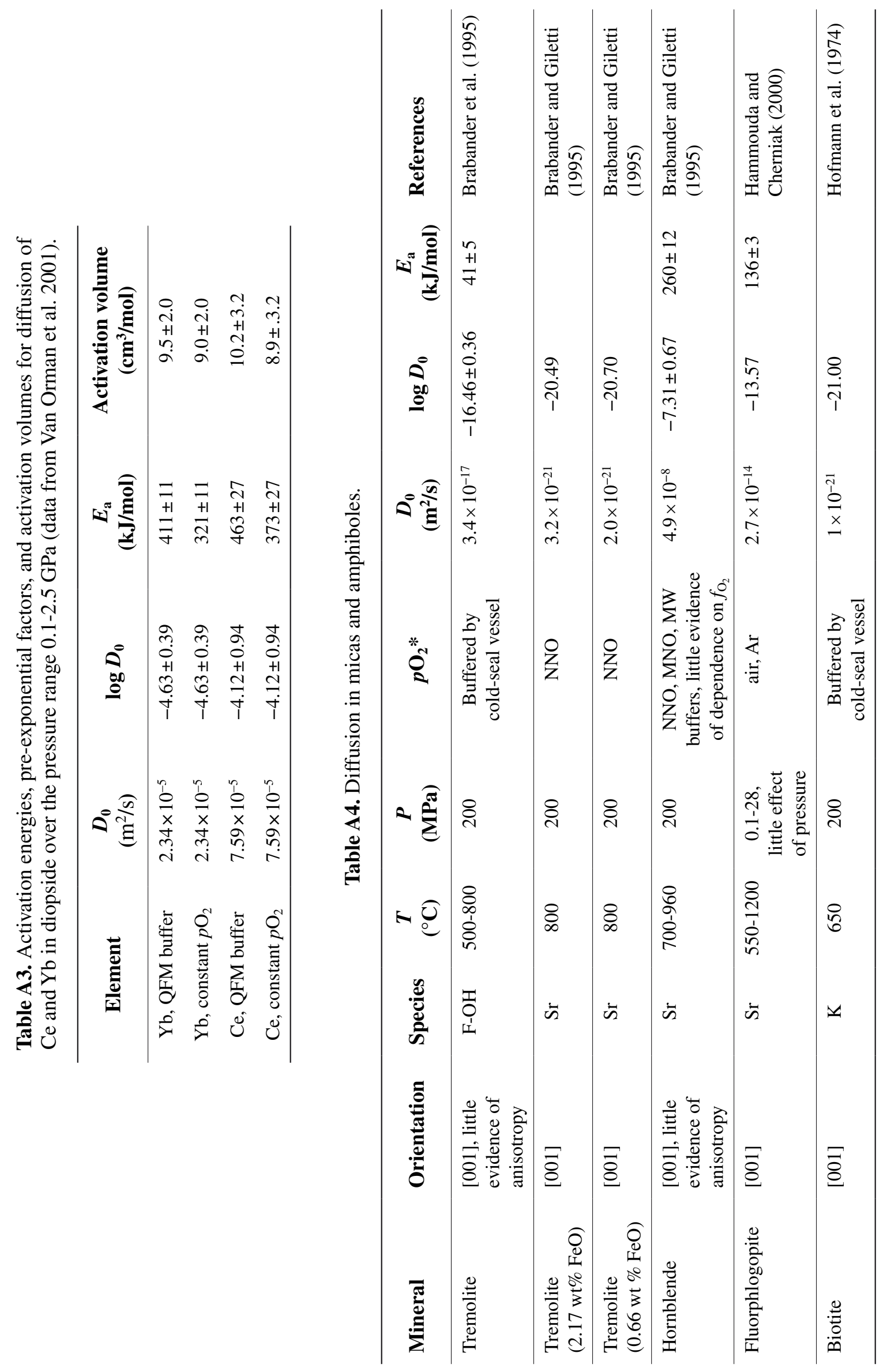

